\title{
RIESGOS PARA LA SALUD CAUSADOS POR IMPLANTES DE SILICONA EN GENERAL, CON ATENCIÓN ESPECIAL A LOS IMPLANTES MAMARIOS
}

(INFORME STOA/PARLAMENTO EUROPEO)

Informe de Evaluación de Tecnologías Sanitarias № 23 Madrid, Diciembre de 2000 


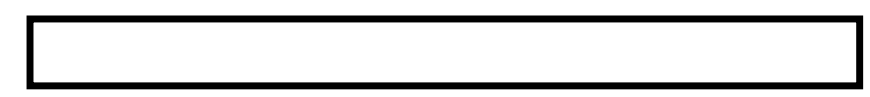

RIESGOS PARA LA SALUD

CAUSADOS POR IMPLANTES DE SILICONA EN GENERAL, CON ATENCIÓN ESPECIAL A LOS IMPLANTES MAMARIOS

(INFORME STOA/PARLAMENTO EUROPEO)

Informe de Evaluación de Tecnologías Sanitarias $\mathrm{N}^{\circ} 23$

Madrid, Diciembre de 2000 
Agencia de Evaluación de Tecnologías Sanitarias (AETS)

Instituto de Salud Carlos III

Ministerio de Sanidad y Consumo

Sinesio Delgado, 6 - Pabellón 3

28029 MADRID (ESPAÑA)

Tels.: $913877840-913877800$

Fax: 913877841

Edita: AGENCIA DE EVALUACIÓN DE TECNOLOGÍAS SANITARIAS

Instituto de Salud Carlos III - Ministerio de Sanidad y Consumo

N.I.P.O.: 354-00-019-9

I.S.B.N.: 84-95463-04-0

Depósito Legal: M-50332-2000

Imprime: Rumagraf, S.A. Avda. Pedro Díez, 25. 28019 Madrid

0.T. 26926 
Este documento es un Informe Técnico de la Agencia de Evaluación de Tecnologías Sanitarias (AETS) del Instituto de Salud Carlos III (ISCIII) del Ministerio de Sanidad y Consumo.

Este documento es una traducción del informe sobre «Riesgos para la salud causados por implantes de silicona en general, con atención especial a los implantes mamarios", realizado por encargo del Parlamento Europeo - a través de la Unidad de Evaluación de Opciones Científicas y Técnicas (STOA)/Parlamento Europeo- en septiembre de 1999 y que fue finalizado en mayo de 2000.

Dirección y coordinación:

José M. ${ }^{a}$ Martín Moreno ${ }^{1}$

Elaboración y redacción: José M. ${ }^{a}$ Martín Moreno ${ }^{1}$

Lydia Gorgojo Jiménez ${ }^{2}$ Jesús González Enríquez ${ }^{1}$

Wendy Wisbaum ${ }^{3}$

Edición y diseminación:

Antonio Hernández Torres ${ }^{1}$ Zuleika Esther Saz Parkinson ${ }^{1}$

\footnotetext{
1 AETS-ISCIII (Agencia de Evaluación de Tecnologías Sanitarias).

2 ENS-ISCIII (Escuela Nacional de Sanidad).

3 OESS-ISCIII (Observatorio Europeo de Sistemas Sanitarios).
}

Para citar este informe:

Agencia de Evaluación de Tecnologías Sanitarias (AETS)

Instituto de Salud Carlos III - Ministerio de Sanidad y Consumo

«Riesgos para la salud causados por implantes de silicona en general, con atención especial a los implantes mamarios» (Informe STOA/Parlamento Europeo)

Madrid: AETS - Instituto de Salud Carlos III, Diciembre de 2000

Este texto puede ser reproducido siempre que se cite su procedencia. 
RESUMEN

RIESGOS PARA LA SALUD CAUSADOS POR IMPLANTES DE SILICONA EN GENERAL, CON ATENCIÓN ESPECIAL A LOS IMPLANTES MAMARIOS

1. Opciones

1.1. Antecedentes para las opciones relevantes europeas

1.1.1. Opciones para los dispositivos implantables. Posiciones del mercado y dinámica social previsibles para la difusión y control de implantes de silicona

1.1.2. Acción europea e internacional en este campo 1.1.3.1. Directivas relacionadas con los implantes/dispositivos médicos

1.1.3.2. Directivas relacionadas con la protección del consumidor

1.1.3.3. Otras referencias legislativas relevantes .......................

1.1.4. Consulta con los Estados miembros de la UE, situación actual de la distribución y uso de implantes, postura gubernamental, políticas legislativas y sanitarias adoptadas

1.1.5. Revisión de otras referencias relevantes relacionadas con la legislación internacional

1.1.6. Instrumentos de la UE relacionados con la armonización de la legislación y el control de los dispositivos médicos

1.2. Alternativas prácticas posibles, incluyendo propuestas alternativas para nuevas Directivas europeas

2. Argumentos y pruebas

2.1. Antecedentes, incluyendo argumentos a favor y en contra de los riesgos para la salud de los implantes de silicona

2.1.1. Riesgos para la salud generales y específicos causados por los implantes de silicona, efectos sistémicos y efectos locales ..........

2.1.2. Efectos de los implantes a corto, medio y largo plazo (cuatro, ocho y doce años)

2.1.3. Efectos en el postoperatorio y seguimiento ...................................

2.1.4. Conclusiones

2.2. Visión global de la investigación primaria y de las revisiones relevantes.

Período 1990-1999

2.2.1. Investigación llevada a cabo actualmente en la UE ..........................

2.2.2. Investigación actual en otros países del mundo .............................. 48

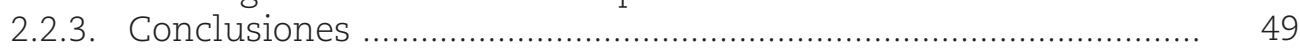

2.3. Información primaria obtenida ......................................................... 50

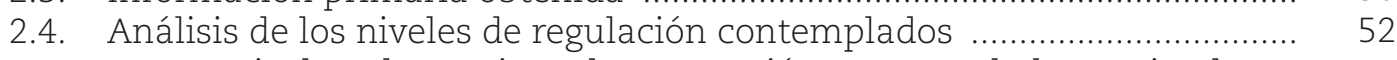

2.4.1. Niveles alternativos de precaución recomendados teniendo en cuenta el conocimiento actual sobre cuestiones de salud ........... 52

2.4.2. Implicaciones de nueva legislación 


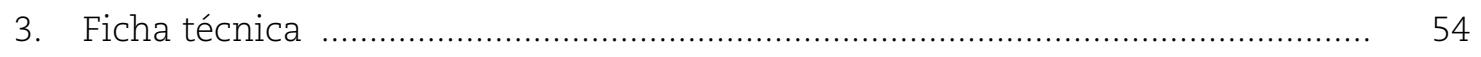

3.1. Terminología y conceptos básicos .................................................... 54

3.1.1. Silicio/Sílice ............................................................................. 54

3.1.2. Silicona y polidimetilsiloxano (PDMS) …...................................... 54

3.2. Exposición general a siliconas. El uso de silicona en dispositivos médi-

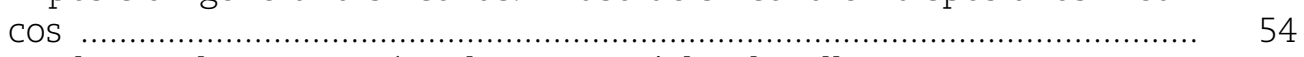

3.3. Implantes de mama. Cápsulas y materiales de relleno ........................... 54

3.3.1. Implantes alternativos según su material de relleno ...................... 55

3.3.1.1. Implantes rellenos de gel de silicona ............................ 55

3.3.1.2. Implantes rellenos de solución salina .......................... 55

3.3.1.3. Otros implantes ...................................................... 55

3.4. Resumen técnico sobre los implantes de silicona y sus posibles efectos. $\quad 56$

3.4.1. Posibles beneficios ..................................................................... 56

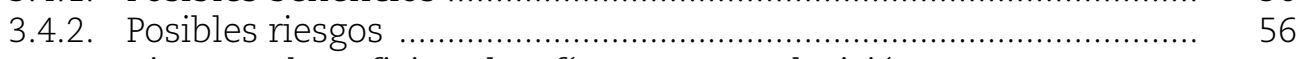

3.4.3. Riesgos y beneficios: desafíos para una decisión .......................... 57

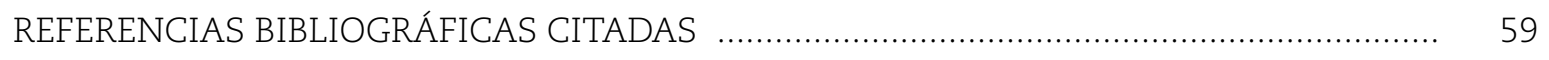

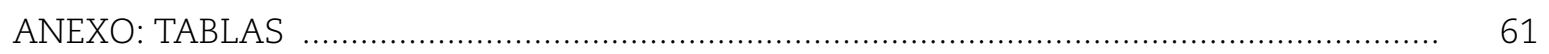

Tabla 1: Efectos graves sobre la salud considerados en estudios relacionados con implantes mamarios de silicona ..............................................................

Tabla 2: Resumen de las respuestas facilitadas por cirujanos expertos consultados.

Tabla 3: Resumen de las respuestas obtenidas mediante cuestionario a mujeres con implantes de mama .............................................................................. 66

Tabla 4: Resumen de las respuestas facilitadas por los fabricantes de implantes de

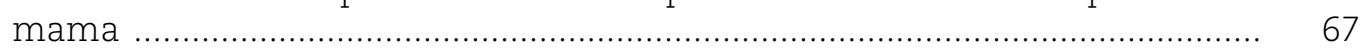

Tabla 5: Resumen de las respuestas facilitadas por los gobiernos de los países consultados 


\section{Nota introductoria de los autores}

La génesis de este trabajo se produjo a raíz de una convocatoria para abordar el tema de «Riesgos para la salud causados por implantes de silicona en general, con atención especial a los implantes mamarios», hecha pública en septiembre de 1999 por la Unidad de Evaluación de Opciones Científicas y Técnicas (STOA) del Parlamento Europeo. Tras el proceso de selección establecido, dicho trabajo se encargó a un equipo investigador independiente compuesto por J. M. Martín Moreno, L. Gorgojo Jiménez, J. González Enríquez y W. Wisbaum. De acuerdo con el plan de trabajo acordado, el informe final fue presentado en el Parlamento Europeo en mayo de 2000. El formato y guión del documento está condicionado por las especifi- caciones técnicas que establece la propia Unidad de Evaluación de Opciones Científicas y Técnicas (STOA) del Parlamento Europeo. Es por ello que en ocasiones pueden aparecer secciones que pueden considerarse parcialmente abordadas en otros puntos del informe, con la consiguiente imagen reiterativa de ciertos aspectos. Por otro lado, y siguiendo la misma filosofía y naturaleza de este tipo de informes, los autores han intentado minimizar los juicios de valor, y las opciones presentadas representan el abanico de posibilidades desde una perspectiva amplia, dado que el informe pretende aportar fundamentos para la toma de una potencial decisión que, en cualquier caso, corresponde al Parlamento Europeo. 


\section{Agradecimientos}

Nos gustaría expresar nuestra gratitud explícita a la Unidad de Evaluación de Opciones Científicas y Técnicas (STOA/Parlamento Europeo), por concedernos la oportunidad de examinar este tema; a las autoridades competentes de dispositivos médicos de la Unión Europea, por la más actualizada información específica de cada país; a los grupos de apoyo mutuo del Reino Unido/Escocia, Países Bajos, Alemania, Bélgica, Suiza e Islandia; a las mujeres con implantes de mama de silicona, por toda la información facilitada y por compartir con nosotros sus historias personales; a los fabricantes, por todos los documentos, tiempo e información aportados; a investigadores particulares/expertos en implantes de mama de silicona, que nos han proporcionado su visión y algunas de las últimas pruebas científicas sobre este tema; a los cirujanos y pacientes particulares contactados, por completar los cuestionarios que les enviamos; a las Sociedades Científicas, por responder a nuestras preguntas y proporcionarnos información; y a la Biblioteca de la Escuela Nacional de Sanidad de España (específicamente a doña Mercedes Alastruey y doña Cristina Gavin), por ayudarnos en la búsqueda bibliográfica exhaustiva sobre el tema. Mención especial merecen todas las personas que nos han proporcionado nuevas perspectivas científicas y humanas e información adicional inestimable, incluyendo al Dr. Jon Samet (Johns Hopkins University Universidad de Johns Hopkins), Dr. Peter Boyle (European Institute of Oncology- Instituto Europeo de Oncología), Dr. Roger Herdman (Institute of Medicine - Instituto de Medicina, EE.UU.), Dr. Louise Brinton (National Cancer Institute - Instituto Nacional de Cáncer, EE.UU.), Dra. Marita Eisenmann-Klein (European Committee on Quality Assurance and Medical Devices in Plastic Surgery - Comité Europeo de Garantía de Calidad y Dispositivos Médicos en Cirugía Plástica), Dr. Samie
Allen (Center for Devices and Radiologic Health - Centro de Dispositivos Médicos y Radiología, EE.UU.), Dr. Ulrich Hinderer (Fundación Internacional de Cirugía Plástica, Reconstructiva y Estética, IPRAF, España), Dr. Julio Villalba (Hospital Universitario de Granada, España), doña Charo Giner (Departamento de Epidemiología y Bioestadística, Escuela Nacional de Sanidad de España), Dra. Julie Kent (University of West of England Universidad del Oeste de Inglaterra) y doña Peggy McGuire (European Institute of Women's Health - Instituto Europeo de Salud de la Mujer), a quien estamos especialmente agradecidos.

También quisiéramos agradecer el interés mostrado en la evaluación de estos implantes al Dr. Víctor García Giménez (Presidente de la Sociedad Española de Medicina y Cirugía Cosmética).

Finalmente, damos las gracias a las autoridades españolas en materia de control de productos sanitarios, particularmente a la Dra. Carmen Abad y a la Dra. Teresa Millán (ambas de la Dirección General de Farmacia y Productos Sanitarios), y a la Dra. Rosa Cepeda (Centro Nacional de Farmacobiología del Instituto de Salud Carlos III), por toda la información que nos han facilitado.

Ésta no es una lista exhaustiva, y nos gustaría manifestar nuestro agradecimiento a aquellas personas no mencionadas aquí que han contribuido a este estudio. Todas estas personas han ayudado a esclarecer este tema tan complejo y hacer de este informe lo que es. Sin embargo, queremos dejar claro que sólo los autores del estudio son responsables de los posibles errores y limitaciones de este informe, cuyo formato sigue las pautas establecidas por la oficina de STOA del Parlamento Europeo. 


\section{Resumen}

El objetivo principal de este documento es presentar al Parlamento Europeo opciones de políticas alternativas bien documentadas en relación a los implantes de silicona (fundamentalmente implantes mamarios), basadas en un análisis exhaustivo e imparcial de la literatura científica sobre el tema y en la consulta a grupos y sectores implicados. Con el objetivo de reflejar todos los puntos de vista sobre este tema (negativos y positivos), hemos entrevistado a pacientes, contactado y recibido información de grupos de apoyo mutuo, grupos de mujeres, cirujanos plásticos y reparadores, fabricantes de implantes de mama de silicona, sociedades científicas y autoridades gubernamentales de los países miembros de la Unión Europea.

Los implantes de silicona se han utilizado durante muchos años antes de que existiera una regulación y un control de su uso. Desde principios de los noventa se ha venido prestando mucha atención a los implantes de mama de silicona. Esto ha facilitado la realización de numerosos estudios epidemiológicos diferentes, cuyos resultados han mostrado consistentemente la ausencia de riesgos claros para la salud. Sin embargo, la mayoría de estos estudios son recientes, por lo que no se han podido evaluar los efectos a largo plazo de los implantes. Además, los estudios se han centrado en determinadas enfermedades sistémicas (cáncer y enfermedades del tejido conjuntivo - las dos causas de mayor preocupación-) y no siempre se han realizado controles adecuados según el tipo de implante. Estas debilidades metodológicas deben considerarse de forma adecuada, ya que un número considerable de mujeres afirman padecer síntomas que creen están asociados con sus implantes. Por otra parte, las complicaciones locales pueden llegar a merecer especial atención. Debido a esta compleja realidad, podrían llegar a considerarse tres opciones como posibles líneas de acción por parte del Parlamento Europeo:

Opción 1: Status quo: ninguna prohibición, mantener la aplicación del actual marco legal.
Ventajas: buena base legal establecida, pruebas poco convincentes acerca de riesgos graves, mantiene la situación actual.

Desventajas: las pruebas apuntan hacia la necesidad de una armonización europea apropiada; grupos de apoyo mutuo y otros han demandado una prohibición inmediata.

Opción 2: Prohibición de los implantes de mama de silicona debido a la ausencia de información detallada con relación a los riesgos y a la petición específica realizada por algunos grupos.

Ventajas: opción más «conservadora» basada en la falta de conocimiento; opción más deseada por algunos grupos.

Desuentajas: gran número de solicitudes de implantes mamarios (y de otras localizaciones) por parte de las mujeres. Las alternativas disponibles podrían ser opciones menos deseables (incluso más peligrosas); los estudios apuntan a pruebas poco convincentes con relación a los riesgos graves para la salud, y enfatizan las complicaciones locales (también presentes en las alternativas) como la principal preocupación sanitaria; potencial perjuicio económico para la industria, que, en comparación con otras opciones, no sería coherente con los "principios de precaución» propuestos por la Comisión de las Comunidades Europeas.

Opción 3: No llegar a la prohibición total, pero adoptar e implementar medidas críticas específicas para mejorar la información de los pacientes, el seguimiento, la vigilancia, el control de calidad y la garantía de calidad y la investigación en líneas prioritarias.

Ventajas: los estudios indican que las complicaciones locales (también presentes en las alternativas) son la principal causa de preocupación.

Desventajas: los grupos de apoyo mutuo y otros han demandado una prohibición inmediata; se necesita realizar una verdadera inversión para que los esfuerzos e investigación coordinada tengan lugar. 


\section{Executive Summary}

The main objective of this project is to present well-informed, relevant, and realistic alternative policy options to the European Parliament on silicone (breast) implants. The identification of these options has been based on a comprehensive, thorough, unbiased analysis of the scientific literature on the subject and of interested actors and parties, aiming to help in the European Parliament process so that more informed legislative and policy decisions on silicone can be made.

\section{Silicone implants in general}

Silicone is used in implants located throughout almost every part of the body (for heart valves and other cardiovascular prostheses; for catheters in many parts of the body; in dentistry; in the gastrointestinal tract; in ophthalmology; in the ear, nose, throat, and respiratory tract; in the urogenital tract, including penile prostheses; as a facilitator for nerve regeneration; as a prosthesis or ingredient in prostheses for many parts of the skeletal system; as a tissue expander; and as a cosmetic agent for treatment of scars and wrinkles). In this study, however, we will mainly focus on silicone implants in the breast.

There is a large variety of breast implants on the market. Most of these implants have a silicone shell, although there are different kinds of fillings used in these implants (silicone-gel filled, saline, soybean oil, hydrogel). In addition, silicone-gel filled implants have experienced a number of changes since their introduction, and have undergone essentially three stages: a first generation, with a thick silicone shell and smooth consistency; a second one, with a thin silicone shell and smooth consistency, and a third generation, with a thick silicone shell and textured consistency. In this study, it should be noted that, from now on, whenever we refer to "silicone implants» we mean "silicone-gel filled implants», the main focus of research on breast implants.

\section{Historical background}

Silicone breast implants were widely used in the United States (US) and Europe before there was any requirement for pre-market assessment of toxicity and complications. For many years, there were no requirements to document the composition of implants or the specific type of implant placed in a particular individual. Furthermore, there was no systematic, comprehensive, post-marketing surveillance of the long-term positive and negative consequences of silicone breast implants. Thus, until concerns about the health risks of silicone were raised in the 1980s, mainly in the US, and all breast implants were placed in a class III category (requiring strict standards for safety and effectiveness) by the US Food and Drugs Administration (FDA), the literature on silicone breast implants up until the early 1990s has not been very useful in assessing risk.

In the course of the 1980s, increasing health concerns arose regarding breast implants, mainly focusing on silicone implants, due to suspicions that the gel leaks out to surrounding tissue, potentially causing cancer or connective diseases. In April 1991, in response to a number of adverse reaction reports that raised safety concerns about these implants, the FDA published a regulation that required manufacturers to submit pre-market approval applications with data showing the safety of the implants by July 9,1991 . The data submitted at that stage did not fully prove the devices safe, so the agency ordered the devices off the market in April 1992.

The health concerns which surfaced in the US during the 1980s and 1990s extended to Europe, even though it is difficult to gauge the number of women with implants, and it appears to be much lower than in the US. In any event, in Europe, various studies were commissioned and conducted on the safety of silicone breast implants. In this context, the issues of safety and regulation of breast implants were discussed on several occasions between the Commission and Member States.

\section{Current context}

In the US, since 1992, silicone breast implants are only available for women with special 
medical needs who need breast reconstruction and who are willing to become part of a clinical trial approved by FDA. In early 1998, the FDA allowed the two existing manufacturers of silicone breast implants in the US (Mentor and McGhan) to conduct studies on women with silicone gel-filled implants who will be followed for 5 years. Saline-filled implants have been allowed to remain on the market for all uses, although beginning in January 1993, the FDA requires manufacturers to submit regular data on safety and effectiveness and conduct clinical trials. It was believed that saline implants have a lower risk than gel-filled implants because leakage would only release salt water into the body.

In Europe, different working groups were set up right after concerns were raised in the US. In general, these groups found no reason to ban silicone breast implants, although careful follow-up and studies were recommended within countries. In France, this issue was kept under discussion. Currently, all EU countries with the exception of France have no restrictions regarding availability of silicone breast implants and accept conformity with the Essential Requirements of the European Directive (93/42/EEC) as a basis for their marketing. This Directive requires manufacturers to conform with safety principles and eliminate risks as much as possible, to take adequate protection measures in relation to risks, and to inform users of existing risks. In addition, the device itself cannot put into jeopardy the clinical condition or the safety of patients or users, and any associated risks must be acceptable when weighed against the benefits. The required standards for «CE» marking of conformity are mainly related to technological standards, materials testing and biocompatibility assessment.

In France, tighter restrictions apply, as silicone breast implants have been banned since 1992, and all implants other than saline have been prohibited since 1995. Surgeons must apply for and be granted exceptions in cases of special patient medical needs (e.g., reconstruction after mastectomy). In addition, surgeons are responsible for providing appropriate information to patients, and patients can hold their doctor liable for not fulfilling this right.

\section{Findings to date}

Silicone implants are particularly complex due to the fact that they were used for years before there was regulation, study, or surveillance of their use and because there are many different varieties and kinds of implants. Thus, and in spite of the relatively long period of use, most epidemiological studies are fairly recent, beginning in the early 1990s. A great deal of attention and focus has been given to silicone breast implants since the early 90s, leading to many different studies and analyses that have driven to highly consistent results showing no evidence of a serious risk for major diseases. But it is also true that, because the studies started so recently, most have not been able to look at long-term effects, have mainly focused on cancer and well-known connective tissue diseases, were usually based on small sample sizes, and have not always controlled for the different types of implants. This must be considered in light of the fact that a significant body of women, supported by some clinicians, claim to be experiencing symptoms which they think are associated with their implants.

A summary of the literature on health risks follows:

\section{Systemic Effects}

\section{Cancer}

There appear to be sufficiently consistent and convincing studies to support the conclusion of no association between breast cancer and implants, although research is currently being conducted to rule out the long-term risk. At the same time, the short average follow-up time of completed studies (and the still limited evidence in this field) does not allow us to conclude whether silicone breast implants are or are not associated with other malignant neoplasms (other solid tumours, sarcoma, lymphoma, or myeloma), and the ongoing and future studies will hopefully shed light on these/point. In the meantime, the available evidence does not support an association of silicone breast implants with other non breast cancers.

\section{Neurological disease}

Neurological symptoms or disease have been reported in some case series of women with breast implants. These findings are not consistent with other experimental and observational studies. Overall, it could be stated that the most properly designed and 
conducted epidemiological studies show no evidence that silicone implants cause neurological signs, symptoms or disease.

\section{Well-defined connective tissue diseases (related to autoimmune disorders)}

Recently published studies have indicated that women with silicone breast implants do not have a greatly increased risk of some well-defined autoimmune diseases (potentially fatal connective diseases), such as schleroderma, lupus erythematosus, rheumatoid arthritis, Sjogren's syndrome, dermatomyositis or polymyositis, and health disorders such as fibromyalgia and «chronic fatigue syndrome».

\section{Other systemic effects}

According to the information provided by selfhelp groups, some clinicians, and some additional sources, a substantial body of women with silicone implants have experienced these disorders, as well as a variety of symptoms that could be related to the immune system. These symptoms include pain and swelling of joints; tightness, redness or swelling of the skin; swollen glands or lymph nodes; unusual or unexplained fatigue; swelling of the hands and feet; excessive hair loss; memory problems; headaches; and muscle weakness or burning. In some cases, women have reported a reduction in symptoms after the implants were removed; in other cases, there was no change in symptoms after explantation. It is unclear at this time whether the signs and symptoms experienced by these women are related to their implants.

In sum, the epidemiological literature has indicated that the evidence for an atypical disease or novel syndrome is insufficient and that there is no robust, convincing support for these disorders. However, the existence of a specific syndrome or syndromes in women with silicone breast implants cannot be completely proven or dismissed at this point in time, and deserves further analysis.

\section{«Vertical» Effects (mother to child)}

\section{Risks to infants}

At this time, there does not appear to be evidence of harmful effects to infants breastfed by women with silicone breast implants, although further study is needed in this area to shed further light on this area.

\section{Local Effects}

\section{Local complications}

Studies points to local complications, including perioperative complications from the surgical procedure itself, as the largest potential health risk from silicone breast implants. The relatively high frequency of these complications is noticeable. While these are normally not life-threatening, they may result in discomfort, inconvenience, explantation, disfigurement, pain and other morbidities, and when further corrective procedures are necessary, an additional potential risk (e.g., additional surgery). Breast implants have a limited lifetime, which is not well-established. In any event, the probability of having a reoperation is high and it increases over time.

\section{Concerns by certain women's groups}

In the US, a major class action litigation, brought on behalf of women with silicone breast implants, was settled with a substantial award to the plaintiffs. Most importantly, assessment of the case points to the lack of appropriate warnings and information on potential risks by manufacturers.

In Europe, in March 1999, two petitions were tabled by self-help groups of women who claim to have suffered adverse effects from implants calling for the European Parliament's immediate ban on silicone implants. The EP is asking for formal replies and evidence to be submitted to the Petitions Committee, and has asked for counsel from the Committee on Women's Rights, the Committee on Public Health and Consumer Protection and the Committee on Research.

Many women with silicone breast implants feel that they were not given sufficient information on the health risks to consent to have these implants. In the US, signing an informed consent form which explains all known and possible risks is now part of the required procedure for all women undergoing breast implant surgery. In Europe, all 
countries have general legislation or rules establishing the right of patients to be clearly informed of risks and benefits, although a common, fully accepted and standardised form does not yet exist.

\section{Potential benefits of breast implants and available alternatives}

There is a clear demand for breast implants by women, both from a cosmetic (augmentation) and reconstructive (reconstruction following mastectomy) standpoint. As a result, breast implants need to be considered also in light of their benefits. Reasons such as interest in improving self-confidence through the apparent improvement of self-image, a subjective sense of attractiveness and social relationships are the main apparent reasons for demanding cosmetic surgery. In addition, silicone breast implants must be compared with available alternatives.

With the aim of reflecting all views on this issue (negative and positive), we have interviewed patients, and have contacted and received information from self-help groups, women's groups, reconstructive surgeons, silicone breast implant manufacturers, countries, and scientific societies. We have incorporated this information and these positions into the report as best as we could, and have sent the Parliament original primary information in order to assess these materials firsthand.

We would like to stress that, in working on this project, we encountered very strong viewpoints, and often conflicting information was received in our quest to be as clear, objective, thorough and unbiased as we possibly can. There are extremely strong interests at stake on either side of this issue, both of which may have valid, legitimate claims. Thus, our aim is to capture the complexity of the issue but try to get to its essence in a way in which the European Parliament can make the most appropriate decision in its regard.

\section{Operational, potential options}

Option 1: Status quo: no ban, keep application of current legal framework (namely, Directive 93/42/EEC, a general guiding directive which sets the basis without entering in further detail).
Pros: good legislative basis in place, inconclusive evidence of serious risks, maintain stability.

Cons: evidence points to need for proper European harmonisation aiming for increased and improved measures for further and better protecting women and women's health in EC; self-help groups and others have called for an immediate ban.

Option 2: Ban on silicone breast implants due to lack of complete information regarding risks and to petitions by some groups.

Pros: most conservative option -currently exercised, for example, by the US, Canada and France- due to lack of complete understanding and knowledge of risks because of short follow-up period of women and other complicating factors, such as variety of implants used, etc.; desired option by some groups/people (e.g., self-help groups of women suffering from adverse effects of silicone implants).

Cons: large demand by women for these implants, especially considering some of problems with main alternative, saline implants — such as a higher risk of rupture, poorer appearance, etc. The available alternatives to silicone implants could even be worse and more studies are needed before promoting these alternatives. Also, studies on silicone-gel filled implants corroborate one another, pointing to inconclusive evidence of risks of serious health concerns, and pointing to local complications as main health concern, also present in alternative implants. Finally, from a social perspective related to health, there would also be the potential for economic damage to industry (e.g., job loss).

Option 3: No complete ban, but the adoption and implementation of critical specific measures to increase and improve information for patients, tracking and surveillance, quality control and assurance and key research (see seven proposed measures below).

Pros: studies do not point to an association between silicone implants and serious health risks, such as cancer and connective tissue diseases. Indicate that local complications -also just as prevalent or more so with other breast implants, such as saline- are the largest cause for concern. Information from self-help groups, surgeons and the literature points to a real need for improved measures, particularly regarding the provision of correct information to patients as to risks. 
Cons: need to make a real investment for coordinated efforts and research investment to happen; self-help groups and others have called for an immediate ban.

In view of the evidence, option 3, which proposes additional measures for maximising the benefits of breast implants and limiting the risks in the EU context, perhaps appears to be the most balanced approach. The further measures proposed are described as follows (and are elaborated on more in the full Options section of this report, section 1.2.):

1. To facilitate consensus on a breast implant consent form, including information related to alternatives, benefits and risks.

2. To guarantee marketing control over breast implants in order to avoid any kind of incorrect and misleading information.

3. To improve certification, technical standards and regulation.

4. To promote the elaboration of clinical guidelines, standards of care and the development of quality assurance systems.
5. To facilitate consensus, promotion and support of effective surveillance systems to report adverse effects and long-term effects.

6. To consider silicone breast implants a research priority and make funds available in the EU research programmes, specifically focusing on some of the shortcomings of research to date.

7. To foster tolerance and self-esteem and other conceptual alternatives to breast implants, in collaboration with active groups in this field.

In summary, the option consisting of no complete ban, but the adoption and implementation of critical specific measures to increase and improve information for patients, tracking and surveillance, clinical guidelines, quality control and assurance and key research could be reasonably consistent with the philosophy underlying the criteria of the European precautionary principles and perhaps is the most balanced alternative after weighing the existing evidence. 


\section{Sumario del informe}

El objetivo principal de este documento es presentar al Parlamento Europeo opciones de políticas alternativas bien documentadas en relación con los implantes de silicona (fundamentalmente implantes mamarios). La identificación de estas opciones se ha basado en un análisis exhaustivo, detallado e imparcial de la literatura científica sobre el tema y la consulta a grupos interesados y sectores implicados, con objeto de ayudar al Parlamento Europeo en el proceso de la toma de decisiones políticas y legislativas sobre los implantes de silicona.

\section{Implantes de silicona en general}

La silicona se utiliza en implantes en prácticamente la totalidad del cuerpo (para válvulas del corazón y otras prótesis cardiovasculares; para catéteres en muchas partes del cuerpo; en odontología; en el tracto gastrointestinal; en oftalmología; en los oídos, nariz, garganta y tracto respiratorio; en el tracto urogenital, incluyendo prótesis de pene; como prótesis o como ingrediente de prótesis para una gran parte del sistema esquelético; como dilatador de tejidos, y como agente cosmético para el tratamiento de cicatrices y arrugas). Sin embargo, en este estudio nos centramos en los implantes de silicona de la mama.

En el mercado existe una gran variedad de implantes de mama. La mayoría de estos implantes tienen una cápsula de silicona, y lo que varía fundamentalmente es el material de relleno utilizado en los implantes (gel de silicona, solución salina, aceite de soja, hidrogel). Los implantes rellenos de gel de silicona han sufrido una gran cantidad de cambios desde su introducción. Esencialmente, el hecho es que se han sucedido tres etapas: una primera generación de implantes, con una cápsula gruesa de silicona y de superficie lisa; una segunda, con una fina cápsula de silicona y de superficie lisa; y una tercera generación, con una gruesa cápsula de silicona y una superficie rugosa. El lector debe saber que en este estudio, a partir de ahora, siempre que nos refiramos a «implantes de silicona», nos referimos a los «implantes rellenos de gel de silicona», por tratarse del enfoque más rele- vante en la investigación relacionada con los implantes mamarios.

\section{Antecedentes históricos}

Los implantes de mama de silicona se usaron extensamente en los Estados Unidos (EE.UU.) y en Europa sin que se exigiese la evaluación de su toxicidad y complicaciones antes de su salida al mercado. Durante muchos años, no se exigía la documentación de la composición de los implantes ni del tipo de implante insertado en una persona en particular. Además, no existía ningún tipo de vigilancia sistemática ni exhaustiva de las consecuencias positivas y negativas a largo plazo de los implantes de mama de silicona posterior a su comercialización. Por tanto, los estudios sobre implantes mamarios de silicona no aportaron información útil sobre la evaluación de riesgos hasta principios de los años noventa, ya que hasta los años ochenta no comenzó la preocupación acerca de los riesgos de la silicona para la salud (principalmente en EE.UU.). Posteriormente, la Administración americana para los Medicamentos y la Alimentación (US Food and Drug Administration, FDA) incluyó todos los implantes mamarios en la categoría de clase III (que requieren estándares estrictos de seguridad y efectividad).

A lo largo de los años ochenta fue creciendo la preocupación por los posibles efectos sobre la salud de los implantes de mama, principalmente centrada en los implantes de silicona, debido a las sospechas de que las fugas del gel hacia el tejido circundante pudieran estar asociadas a cáncer o a enfermedades del tejido conjuntivo. En abril de 1991, como respuesta a varios informes sobre efectos adversos que levantaron inquietud acerca de la seguridad de estos implantes, la FDA publicó una regulación exigiendo que, antes del 9 de julio de 1991, los fabricantes presentaran solicitudes de aprobación antes de permitir su salida al mercado, aportando datos que demostraran la seguridad de los implantes. Los datos presentados en este momento no llegaron a demostrar de forma inequívoca la seguridad de estos dispositivos, con lo cual la agencia ordenó que se retirasen del mercado en abril de 1992. 
La preocupación respecto a los posibles efectos de estos implantes surgida en EE.UU. durante los años ochenta y noventa se extendió a Europa. Aunque es difícil calcular el número exacto de mujeres con implantes en Europa, parece ser mucho menor que en EE.UU. En cualquier caso, en Europa se llevaron a cabo varios estudios acerca de la seguridad de los implantes de mama. En este contexto, se trataron en numerosas ocasiones las cuestiones de seguridad y regulación de los implantes de mama entre la Comisión y los Estados miembros.

\section{Contexto actual}

En EE.UU., desde 1992, los implantes de mama de silicona sólo están disponibles para mujeres con necesidades médicas especiales que necesitan una reconstrucción de la mama y, voluntariamente, desean participar en algún ensayo clínico aprobado por la FDA. A principios de 1998, la FDA permitió a dos fabricantes actuales de implantes de mama de silicona en EE.UU. (Mentor y McGhan) dirigir estudios con mujeres con implantes rellenos de gel de silicona que serán seguidas durante cinco años. En cuanto a otras alternativas, se pensaba que los implantes salinos tenían menor riesgo que los implantes rellenos de gel debido a que las posibles fugas sólo liberarían agua salina. Por ello, se ha permitido que los implantes rellenos de solución salina permanecieran en el mercado, aunque desde principios de enero de 1993 la FDA requiere que los fabricantes proporcionen de manera regular datos acerca de la seguridad y efectividad y realicen ensayos clínicos.

En Europa se instauraron distintos grupos de trabajo inmediatamente después de que aflorase la preocupación en EE.UU. En general, estos grupos no encontraron razones para prohibir los implantes de mama de silicona, aunque se recomendó el seguimiento y la realización de estudios de investigación en distintos países. En Francia, este tema está aún bajo estudio. Actualmente, todos los países de la UE, a excepción de Francia, no poseen restricciones en cuanto a la disponibilidad de los implantes de mama de silicona y están de acuerdo con los Requisitos Esenciales de la Directiva europea (93/42/EEC) como base de su comercialización. Esta Directiva requiere que los fabricantes se ajusten a los principios de seguridad y eliminen el riesgo en la mayor medida posible, tomen las medidas de protección adecuadas en relación con los riesgos e informen a los usuarios de los posibles riesgos existentes. Adicionalmente, el dispositivo en sí no puede comprometer la condición clínica o seguridad del paciente o usuario, y cualquier riesgo asociado debe ser aceptable al contraponerlo con los beneficios. Los estándares requeridos para la marca de conformidad «CE» están relacionados principalmente con los estándares tecnológicos, la comprobación de los materiales y la evaluación de la biocompatibilidad.

En Francia, donde las medidas adoptadas son más restrictivas, los implantes de mama de silicona fueron prohibidos en 1992, y el resto de los implantes, a excepción de los salinos, se prohibieron en 1995. Los cirujanos deben solicitar la concesión de permisos excepcionales en casos de pacientes con necesidades médicas especiales (por ejemplo, reconstrucción tras una mastectomía). Además, los cirujanos están obligados a proporcionar la información apropiada a los pacientes, y los pacientes pueden responsabilizar al médico si no se cumplen sus derechos.

\section{Hallazgos hasta la fecha}

El estudio de los efectos sobre la salud de los implantes de silicona resulta difícil debido a que estos implantes se utilizaron durante años, antes de que hubiera regulación, estudio o control de su uso, y a que existe una gran variedad de tipos de implantes. Por tanto, a pesar de su dilatado período de uso, la mayoría de los estudios epidemiológicos son relativamente recientes, comenzando a principios de los noventa. Desde entonces se ha prestado mucha atención a los implantes de mama de silicona, y se han realizado numerosos estudios epidemiológicos diferentes cuyos resultados han sido muy consistentes respecto a la ausencia de graves riesgos para la salud.

Pero también es cierto que, debido al reciente comienzo de dichos estudios, la mayoría de los mismos no han podido examinar los efectos a largo plazo y se han centrado en el cáncer y las enfermedades conocidas del tejido conjuntivo; se han basado, normalmente, en tamaños muestrales pequeños, y no siempre se han realizado controles adecuados según el tipo de implante. Los posibles efectos sobre la salud de los implantes de silicona deben ser adecuadamente considerados ya que un gran número de mujeres, apoyadas por algunos clínicos, refieren padecer 
síntomas que creen están asociados a sus implantes.

A continuación se presenta un resumen de la literatura con relación a los riesgos para la salud de los implantes de mama:

\section{$\overline{\text { Efectos sistémicos }}$}

\section{Cáncer}

Parece ser que existen estudios suficientemente consistentes y convincentes que apoyan la conclusión de falta de asociación entre cáncer de mama e implantes, aunque actualmente todavía se están desarrollando investigaciones para descartar el riesgo a largo plazo. Al mismo tiempo, el corto período medio de seguimiento de los estudios completados (y las todavía limitadas pruebas existentes en este campo) no permiten concluir si los implantes de mama de silicona están o no asociados a otras neoplasias malignas (otros tumores sólidos, sarcoma, linfoma o mieloma), pero se espera que los estudios futuros y en curso aclaren estas dudas. Mientras tanto, las pruebas disponibles no permiten determinar la existencia de asociación entre los implantes de mama de silicona con otras neoplasias malignas (diferentes a tumores de mama).

\section{Enfermedad neurológica}

Se ha informado acerca de algunas series de casos de mujeres con implantes de mama que sufren de enfermedad o síntomas neurológicos. Estos hallazgos no son consistentes con otros estudios observacionales o experimentales. En general, se puede concluir que los estudios epidemiológicos mejor diseñados y dirigidos no obtienen pruebas de que los implantes de silicona causen signos, síntomas o enfermedades neurológicos.

\section{Enfermedades del tejido conjuntivo bien definidas (relacionadas con trastornos autoinmunes)}

Los estudios disponibles, incluyendo los publicados recientemente, indican que las mujeres con implantes de mama de silicona no presentan un mayor riesgo de padecer algunas enfermedades autoinmunes bien definidas (potencialmente enfermedades del tejido conjuntivo mortales), como esclerodermia, lupus eritematoso, artritis reumatoide, síndrome de Sjogren, dermatomiositis o polimiositis, y otros trastornos de salud como, por ejemplo, la fibromialgia y el síndrome de fatiga crónica.

\section{Otros efectos sistémicos}

De acuerdo con la información proporcionada por grupos de apoyo mutuo, algunos médicos y algunas fuentes adicionales, un cierto número de mujeres con implantes de silicona han experimentado trastornos de este tipo, además de una gran variedad de síntomas que se pueden relacionar con el sistema inmune. Estos síntomas incluyen, dolor e inflamación de las articulaciones; tirantez, enrojecimiento o inflamación de la piel; glándulas o nódulos linfáticos inflamados; fatiga inusual o inexplicable; tumefacción de las manos y los pies; pérdida excesiva de cabello; problemas de memoria; cefalea; debilidad o molestias musculares. En algunos casos, las mujeres han notado una reducción en los síntomas tras la extirpación de los implantes; en otros casos, no hubo cambio en los síntomas tras la eliminación. En este momento, no está claro si los signos o síntomas experimentados por estas mujeres se deben a sus implantes.

En resumen, la literatura epidemiológica muestra que las pruebas sobre la existencia de una enfermedad atípica o un síndrome nuevo son insuficientes y no existe ninguna base suficientemente robusta o convincente para explicar estos trastornos. Sin embargo, la existencia de un síndrome o síndromes específicos en mujeres con implantes de mama de silicona no se puede demostrar ni descartar completamente en este momento, y merece un análisis adicional.

\section{Efectos «verticales» (de madre a hijo)}

\section{Riesgos a lactantes}

En este momento, no parecen existir pruebas de efectos dañinos a lactantes amamantados por mujeres con implantes de mama de silicona, aunque se necesitan estudios adicionales en este campo para esclarecer este tema. 


\section{Efectos locales}

\section{Complicaciones locales}

Los estudios apuntan a las complicaciones locales, incluyendo complicaciones perioperatorias debidas al propio procedimiento quirúrgico, como el principal riesgo potencial para la salud de los implantes de mama de silicona. Es notable la alta frecuencia (en términos relativos) de estas complicaciones. Aunque normalmente éstas no son peligrosas para la vida, pueden causar malestar, molestias, desfiguración, dolor y otras alteraciones que pueden llevar a la explantación y, cuando se requieren procedimientos correctores adicionales, pueden suponer un riesgo potencial suplementario (por ejemplo, cirugía adicional). Los implantes de mama tienen una vida limitada, que aún no está bien establecida. En cualquier caso, se constata que la probabilidad de necesitar una segunda operación es alta y aumenta con el tiempo.

\section{$\overline{\text { Preocupaciones }}$ de ciertos grupos de mujeres}

En EE.UU., una demanda judicial presentada a favor de mujeres con implantes de silicona se resolvió con una compensación sustancial para los demandantes. Aún más importante es el hecho de que este caso señaló la falta de advertencias e información apropiadas por parte de los fabricantes acerca de los riesgos potenciales.

En Europa, en marzo de 1999 se presentaron dos peticiones por parte de grupos de apoyo mutuo de mujeres que afirmaban haber sufrido efectos adversos de implantes y pedían al Parlamento Europeo (PE) una prohibición inmediata de los implantes de silicona. El PE ha solicitado que se presente una respuesta formal y pruebas al Comité de Peticiones, y ha pedido consejo al Comité de los Derechos de la Mujer, al Comité de Salud Pública y Protección del Consumidor y al Comité de Investigación (Committee on Women's Rights, the Committee on Public Health and Consumer Protection and the Committee on Research).

Muchas mujeres con implantes de mama de silicona consideran que no se les proporcionó la información suficiente sobre los riesgos para la salud para poder consentir de una manera fundamentada (previamente infor- madas). En EE.UU., un requerimiento esencial para todas las mujeres que se someten a cirugía de implante de mama es la firma de un formulario de consentimiento informado que explica todos los posibles riesgos conocidos. En Europa, todos los países han adoptado normas o una legislación general que reconocen a los pacientes el derecho de recibir información clara acerca de los riesgos y beneficios de estas intervenciones médicas, aunque todavía no existe un formulario común estandarizado y aceptado y utilizado de forma generalizada.

\section{Posibles beneficios de los implantes de mama y las alternativas disponibles}

Existe una clara demanda por parte de las mujeres de implantes de mama, tanto desde un punto de vista cosmético (aumento) como reconstructivo (después de una mastectomía). Por tanto, han de considerarse también de forma adecuada los beneficios potencialmente aportados por los implantes de mama. Parece ser que las principales razones para la demanda de cirugía cosmética son el interés en aumentar la autoestima a través de la mejora de la imagen, el percibirse como más atractiva y la mejora en las relaciones sociales. Adicionalmente, se deben comparar los implantes de mama de silicona con las alternativas disponibles.

Con el objetivo de reflejar todos los puntos de vista sobre este tema (negativos y positivos), hemos entrevistado a pacientes, contactado y recibido información de grupos de apoyo mutuo, de grupos de mujeres, de cirujanos plásticos y reparadores, de fabricantes de implantes de mama de silicona, de sociedades científicas y de autoridades de los países miembros de la Unión Europea. Hemos incorporado esta información y las distintas posiciones en este informe de la mejor manera posible y enviado al Parlamento la información primaria para que pueda evaluar la documentación original.

Nos gustaría enfatizar que, durante la realización de este informe, nos encontramos con puntos de vista confrontados y, en ocasiones, recibimos información contradictoria, lo que hizo complejo el reto de reflejar de forma clara, objetiva, meticulosa e imparcial todos los puntos de vista. Están en juego intereses relevantes a ambos lados del tema, todos válidos y legítimos. Por tanto, nuestro objetivo es reflejar la complejidad del problema, tratando de resaltar lo esencial, de manera que el Par- 
lamento Europeo pueda tomar la decisión más apropiada con relación a este tema.

\section{Líneas de acción posibles}

Opción 1: Status quo: ninguna prohibición específica, mantener la aplicación del actual marco legal (es decir, la Directiva 93/42/EEC, que establece las bases generales).

Ventajas: buena base legal establecida, pruebas poco convincentes acerca de riesgos graves, mantiene la situación actual.

Desventajas: las pruebas apuntan hacia la necesidad de una armonización europea apropiada con objeto de aumentar y mejorar las medidas para mayor y mejor protección de las mujeres y de su salud en la CE; grupos de apoyo mutuo y otros han demandado una prohibición inmediata.

Opción 2: Prohibición de los implantes de mama de silicona debido a la ausencia de información detallada con relación a los riesgos $\mathrm{y}$ a las peticiones formuladas por algunos grupos.

Ventajas: opción más "conservadora» -actualmente ejercida, por ejemplo, por los EE.UU., Canadá y Francia- debido a la falta del conocimiento completo con relación a los riesgos por el corto período de seguimiento de las mujeres y otros factores, como la variedad de los implantes utilizados, etc.; opción más deseada por algunos grupos y personas (por ejemplo, grupos de apoyo mutuo de mujeres que sufren de los efectos adversos de los implantes de silicona).

Desuentajas: importante demanda por parte de las mujeres de estos implantes, especialmente teniendo en cuenta los problemas asociados con las principales alternativas -los implantes salinos y los que utilizan otros geles-, como por ejemplo un mayor riesgo de ruptura, peor apariencia, etc. Las alternativas a los implantes de silicona disponibles podrían ser opciones menos deseables (incluso más peligrosas) y se necesitan más estudios antes de fomentar su uso. Adicionalmente, los estudios sobre implantes rellenos de gel de silicona son consistentes, apuntando a pruebas poco concluyentes acerca de los riesgos de graves problemas para la salud y señalando como principal preocupación sanitaria las complicaciones locales, que también están presentes en los implantes alternativos. Finalmente, desde una perspectiva social relacionada con la salud, también podría existir un potencial daño económico para la indus- tria (por ejemplo, pérdida de empleo), sin que exista una base sólida para restringir este tipo de prótesis, manteniendo otras que podrían ser más problemáticas.

Opción 3: No establecer una prohibición total, pero adoptar e implementar medidas críticas específicas para aumentar y mejorar la información a los pacientes, el seguimiento, la vigilancia y el control de calidad y apoyar líneas prioritarias de investigación (véanse las siete medidas propuestas a continuación).

Ventajas: los estudios no apuntan a una asociación entre los implantes de silicona y riesgos serios para la salud, como el cáncer o las enfermedades del tejido conjuntivo. Las complicaciones locales - tanto o más prevalentes que en otros implantes de mama, como los salinos - son la principal causa de preocupación. La información obtenida de los grupos de apoyo mutuo, de los cirujanos y de la literatura apunta a una verdadera necesidad de introducir mejoras, particularmente en relación con el suministro de información correcta a los pacientes con respecto a los riesgos.

Desventajas: los grupos de apoyo mutuo y otros han demandado una prohibición inmediata; se necesita realizar una verdadera inversión para que las acciones propuestas se lleven a cabo.

En vista de las pruebas, la opción 3, que propone medidas adicionales para maximizar los beneficios de los implantes de mama y limitar los riesgos en el contexto de la UE, parece ser el enfoque más equilibrado. Las medidas adicionales propuestas se describen a continuación (y se detallan en la sección de Opciones de este informe, sección 1.2):

1. Facilitar el consenso acerca de un documento de consentimiento informado para implantes de mama, incluyendo información con relación a las distintas alternativas, los beneficios y los riesgos.

2. Garantizar el control de la comercialización de los implantes de mama para evitar cualquier información incorrecta o engañosa.

3. Mejorar la certificación, los estándares técnicos y la regulación.

4. Promover la elaboración de guías y protocolos clínicos y el desarrollo de sistemas de control de calidad.

5. Facilitar el consenso, promover y apoyar el desarrollo de sistemas efectivos de vigilancia de los efectos adversos y los efectos a largo plazo. 
6. Considerar los implantes de mama de silicona una investigación prioritaria y proporcionar fondos en los programas de investigación de la UE, especialmente enfocados a algunas de las deficiencias de la investigación hasta la fecha.

7. Fomentar la tolerancia y autoestima y otras alternativas conceptuales a los implantes de mama, en colaboración con grupos activos en este campo.

En resumen, la opción que consiste en no establecer una prohibición, pero sí adoptar e implementar medidas críticas específicas para aumentar y mejorar la información que reciben las pacientes, el seguimiento y la vigilancia, las guías y protocolos clínicos, el control y garantía de calidad y apoyar líneas prioritarias de investigación. Estas medidas podrían ser razonablemente coherentes con la filosofía que subyace en los criterios de los principios de precaución europeos y, posiblemente, la alternativa más equilibrada tras considerar las pruebas existentes. 


\section{Riesgos para la salud causados por implantes de silicona en general, con atención especial a los implantes mamarios}

\section{Opciones}

\subsection{Antecedentes para las opciones relevantes europeas}

\subsubsection{Opciones para los dispositivos implantables. Posiciones del mercado y dinámica social previsibles para la difusión y control de implantes de silicona}

\section{Antecedentes y principios}

El desarrollo de tecnologías innovadoras y la creciente necesidad de armonizar el contexto político europeo han atraído mucha atención hacia el entorno regulatorio de nuevos dispositivos médicos. Las nuevas tecnologías pueden potencialmente ofrecer ventajas a la hora de mejorar la salud o aliviar el sufrimiento, pero también pueden presentar riesgos para la salud, costes sociales y/o económicos, o plantear problemas éticos relevantes. Por tanto, sería sensato afirmar que se necesita cierta protección para impedir la adopción de tecnologías potencialmente dañinas, al mismo tiempo que se hace posible el entorno adecuado para la innovación y el acceso de nuevos dispositivos médicos eficaces destinados a satisfacer las demandas y necesidades de la población europea.

\section{Tipos de implantes}

Existe una enorme variedad de implantes de mama en el mercado. Se han comercializado y utilizado cientos de modelos distintos. Se han presentado numerosas variaciones en el tipo de cápsula, los materiales de relleno, el número de cavidades, el tamaño, la forma, el tipo de intervención y otras características. Desde su introducción en 1962, se han realizado un gran número de cambios en los implantes de mama de silicona. Estos cambios representan una dificultad suplementaria a la hora de evaluar sus efectos sobre la salud. Además, estas modificaciones se introdujeron con pocas o ninguna prueba para comprobar los efectos biológicos o clínicos. Entre los cambios que afectaron al comportamiento clínico de los implantes de silicona se encuentran: las variaciones del control de la difusión de la silicona a través de la cápsula de gel del implante, el grosor de la cápsula y, por tanto, la durabilidad tanto de los implantes rellenos de gel como de los salinos, así como de la cobertura de poliuretano. A medida que los cirujanos plásticos y fabricantes adquirían conocimientos acerca de los problemas asociados con modelos existentes de implantes, se realizaban modificaciones con objeto de mejorar dichos implantes. Algunos de esos cambios han sido variaciones en las cápsulas, la textura, la mejora de las válvulas en los implantes salinos y uso de cápsulas más gruesas que resisten mejor las rupturas o pérdidas de volumen. Por ejemplo, con este objetivo se han desarrollado implantes de mama con cápsulas de poliuretano, implantes de mama de lípidos (nuevos implantes rellenos de aceite de soja; por cierto, con riesgos que se están evidenciando) o de polímeros y otros tipos de implantes.

Desde que comenzaron a comercializarse en los años sesenta, se han sucedido tres generaciones de implantes de mama rellenos de gel de silicona. La primera generación de implantes estaban compuestos por un gel denso de silicona y una cápsula gruesa (de superficie lisa). Estos implantes presentan una tasa de ruptura baja y una tasa elevada de difusión del gel y contractura capsular. La segunda generación, utilizada desde mediados de los años setenta hasta finales de los ochenta, se fabricaron con una fina cápsula (lisa) de silicona y presentaban una tasa alta de difusión del gel y ruptura. La tercera generación, fabricada desde mediados de los ochenta, poseían una cápsula gruesa de silicona (rugosa) y presumiblemente presentan una tasa más baja de difusión del gel, ruptura y contractura capsular, aunque es necesario un seguimiento cuidadoso a más largo plazo de estos implantes antes de poder realizar una afirmación definitiva sobre sus características. 
Existen otros tipos de implantes de mama. Por ejemplo, como hemos mencionado anteriormente, existen implantes cubiertos de poliuretano cuya cobertura pretende reducir el riesgo de contractura. Las inquietudes sobre este material surgieron al observar que podía causar cáncer en animales al descomponerse, lo que ha llevado recientemente a la realización de un estudio en mujeres. Los hallazgos de este estudio indican que el poliuretano no aumenta el riesgo de cáncer en las mujeres. No se ha descartado completamente un aumento del riesgo de cáncer en lactantes, aunque la ausencia de este incremento de riesgo en mujeres es alentadora.

Mientras que la mayoría de los implantes de mama contienen una cápsula de silicona, se utilizan distintos tipos de relleno en estos implantes (rellenos de gel de silicona, salinos, aceite de soja, hidrogel). Los implantes rellenos de gel de silicona (objeto principal de este estudio) y los salinos han sido mencionados anteriormente, pero también existe un implante fabricado con aceite purificado de soja. En EE.UU. se ha realizado un estudio clínico para evaluar la seguridad de este tipo de implante y, actualmente, la FDA está analizando los resultados. En el Reino Unido, este tipo de implantes fueron prohibidos en 1999 debido a la aparición de algunos problemas y a la falta de información con respecto a sus efectos a largo plazo. Finalmente, también existen en el mercado implantes de hidrogel, cuya seguridad tampoco está suficientemente contrastada.

A continuación se enumeran algunas ventajas y desventajas de los distintos tipos de implantes mamarios:

Silicona.-Ventajas: larga experiencia acerca de su uso, relativamente baja tasa de ruptura, mejor apariencia y sensación, normalmente permanece en la cápsula si se rompe. Desventajas: inquietudes y prejuicios sobre la silicona y su seguridad, algunos médicos y grupos de mujeres afirman padecer síntomas adversos asociados con la silicona.

Salino.-Ventajas: fisiológico, no se hincha ni se encoge, el contenido del implante es asimilado por el propio cuerpo. Desventajas: tasa más alta de ruptura y pérdida de volumen que la silicona, aumento de la probabilidad de deformación de la cápsula, propensa a debilitarse. Presenta peor aspecto y se puede percibir ruido asociado al movimiento del contenido (en ocasiones se puede escuchar la solución salina).

«Trilucent»/aceite de soja purificado.-Ventajas: aceite de soja, percibido inicialmente como más seguro. Desventajas: existen informes de hinchazón y dolor, experiencia corta de uso y falta de suficiente información acerca de su seguridad. Existen datos pendientes, pero los riesgos potenciales están empezando a constatarse.

Hidrogel.-Ventajas: más consistentes que los salinos, material natural, percibidos como seguros. Desventajas: no son isotónicos; absorben agua y pueden hincharse hasta romperse, la seguridad no está establecida y no se ha descartado algún tipo de toxicidad, no existen estudios a largo plazo.

Tejido autógeno.-Empleado principalmente en reconstrucciones de mama. Dichas reconstrucciones se combinan frecuentemente con implantes. Se han empleado injertos de dermis, injerto de musculocutáneo abdominal o de otras localizaciones e injertos microquirúrgicos. Ventajas: seguros, generalmente dan buenos resultados. Desventajas: utilizar con cautela, dependiendo del origen del tejido pueden presentar problemas.

\section{Fabricantes de implantes de mama}

Los principales fabricantes de implantes de mama son compañías multinacionales americanas, pero también existe un claro componente europeo en este sector comercial. Grandes compañías como McGhan y Mentor Corporation producen implantes de silicona y salinos. Hutchinson International y Poly Implants Prostheses también producen implantes rellenos de solución salina. Muchos fabricantes importan implantes de mama a países de la UE. Otras empresas que fabrican o han fabricado implantes de mama en la UE incluyen: Polytech/Silimed y Novamed en Alemania; Nagor y Jutchinson en el Reino Unido; Poly Implant Protheses, Laboratories Eurosilicone, Sebbin y Arion en Francia; y Biomedica Sviluppo e Impax Diffusion en Italia. EUCOMED es una organización que representa a las principales empresas de este sector y sus intereses en Europa.

\section{Demanda de implantes}

Acerca de la dinámica social referente a implantes de silicona, es importante enfatizar la gran demanda de implantes de mama, tanto por razones cosméticas como reconstructivas, en los países industrializados. Según reseñas en EE.UU., desde 1997, aproximadamente el $70 \%$ de los implantes de mama se 
realizaron por razones de aumento de mama y el 30\% por reconstrucciones mamarias. La demanda de implantes de mama existe desde los años sesenta, y continúa creciendo. Recientemente, la demanda de implantes, además de para mujeres, también ha mostrado un incremento por parte de hombres (por ejemplo, en cirugía de cambio de sexo).

En términos de mejora de salud y calidad de vida, la demanda por parte de muchas mujeres y hombres de cirugía cosmética de mama se debe a los importantes beneficios que afirman que les proporciona. Aunque las razones para la obtención de implantes de mama no están muy bien estudiadas, el interés en la mejora de la autoestima a través de la aparente mejora de la imagen, el sentirse más atractivo y la mejora en las relaciones sociales parecen ser las razones principales a la hora de solicitar cirugía cosmética. Los implantes de mama parecen ser un procedimiento eficaz para satisfacer estas peticiones.

\section{Satisfacción}

La mayoría de los informes sobre satisfacción presentan unos resultados muy buenos, pero se deben tener en cuenta dos cosas. Primero, la satisfacción es una dimensión subjetiva. También es cierto que muchos informes publicados sobre satisfacción contienen limitaciones obvias. Frecuentemente, estudios de satisfacción se llevan a cabo sin contar con un diseño apropiado y por los mismos cirujanos plásticos que realizan la intevención, lo cual puede llevar a informes incompletos o incluso sesgados. Adicionalmente, el intervalo postoperatorio explorado es muy corto o no está bien especificado. Otros posibles sesgos o distorsiones de las respuestas de los pacientes son el pequeño número o la falta de representatividad de las mujeres entrevistadas, el carácter voluntario de las encuestas y la utilización como principal resultado de la satisfacción global, en términos muy generales. Las mujeres han demostrado una tolerancia considerable a la contractura del implante, optando por no solicitar atención médica con grados de contractura serios (de clases III o IV) y, en general, mostrándose satisfechas con sus implantes al ser encuestadas. Un estudio de 1990 concluyó que el 85\% de las mujeres parecían estar satisfechas con sus implantes, a pesar de que el 35\% habían sufrido una contractura severa (Gylbert LO et al., 1990). Los estudios presentan altos grados de satisfacción de las mujeres con implantes de mama (entre el 80 y el 95\%). Una encuesta llevada a cabo por cirujanos plásticos en EE.UU. obtuvo que el $84 \%$ de las mujeres implantadas por razones de aumento de tamaño de la mama y el 91\% de las mujeres con implantes por reconstrucción estaban satisfechas o muy satisfechas, en un intervalo desde la operación de uno a diez años (Park AJ et al., 1996).

Por otro lado, datos nacionales de EE.UU. sobre satisfacción y efectos adversos (desde 1984 a 1995) presentan 94.120 eventos adversos comunicados, la mayoría de los cuales se deben a complicaciones locales o perioperatorias (contractura y ruptura). El número de experiencias adversas alcanzó un máximo en el período 1992-1994 y disminuyó notablemente en 1995.

Con motivo de recoger datos primarios para este informe, por petición del Scoping Meeting (organizado en el Parlamento Europeo para especificar los objetivos de este informe), hemos entrevistado a pacientes con implantes de mama para valorar sus puntos de vista y el grado de satisfacción con sus implantes. Conseguimos identificar a mujeres dispuestas a conversar con nosotros y ser entrevistadas. Nos gustaría subrayar que el muestreo utilizado en esta exploración no permite generalizar los resultados (debido a que las mujeres que participaron fueron voluntarias) y el número de participantes era reducido. A pesar de esto, pensamos que es interesante considerar esta información de carácter anecdótico que muestra también un elevado grado de satisfacción. También pudimos experimentar directamente la complejidad y dificultad de este ejercicio de evaluación, debido a la inherente naturaleza personal de los implantes de mama y al sentido de intimidad de las mujeres intervenidas. Al mismo tiempo, puede producirse un sesgo de selección si, únicamente, algunas mujeres están dispuestas a proporcionar su punto de vista sobre su satisfacción. Por esta razón, hemos sido testigos de algunas de las limitaciones de las entrevistas directas, empleadas normalmente en la obtención de indicadores de satisfacción.

Parece lógico que la existencia de posibles riesgos asociados con la intervención deba ser contrapuesta con los beneficios percibidos por las mujeres. La percepción de buenos resultados por parte de las mujeres mantiene la demanda de implantes de mama. Sin embargo, junto a esta demanda, existe un aumento de la preocupación por los problemas potenciales, particularmente agravados por la atención que ha recibido este tema en EE.UU. a lo largo de esta última década. Estas inquietudes se han trasladado al contexto europeo. 


\subsubsection{Acción europea e internacional en este campo}

Es difícil comprender los antecedentes que rodean a los esfuerzos realizados en Europa en este campo sin entender previamente los antecedentes de EE.UU.

\section{La experiencia de EE.UU.}

En EE.UU., las Enmiendas sobre Dispositivos Médicos, en vigor desde 1976, atribuyen a la FDA autoridad para regular los dispositivos médicos tales como los implantes de mama, que se encontraban en el mercado desde los años sesenta.

La FDA clasifica en tres categorías los dispositivos médicos. Las clases I y II corresponden a dispositivos cuya seguridad y efectividad están bien establecidas. Los de clase I son dispositivos simples, cuyos riesgos se pueden controlar en el proceso de fabricación; los dispositivos de clase II requieren medidas suplementarias para controlar los riesgos potenciales, denominadas controles especiales. Los controles especiales pueden incluir normativas de funcionamiento, estudios de vigilancia postcomercialización, formación del usuario u otras medidas. En caso de ausencia de información para determinar si un dispositivo es seguro y eficaz se incluye en la clase III, que exige el máximo grado de revisión antes de su salida al mercado. Los dispositivos de clase III incluyen dispositivos médicos innovadores y nuevas tecnologías, además de dispositivos de efectividad y seguridad poco establecidos o cuestionables.

Una breve revisión de la regulación por parte de la FDA permite clarificar la situación actual, en la que se utilizan principalmente los implantes de mama rellenos de solución salina, y describe los efectos de las acciones emprendidas por parte de la autoridad gubernativa respecto a los implantes rellenos de gel, cubiertos de poliuretano y otros implantes, y respecto a las compañías que los fabrican.

En 1976, el FDA General and Plastic Surgery Devices Panel (Panel de Dispositivos de Cirugía General y Plástica de la FDA) (referida como el Panel) recomendó la colocación de los implantes de mama en la clase II, que requieren controles y estándares de funcionamiento generales. El 19 de enero de 1982, debido a la comunicación en la literatura médica de efectos adversos, la FDA anunció su propuesta de incluir los implantes de mama en la clase III, y la aplicación de los controles más rigurosos de seguridad y efectividad.

En 1988, la FDA clasificó todos los implantes de mama en la clase III. Después de un período de espera de treinta meses, la FDA puede requerir solicitudes de aprobación previas a su comercialización (PMAs), en las que los fabricantes han de presentar datos que demuestren la seguridad y efectividad de estos dispositivos. En abril de 1991, en respuesta a un creciente número de informes sobre reacciones adversas que crearon inquietud acerca de la seguridad de los implantes rellenos de gel de silicona, la FDA publicó una reglamentación que exigía a los fabricantes la presentación de solicitudes de aprobación previas a su comercialización, con datos que demuestren la seguridad y efectividad de los implantes antes del 9 de julio de 1991. Los datos aportados por los fabricantes no probaron de forma inequívoca la seguridad de los implantes, por lo que la agencia los retiró del mercado en abril de 1992 y restringió su uso a ensayos clínicos en casos de reconstrucción tras una mastectomía, corrección de anomalías congénitas o reemplazo de implantes de silicona por ruptura realizados para aumento de volumen mamario. La FDA denegó solicitudes de implantes de mama de silicona con la finalidad de aumentar el tamaño de la mama, pero contempló la posibilidad de que los fabricantes pudieran realizar con posterioridad ensayos clínicos con un número limitado de casos de implantes para aumentar el volumen mamario.

El 5 de junio de 1998, la FDA aprobó el estudio médico IDE (Investigational Device Exemptions - Exenciones a Dispositivos en Investigación) de McGhan sobre implantes de mama de silicona para reconstrucción, aumento del tamaño de la mama y revisión de un limitado número de pacientes en centros determinados. El estudio de Mentor's Corporation (la Corporación Mentor) también fue aprobado por la FDA. Los implantes de mama rellenos de gel de silicona y otros implantes alternativos también están disponibles para mujeres que participan en estudios IDE.

Con relación a los implantes de mama salinos, aunque todavía permanecen en el mercado en EE.UU., el 23 de diciembre de 1994 la FDA anunció que las empresas que los comercializan debían inscribir a pacientes en ensayos clínicos y realizar estudios clínicos y de laboratorio para determinar la seguridad y efectividad de estos implantes. Desde entonces, los fabricantes han estado remitiendo da- 
tos a la FDA para solicitar la aprobación previa a su comercialización (PMA).

Actualmente, la FDA está evaluando estos datos y la ley obliga a que se aprueben dichas solicitudes para que las empresas puedan continuar vendiendo los implantes salinos. Una reunión sobre las PMA de implantes salinos tuvo lugar del 1 al 3 de marzo de 2000, y el Comité Asesor de la FDA recomendó la aprobación de los implantes de Mentor y McGhan, aunque, en el momento de finalización de este informe, la FDA no ha adoptado aún una decisión a este respecto.

Una demanda judicial presentada a favor de mujeres con implantes de silicona se resolvió con una elevada compensación económica para los demandantes. Aún más importante, en este caso se señaló la falta de advertencias e información apropiadas por parte de los fabricantes acerca de los riesgos potenciales y reales. El juzgado solicitó a un panel de expertos la realización de un informe acerca de las consecuencias para la salud de los implantes de mama de silicona. A raíz de esto, el National Science Panel (NSP/Panel Nacional Científico) (cuatro expertos en toxicología, inmunología, epidemiología y reumatología) presentó en 1998 un informe al Honorable S. C. Pointer, Juez para el Federal Breast Implant Multi-District Litigation (Demanda Judicial Federal sobre Implantes de Mama). Este informe revisó la literatura científica relacionada con los implantes de mama de silicona y las enfermedades del tejido conjuntivo y disfunciones inmunológicas.

En 1999, el Institute of Medicine (IOM) of the National Academy of Sciences (Instituto de Medicina de la Academia Nacional de las Ciencias), a solicitud del Departamento americano de Salud y Servicios Humanos, completó una revisión exhaustiva de las pruebas que relacionaban los implantes de mama de silicona con problemas de salud. El objetivo del estudio consistía en realizar una revisión independiente e imparcial de toda la investigación científica disponible en relación con la seguridad de los implantes de mama de silicona. Con este objetivo, un comité de expertos en áreas científicas y clínicas relacionadas evaluó los estudios publicados y en desarrollo sobre la relación entre los implantes y enfermedades sistémicas; los efectos biológicos e inmunológicos de la silicona y otros componentes químicos del implante de mama, y el posible efecto de los implantes de mama sobre la descendencia de mujeres con implantes o las dificultades que los implantes presentaban para la obtención de mamografías de calidad.
Los estudios del NSP y del IOM no encontraron ninguna prueba de asociación entre los implantes de mama de silicona y un aumento del riesgo de cáncer o de enfermedades del tejido conjuntivo, las dos principales causas de preocupación. Los resultados de estos (y otros) estudios se comentan con más detalle en el apartado 2 de este documento.

Según el estudio del IOM, se estima que en EE.UU. existen entre 1,5 y 1,8 millones de mujeres con implantes mamarios. Aproximadamente el $70 \%$ de estos implantes se colocaron por razones estéticas (por ejemplo, para aumentar el tamaño o cambiar la apariencia de la mama), y el 30\% por razones de reconstrucción (por ejemplo, para restablecer la forma de la mama tras una mastectomía por cáncer, enfermedad fibroquística u otras indicaciones médicas). Datos proporcionados por la American Society of Plastic Surgeons (Sociedad Americana de Cirujanos Plásticos) indican que, únicamente en 1998, se realizaron 132.378 intervenciones para aumentar la mama (97\% rellenos de solución salina y 3\% rellenos de gel, $61 \%$ en mujeres menores de 35 años) y 69.683 intervenciones de reconstrucción de mama (75\% rellenos de solución salina y 15\% rellenos de gel, 94\% en mujeres menores de 35 años). Al mismo tiempo, se realizaron 43.681 extracciones de implantes (eliminación de los implantes), principalmente por síntomas físicos causados por estos implantes (93\%), como por ejemplo contractura capsular. La cirugía mamaria cosmética o reconstructiva representa más del 10\% del total de las intervenciones de cirugía plástica. Desde 1992 hasta 1998 se ha observado un aumento en estas intervenciones: aumento de mama (306\%), reconstrucción de mama (135\%), extracción de implante (76\%). Asimismo, más de 10 millones de personas en Estados Unidos tienen algún tipo de implante (articulaciones, marcapasos, etc.), y una gran cantidad de estos implantes se componen, al menos en parte, de silicona.

Actualmente, la FDA dirige un estudio iniciado a principios de 1998 para evaluar la tasa de ruptura de los implantes mamarios rellenos de gel de silicona. El estudio incluirá a más de 1.200 mujeres con implantes. En caso de ruptura, serán revisados sus historias e informes clínicos. Un subgrupo de mujeres que conserven sus implantes se someterán a un estudio de resonancia magnética para detectar posibles rupturas. 


\section{La experiencia europea}

Como resultado de la creciente preocupación en EE.UU. por los posibles riesgos para la salud de los implantes de mama durante los años ochenta, también en Europa se focalizó la atención en este tema. Así, se desarrollaron una variedad de iniciativas de grupos de estudio e investigación para responder a estas preocupaciones. Una revisión exhaustiva de los estudios toxicológicos de la silicona y de otros estudios no proporciona base suficiente para asociar los implantes de silicona a riesgos importantes para la salud. Sin embargo, la necesidad de realizar procedimientos quirúrgicos correctores adicionales y las frecuentes complicaciones locales y perioperatorias podrían llegar a merecer especial atención. Los riesgos se acumulan a lo largo de la vida del implante, pero faltan datos cuantitativos al respecto para los implantes modernos puesto que históricamente son bastante deficientes. Debido a los riesgos para la salud, especialmente con relación a la naturaleza y elevada frecuencia (en términos relativos) de complicaciones locales y a la necesidad de operaciones adicionales, la necesidad de obtener un consentimiento informado apropiado (con información completa y adecuada) se ha convertido en un elemento imprescindible para las mujeres que se someten a una operación de implante de mama. También se debe tener en cuenta que, a pesar de las pruebas poco concluyentes acerca del riesgo para la salud asociado a los implantes de silicona, un grupo considerable de mujeres implantadas han experimentado síntomas variados y de díficil explicación y han formado grupos de apoyo mutuo en Europa. Hemos recibido información y documentación de grupos de apoyo mutuo en el Reino Unido/Escocia, Países Bajos, Alemania, Bélgica, Suiza e Islandia. Dos de estos grupos han demandado la prohibición inmediata de estos dispositivos (véase el Parlamento Europeo, Noticias de Prensa del 22-3-99). Esta postura también debe ser adecuadamente considerada y, junto a la complejidad intrínseca de descartar por completo cualquier riesgo asociado con estos implantes, debe explicar la razón por la cual esta cuestión sigue suscitando cierta preocupación.

Es muy difícil determinar con exactitud el número de mujeres con implantes en la UE, y sólo se dispone de datos en algunos países como el Reino Unido, que ha desarrollado un registro de implantes mamarios. Así, durante el período 1996-1997 se registraron 12.829 implantes mamarios en el Reino Unido, de los que el $80 \%$ son de gel de silicona, el $2 \%$ salinos, el $12 \%$ de lípidos o polímeros y el $6 \%$ de otro tipo. La mayoría de las mujeres recibieron un implante mamario para aumentar el tamaño de su mama o por otras razones cosméticas (70-80\%). En muchos países, sin embargo, la ausencia de un registro y un sistema obligatorio de notificación constituye una limitación para determinar la frecuencia de aparición de complicaciones locales. Éstas son solamente algunas de las limitaciones que deben reconocerse a la hora de examinar los antecedentes en esta materia.

Sin embargo, al mismo tiempo, las sociedades científicas y profesionales han progresado mucho respecto a sus guías clínicas, protocolos, normas de calidad y otros aspectos relevantes, como por ejemplo el consentimiento informado, para proporcionar mejores opciones a las mujeres que demanden implantes mamarios.

Se han realizado varias iniciativas de revisión e investigación en Europa, como el informe publicado en Francia por ANDEM (1996) y la exhaustiva revisión llevada a cabo por el UK Independent Review Group (Grupo de Revisión Independiente del Reino Unido) (1998). También se han realizado estudios observacionales, incluyendo un estudio poblacional de cohortes en Dinamarca (1998) y un estudio retrospectivo de cohortes en Suecia (1998).

En relación con los esfuerzos emprendidos para clarificar cuestiones de seguridad y certificación apropiada de los implantes mamarios en Europa, esta materia ha sido tratada con mucha atención y ha llevado a distintos debates entre la Comisión y los Estados miembros. Este proceso ha conducido a la adopción de diferentes medidas por parte de los Estados miembros en Europa. La Directiva del Consejo 93/42/EEC, del 14 de junio de 1993, es actualmente la piedra angular en este campo (véase 1.1.4).

En el Reino Unido, la Medical Devices Agency (MDA) (Agencia de Dispositivos Médicos) estableció un Grupo Asesor Independiente de Expertos y publicó un informe de revisión en 1992, que fué actualizado en 1994. En 1993 se creó el Registro Nacional de Implantes de Mama. Para más detalles, véase la sección 1.1.4.

En España, un grupo de trabajo de expertos independientes revisó las pruebas existentes y concluyó con una propuesta de registros de implantes y explantes. Al cierre de este informe se nos ha informado que en los póximos 
meses podrían estar disponibles los primeros datos relativos a estos registros.

En cuanto a inversiones y esfuerzos tecnológicos, nuevos desarrollos en la tecnología de implantes mamarios pueden cambiar la perspectiva actual, pero necesitan ser considerados y evaluados con cautela. El gel de silicona cohesivo representa una innovación. Se ha probado y utilizado en Europa una nueva fórmula de hidrogel de polivinilpirrolidona (PVP) en implantes mamarios. Asimismo, el uso de implantes salinos previamente rellenos, en lugar de rellenarse durante la implantación en el acto quirúrgico, con una solución estéril de agua salina puede eliminar las fugas de la válvula y mejorar la esterilidad. En breve, estas innovaciones podrían proporcionar opciones suplementarias para mujeres que soliciten un aumento o reconstrucción de mama, pero necesitan revisión y atención adicionales.

\subsubsection{Revisión de la legislación europea}

\subsubsection{Directivas relacionadas con los implantes/dispositivos médicos}

Los implantes mamarios están regulados por la Directiva del Consejo 93/42/EEC, del 14 de junio de 1993, que concierne a los dispositivos médicos.

Como regla general, en Europa, todos los dispositivos médicos están obligados a mostrar la marca «CE» que denota un estándar de conformidad europea. La marca «CE» permite al producto ser comercializado en la UE, aunque no garantiza su absoluta seguridad. Es importante tener en cuenta la dificultad de asegurar completamente la ausencia de riesgo en todas las circunstancias. De acuerdo con la Directiva europea de etiquetado «CE», los dispositivos deben cumplir unos requisitos esenciales precisados en el Anexo I de la Directiva, teniendo en cuenta el propósito previsto del dispositivo. El dispositivo no puede representar un peligro excesivo para la condición clínica o la seguridad del paciente, la seguridad o salud del usuario o de terceras personas. Adicionalmente, cualquier riesgo que pueda asociarse con su uso debe suponer un riesgo aceptable respecto a los beneficios esperados para el paciente. Los fabricantes deben ceñirse a unos principios de seguridad y eliminar o reducir los riesgos en la mayor medida posible, adoptar medidas de protección adecuadas en relación con los riesgos e informar a los usuarios de los riesgos existentes. Durante la vida del dispositivo, indica- da por el fabricante, sus características y funcionamiento no deben resultar afectadas adversamente hasta tal punto que las condiciones clínicas y la seguridad de los pacientes se vean comprometidas.

En cuanto al diseño y a las propiedades químicas, físicas y biológicas del dispositivo, se debe prestar especial atención al tipo de material empleado (toxicidad) y a su compatibilidad con los tejidos biológicos y los fluidos corporales.

Las normas aplicables a los productos sanitarios para el etiquetado «CE» están principalmente relacionadas con estándares tecnológicos, pruebas de materiales y evaluación de biocompatibilidad. Los efectos a largo plazo de los implantes, incluyendo efectos adversos, deben evaluarse mediante un sistema de vigilancia posterior a su comercialización, competencia y responsabilidad de cada Estado miembro, que normalmente se organiza como un sistema voluntario de notificación de incidentes, efectos secundarios no deseados, fallos, etc.

La conformidad con los Requisitos Esenciales para la seguridad y el funcionamiento se puede demostrar mediante el cumplimiento de las normas armonizadas. Las normas europeas relativas a los implantes mamarios incluyen normativas genéricas para el análisis de riesgos (EN 1441), normas para implantes no activos (EN ISO 14630), esterilización, seguridad biológica y otros requerimientos específicos para implantes mamarios (EN 12180, recientemente aprobado). Las diferentes características de los implantes mamarios relacionadas con su seguridad, incluyendo biocompatibilidad, propiedades mecánicas, desplazamiento del material de relleno y de la cápsula, compatibilidad entre el material de la cápsula y el de relleno, envejecimiento, estabilidad y etiquetado, están siendo tratadas por el European Committee for Standardisation (Comité Europeo de Normalización/ CEN) y un grupo de trabajo específico formado por organismos de certificación competentes en la valoración de estos productos, de acuerdo con la Directiva 93/42/EEC.

Existe una clasificación sistemática de los diferentes dispositivos médicos. Los implantes mamarios son considerados, específicamente, dispositivos médicos implantables no activos. Por lo tanto, al igual que el resto de dispositivos implantables y dispositivos quirúrgicamente invasivos a largo plazo, los implantes mamarios se han clasificado según su riesgo en la clase IIb. Este grupo lo forman productos con un elevado riesgo potencial, en los que se impone un control efectuado por un 
organismo notificado en lo relativo al diseño y la fabricación de estos dispositivos.

En el caso de los dispositivos de la clase IIb, para emplear la etiqueta CE, los fabricantes deben:

A) Seguir el procedimiento relativo a la declaración CE de conformidad (sistema completo de garantía de calidad según Anexo II de la Directiva). Los fabricantes deben asegurar la aplicación del sistema de calidad aprobado para el diseño, fabricación e inspección final de los productos en cuestión, y están sujetos a una inspección y vigilancia comunitaria.

O bien:

B) Seguir el procedimiento relativo al examen CE de tipo (Anexo III), en combinación con el procedimiento relativo a la verificación CE (Anexo IV), o bien con el procedimiento relativo al marchamo CE de conformidad (garantía de calidad de la producción según Anexo V), o bien con el procedimiento relativo al marchamo CE de conformidad (garantía de calidad del producto según Anexo VI).

La Directiva del Consejo 85/374/EEC, de 25 de julio de 1985, sobre las aproximaciones de leyes, reglamentos y estipulaciones administrativas de los Estados miembros con relación a la responsabilidad de productos defectuosos, también afecta a la responsabilidad de los fabricantes de los implantes de silicona.

\subsubsection{Directivas relacionadas con la protección del consumidor}

La necesidad de garantizar la seguridad y proteger la salud de los consumidores es una prioridad para la Unión Europea y los Estados miembros.

La acción comunitaria, en cuanto a la protección del consumidor, se basa en el artículo 129A del Tratado de la Unión Europea, que establece que la Unión Europea contribuirá con un nivel supremo de protección de los consumidores por medio de:

- Medidas adoptadas de acuerdo con el artículo 100A.

- Apoyo y acciones complementarias a las desarrolladas por los Estados miembros para proteger la salud, la seguridad y los intereses económicos de los consumidores, y garantizar a la población la información apropiada.
El número de directivas en este sector es muy elevado. La mayoría de las relacionadas con la salud se refieren a la seguridad y control de alimentos (sustancias con efectos hormonales, aditivos, etiquetado, alimentación especial) y seguridad general de los productos de consumo.

La fabricación, comercialización, clasificación, etiquetado, promoción y procedimiento de autorización de medicamentos y dispositivos médicos también han sido regulados por las directivas europeas.

\subsubsection{Otras referencias legislativas relevantes}

La Directiva del Consejo del 20 de junio de 1990 sobre las aproximaciones de leyes de los Estados miembros en relación con los dispositivos médicos implantables activos (90/385/EEC) es la única referencia legislativa adicional relacionada con implantes, pero, de hecho, no es aplicable directamente a implantes mamarios puesto que únicamente se refiere a «dispositivos médicos activos» (aquellos dispositivos que funcionan a partir de una fuente de alimentación eléctrica o cualquier otro tipo de fuente de energía distinta de la generada directamente por el cuerpo humano o la gravedad).

\subsubsection{Consulta con los Estados miembros de la UE, situación actual de la distribución y uso de implantes, postura gubernamental, políticas legislativas y sanitarias adoptadas}

En los Estados miembros de la UE (excepto en Francia) no se han adoptado restricciones legislativas para el uso de implantes mamarios rellenos de gel de silicona. Por tanto, no existe legislación específica acerca de los implantes de silicona y la mayoría de estos países ni siquiera ha considerado o planeado ninguna en particular, aparte de la conformidad y aplicación de la Directiva relativa a los Productos Sanitarios (93/42/EEC). Todos estos países han adoptado una legislación general o normas que establecen la responsabilidad de proporcionar información y el derecho de los pacientes a ser debidamente informados de los riesgos y beneficios antes de someterse a cualquier tipo de cirugía. Algunos países han implementado una reglamentación específica sobre información relacionada con los implantes de mama, a través de directrices dirigidas a pacientes y a cirujanos. Adicionalmente, sociedades nacionales científicas y 
profesionales relacionadas con cirugía cosmética y cirugía de la mama, y también el European Committee on Quality Assurance and Medical Devices in Plastic Surgery (EQUAM) (Comité Europeo de Garantía de Calidad y Dispositivos Médicos en Cirugía Plástica), han propuesto formularios de consentimiento informado específicos y documentos para proporcionar información a los pacientes sobre los riesgos y beneficios de esta intervención.

En el contexto europeo, las cuestiones sobre la seguridad y la certificación de los implantes de mama fueron discutidas en numerosas ocasiones entre la Comisión y los Estados miembros. Excluyendo a Francia, todos los países de la UE mostraron su conformidad con los Requerimientos Esenciales de la Directiva europea (93/42/EEC) como bases para la comercialización de los implantes de silicona. En el Reino Unido y en Francia, publicaciones científicas recientes sobre los riesgos de los implantes mamarios rellenos de gel de silicona fueron revisadas en 1996 y 1994 por científicos independientes expertos en el tema, de manera que estos Estados miembros adoptaron posturas diferentes.

En el Reino Unido, en 1991, el Medical Devices Directorate of the Department of Health (Dirección de Dispositivos del Departamento de Salud) revisó las pruebas para determinar la relación entre los implantes de mama de gel de silicona y las enfermedades del tejido conjuntivo. Más tarde, la nueva Medical Devices Agency (MDA) (Agencia de Dispositivos Médicos) estableció un Grupo Asesor Independiente de Expertos y publicó una extensa revisión en 1992, que fue actualizada en 1994. El Registro Nacional de Implantes de Mama se estableció en 1993. Desde entonces, la MDA ha elaborado varios informes relacionados con los implantes de mama de silicona y los de aceite de soja. En 1998, el Grupo de Revisión Independiente (IRG) publicó un nuevo informe, por petición del Ministro de Sanidad, en el que se revisaban todas las pruebas relacionadas con posibles riesgos para la salud de los implantes mamarios de silicona y las cuestiones concernientes a la información preoperatoria al paciente En marzo de 1999, la MDA y el Departamento de Salud decidieron retirar los implantes mamarios Trilucent y de aceite como medida de precaución, tras recibir informes sobre complicaciones locales (inflamación asociada con la ruptura del implante) en algunas mujeres. Los implantes mamarios rellenos de gel de silicona están disponibles sin ningún tipo de restricción.
Desde 1992 se ha restringido el uso de los implantes mamarios de silicona en Francia. En 1995 se prohibieron todos los implantes mamarios, excepto los salinos. Los cirujanos deben solicitar permiso para emplear los implantes de silicona en situaciones excepciones, en el caso de necesidades médicas específicas (reconstrucción tras una mastectomía y otras). La prohibición ha sido renovada anualmente. El informe de ANDEM (1996) básicamente coincidía con las conclusiones y recomendaciones posteriores del IOM (EE.UU.) y con el Grupo de Revisión Independiente del Reino Unido, considerando como los principales problemas para la salud la contractura quirúrgica y del implante y los riesgos de ruptura. Sin embargo, y como medida de precaución, ANDEM solicitó criterios restrictivos (toxicológicos y clínicos) para autorizar la comercialización de los implantes mamarios bajo la Directiva europea (93/42/ EEC). En 1996, el Ministro de Sanidad francés decretó cuáles eran los implantes mamarios considerados como de alto riesgo de ruptura y, por consiguiente, con efectos adversos. Se ha de ratificar la conformidad de los implantes mamarios de silicona con estándares estrictos y requisitos de seguridad. La Comisión Europea estableció un Grupo (Project Group) para desarrollar directrices uniformes para la evaluación de los implantes de mama de acuerdo con la Directiva. Las especificaciones técnicas para certificar la conformidad con los Requisitos Esenciales de Seguridad y Funcionamiento se remitieron a la CE, y también se adjuntó un nuevo informe francés estableciendo las recomendaciones técnicas para la comercialización.

En España, un grupo de trabajo compuesto por expertos en dispositivos médicos, oncología, reumatología, cirugía plástica, inmunología y otros campos relacionados concluyó que, según las pruebas existentes, no existía razón alguna para la moratoria de los implantes de silicona. Se han desarrollado registros de implantes y explantes y se realizan revisiones periódicas.

Además de haber revisado fuentes secundarias de información legislativa con relación a la postura de los Estados miembros de la UE en este tema, también remitimos cartas formales a las autoridades responsables de productos sanitarios de cada país de la UE, no sólo con el propósito de solicitar información acerca de los más recientes cambios en la legislación, sino para obtener los puntos de vista de cada Estado miembro referentes al desarrollo de una posición común europea sobre los implantes de silicona. 


\subsubsection{Revisión de otras referencias relevantes relacionadas con la legislación internacional}

La situación de la legislación de los EE.UU. ha sido ya descrita en la sección 1.1.2.

En Canadá se aprobó en 1992 una moratoria para la comercialización y uso de los implantes mamarios rellenos de gel de silicona, pero los implantes rellenos de solución salina sí están disponibles. El Canadian Department of National Health and Welfare (Departamento Canadiense de Salud y Bienestar Nacional) también creó un Comité de Consejo Independiente para revisar los problemas de salud provocados por los implantes mamarios rellenos de gel. En 1992, este Comité informó de la falta de suficientes pruebas para asociar las enfermedades autoinmunes con los implantes mamarios de silicona, y reconoció la ausencia de datos precisos sobre la frecuencia de complicaciones locales y la necesidad de realizar nuevas investigaciones. La Canadian Society of Plastic Surgeons (Sociedad Canadiense de Cirujanos Plásticos) realizó recientemente recomendaciones para proporcionar información a las mujeres que desean aumentar el volumen de sus mamas y examinar detalladamente con ellas los riesgos (cirugía, contractura, ruptura, vida media limitada) y los beneficios de este procedimiento. En Canadá existe una doctrina de consentimiento informado bien establecida y ha sido reforzada por el caso de Hollis contra Dow Corning, que resolvió la Corte Suprema de Canadá.

En Australia se puede disponer de los implantes de silicona mediante una solicitud a la autoridad reguladora, la Therapeutic Goods Administration (TGA) (Administración de Productos Terapéuticos), situada en Canberra. Sin embargo, los implantes rellenos de solución salina están disponibles sin autorización previa. En Australia no se han autorizado otros tipos de implante como, por ejemplo, el de aceite de soja. La Australian Society of Plastic Surgeons (Sociedad Australiana de Cirujanos Plásticos) ha realizado una guía detallada para mujeres que demandan intervenciones para aumento de volumen mamario.

\subsubsection{Instrumentos de la UE relacionados con la armonización de la legislación y el control de los dispositivos médicos}

En general, existe una buena base legislativa en la UE para el futuro desarrollo de este campo. Es importante puesto que cubre mu- chos de los reglamentos adoptados por los Estados miembros y ha sido un punto de referencia para la aproximación de leyes y reglamentos nacionales. Bajo la actual legislación se podrían desarrollar nuevas medidas. Las principales directivas de la UE, y específicamente las más relacionadas con los dispositivos médicos, se exponen a continuación:

- Directiva del Consejo 83/189/CEE, del 28 marzo de 1983, por la que se establece un procedimiento de información en materia de las normas y reglamentaciones técnicas.

- Directiva del Consejo 85/374/CEE, del 25 de julio de 1985, relativa a la aproximación de las legislaciones, reglamentaciones y estipulaciones administrativas de los Estados miembros con relación a la responsabilidad de productos defectuosos.

- Directiva del Consejo 89/336/CEE, del 3 de mayo de 1989, relativa a la aproximación de las legislaciones de los Estados miembros sobre compatibilidad electromagnética.

- Directiva del Consejo 90/385/CEE, del 20 de junio de 1990, relativa a la aproximación de las legislaciones de los Estados miembros sobre los productos sanitarios implantables activos.

- Directiva del Consejo 93/42/CEE, del 14 de junio de 1993, relativa a los productos sanitarios, que es la actual piedra angular en esta área.

\subsection{Alternativas prácticas posibles, incluyendo propuestas alternativas para nuevas Directivas europeas}

Durante la realización de este informe, y más específicamente al abordar los elementos centrales del documento, referidos al desarrollo de opciones alternativas, nos encontramos con puntos de vista confrontados y, en ocasiones, recibimos información contradictoria, lo que hizo complejo el reto de reflejar de forma clara, objetiva, meticulosa e imparcial todos los puntos de vista. Están en juego intereses relevantes a ambos lados del tema, todos válidos y legítimos. Por tanto, nuestro objetivo es reflejar la complejidad del problema, tratando de resaltar lo esencial, de manera que el Parlamento Europeo pueda tomar la decisión más apropiada con relación a este tema.

Opción 1: Status quo: ninguna prohibición específica, mantener la aplicación del actual marco legal (es decir, la Directiva 93/42/CEE, que establece las bases generales ). 
Ventajas: buena base legal establecida, pruebas poco convincentes acerca de riesgos graves, mantiene la situación actual

Desventajas: las pruebas apuntan hacia la necesidad de una armonización europea apropiada con objeto de aumentar y mejorar las medidas para mayor y mejor protección de las mujeres y de su salud en la CE; grupos de apoyo mutuo y otros han demandado una prohibición inmediata.

Opción 2: Prohibición de los implantes de mama de silicona debido a la ausencia de información detallada con relación a los riesgos $\mathrm{y}$ a las peticiones formuladas por algunos grupos.

Ventajas: opción más "conservadora»-actualmente ejercida, por ejemplo, por los EE.UU., Canadá y Francia- debido a la falta del conocimiento completo con relación a los riesgos por el corto período de seguimiento de las mujeres y otros factores, como la variedad de los implantes utilizados, etc.; opción más deseada por algunos grupos y personas (por ejemplo, grupos de apoyo mutuo de mujeres que sufren los efectos adversos de los implantes de silicona).

Desuentajas: importante demanda por parte de las mujeres para estos implantes, especialmente teniendo en cuenta los problemas asociados con las principales alternativas -los implantes salinos y los que utilizan otros geles-, como por ejemplo un mayor riesgo de ruptura, peor apariencia, etc. Las alternativas a los implantes de silicona disponibles podrían ser opciones menos deseables (incluso más peligrosoas) y se necesitan más estudios antes de fomentar su uso. Adicionalmente, los estudios sobre implantes rellenos de gel de silicona son consistentes, apuntando a pruebas poco concluyentes acerca de los riesgos de graves problemas para la salud y señalando como principal preocupación sanitaria las complicaciones locales, que también están presentes en los implantes alternativos. Finalmente, desde una perspectiva social relacionada con la salud, también podría existir un potencial daño económico para la industria (por ejemplo, pérdida de empleo), sin que exista una base sólida para restringir este tipo de prótesis, manteniendo otras que podrían ser más problemáticas.

Opción 3: No establecer una prohibición total, pero adoptar e implementar medidas críticas específicas para aumentar y mejorar la información a los pacientes, el seguimiento, la vigilancia y el control de calidad y apoyar líneas prioritarias de investigación (véanse las siete medidas propuestas a continuación).

Ventajas: los estudios no apuntan a una asociación entre los implantes de silicona y riesgos serios para la salud, como el cáncer o las enfermedades del tejido conjuntivo. Las complicaciones locales - tanto o más prevalentes que en otros implantes de mama, como los salinos - son la principal causa de preocupación. La información obtenida de los grupos de apoyo mutuo, de los cirujanos y de la literatura apunta a una verdadera necesidad de introducir mejoras, particularmente en relación con el suministro de información correcta a los pacientes con respecto a los riesgos.

Desventajas: los grupos de apoyo mutuo y otros han demandado una prohibición inmediata; se necesita realizar una verdadera inversión para que las acciones propuestas se lleven a cabo.

Los beneficios para la salud y otros beneficios de los tratamientos cosméticos no pueden estimarse o medirse fácilmente y, normalmente, no se consideran a la hora de evaluar los riesgos y la efectividad de estas intervenciones. Sin embargo, la demanda para implantes mamarios y otras intervenciones cosméticas está creciendo, y las razones por las que las mujeres los solicitan no están bien estudiadas. La existencia de los riesgos asociados con la intervención debe contraponerse con los beneficios obtenidos por las mujeres. La regulación afecta al mercado europeo de implantes mamarios, y debería centrarse en garantizar una seguridad razonable y asegurar que los efectos secundarios no deseados suponen un riesgo aceptable en relación con los beneficios esperados.

En vista de las pruebas, la opción 3, que propone medidas adicionales para maximizar los beneficios de los implantes de mama y limitar los riesgos en el contexto de la UE, parece ser el enfoque más equilibrado. Las medidas adicionales propuestas se describen a continuación:

1) Facilitar el consenso acerca de un documento de consentimiento informado para implantes de mama, incluyendo información con relación a las distintas alternativas, los beneficios y los riesgos.

La falta de información apropiada sobre los riesgos y beneficios ha sido subrayada como el principal problema en torno a la cuestión de los implantes mamarios de silicona en todos los frentes (por ejemplo, este problema ha sido citado por la literatura científica, los informes de revisión, por grupos de apoyo mutuo, por cirujanos, etc.). 
Se debería desarrollar un documento normalizado de consentimiento, que incluya los riesgos inherentes en la cirugía, complicaciones locales, la vida media realista de los implantes y la necesidad de reemplazarlos, la incidencia de complicaciones postoperatorias y a largo plazo, otros posibles peligros para la salud, etc. Existe una gran cantidad de buenos modelos de documentos de consentimiento informado sobre este tema que podrían utilizarse como base para un documento normalizado de consentimiento informado para Europa. Adicionalmente, se debería enfatizar en el documento que, tras leerlo, las mujeres necesitan tiempo para reconsiderar la posibilidad de someterse o no a dicha cirugía.

2) Garantizar el control de la comercialización de los implantes de mama para evitar cualquier información incorrecta o engañosa.

Existe una enorme cantidad de información inadecuada, tanto favorable como desfavorable, en torno a los implantes mamarios de silicona. Esta medida se centra en facilitar el acceso a información fidedigna sobre los riesgos y beneficios de los implantes mamarios, y en imponer controles más estrictos a la difusión de información errónea o engañosa.

3) Mejorar la certificación, los estándares técnicos y la regulación.

La Directiva del Consejo 93/42/EEC debería aplicarse, junto con la adopción y ratificación de normativas técnicas estrictas para la comercialización de implantes mamarios en la UE. Una norma armonizada es una especificación técnica (norma europea o documento de armonización) adoptada, por mandato de la Comisión a los organismos competentes reconocidos (Comité Europeo de Normalización-CEN y CENELEC), de acuerdo con las directrices generales sobre cooperación entre la Comisión y los organismos (Directiva del Consejo 83/189/CEE). Las normativas europeas relativas a los implantes mamarios incluyen normativas genéricas para análisis de riesgos (EN 1441), normativas para implantes no activos (EN ISO 14630), esterilización, seguridad biológica y otros requerimientos específicos para implantes mamarios (EN 12180, recientemente aprobado). Las diferentes características de los implantes mamarios relacionados con su seguridad, incluyendo biocompatibilidad, propiedades mecánicas, desplazamiento del material de relleno y de la cápsula, compatibilidad entre el material de la cápsula y el de relleno, envejecimiento, estabilidad y etiquetado, se encuentran actualmente bajo examen por el Comité Europeo de
Normalización (CEN) y un grupo de trabajo específico formado por organismos de certificación competentes en la valoración de estos productos, de acuerdo con la Directiva 93/42/ EEC. Los estándares se deberían examinar y revisar diligentemente por oficiales europeos competentes, con la posible participación de expertos cualificados.

4) Promover la elaboración de guías y protocolos clínicos y el desarrollo de sistemas de control de calidad.

Algunos problemas han surgido por falta de estándares de calidad y guías clínicas explícitamente formulados. Para realizar cirugía plástica reconstructiva y estética en la UE los cirujanos deberían acreditar formación y competencia específicas. Un objetivo a alcanzar es la armonización de los estándares de las unidades e instalaciones que puedan ofertar estos implantes. Esta medida pretende mejorar y armonizar los procedimientos y estándares de calidad por toda Europa; incluye fomentar un marco de reglamentación para promover un comportamiento profesional transparente, de estándares éticos elevados y, cuando sea apropiado, exigir la responsabilidad que corresponda. Una indicación apropiada y la correcta realización de los procedimientos quirúrgicos son componentes imprescindibles. Las sociedades científicas competentes podrían participar activamente en esta área.

5) Facilitar el consenso, promover y apoyar el desarrollo de sistemas efectivos de vigilancia de los efectos adversos y los efectos a largo plazo.

Debido a la ausencia de registros de implantes mamarios en la mayoría de los países europeos, actualmente existen pocos datos descriptivos acerca de las mujeres que han recibido implantes, los tipos de implantes, los procedimientos y técnicas utilizados, los problemas y complicaciones, etc.

El desarrollo de un registro sistemático y prospectivo de mujeres europeas con implantes mamarios podría permitir seguir los efectos adversos para la salud y podría proporcionar información acerca de la diseminación y las características de este mercado. A menudo se utilizan los registros con múltiples propósitos. Por tanto, debería discutirse la posibilidad de desarrollar un registro prospectivo estándar por país que, posteriormente, podría recopilarse a nivel central para Europa.

6) Considerar los implantes de mama de silicona una investigación prioritaria y proporcionar fondos en los programas de investigación de la UE, especialmente enfocados a al- 
gunas de las deficiencias de la investigación hasta la fecha.

Las prioridades de la investigación deberían concentrarse en:

- Resultados a largo plazo —enfermedad y salud-, efectos sistémicos sobre la salud en lugares lejanos al implante (no sólo trastornos autoinmunes y cáncer) y posibles efectos sobre la salud de hijos de mujeres con implantes.

- Técnicas fidedignas para medir la concentración de silicona en fluidos y tejidos corporales, y la respuesta de los tejidos a la presencia de silicona.

- Complicaciones locales, incluyendo efectos locales en el lugar del implante.

Los estudios deberían contar con los tamaños muestrales necesarios, controlar las variaciones en los tipos de implantes e incluir análisis estratificados (diferenciar intervenciones para reconstrucción mamaria de las estéticas para aumento de volumen mamario).

7) Fomentar la tolerancia al propio cuerpo y la autoestima, así como otras alternativas conceptuales a los implantes de mama, en colaboración con grupos activos en este campo.

A la luz del riesgo potencial de cualquier procedimiento quirúrgico, es importante fomentar la autoestima y la tolerancia (respeto adecuado a la apariencia propia de un individuo) y sensibilizar a las mujeres europeas acerca de los beneficios y riesgos, en especial, de los implantes cosméticos de mama. Al mismo tiempo, se debería impulsar la búsqueda de buenas alternativas para satisfacer las demandas de implantes. La propuesta presentada por el European Institute of Women's Health (Instituto Europeo de la Salud de la Mujer) parece especialmente sensata. 


\section{Argumentos y pruebas}

\subsection{Antecedentes, incluyendo argumentos a favor y en contra de los riesgos para la salud de los implantes de silicona}

\subsubsection{Riesgos para la salud generales y específicos causados por los implantes de silicona, efectos sistémicos y efectos locales}

Una de las dificultades a la hora de estudiar los implantes mamarios y sus riesgos asociados es la variabilidad de los tipos de implantes de silicona utilizados a lo largo del tiempo. Estos implantes mamarios han experimentado esencialmente tres etapas diferentes: una primera generación (desde los años sesenta hasta mediados de los setenta: cápsula gruesa de silicona y superficie lisa), que presentaba una elevada tasa de fugas del gel y contractura capsular; una segunda generación (desde mediados de los setenta hasta finales de los ochenta: fina cápsula de silicona y superficie lisa), que mostraba una elevada tasa de fugas del gel y ruptura; una tercera generación (desde mediados de los ochenta hasta la actualidad: cápsula gruesa de silicona y superficie rugosa), que apunta a tasas bajas de fugas del gel, ruptura y contractura capsular. Adicionalmente, la gran variedad de implantes comercializados, más de cien modelos diferentes, complica su estudio.

Recientemente se han revisado de forma exhaustiva los efectos sobre la salud relacionados con los implantes mamarios de silicona. En los últimos años se han publicado varios estudios dirigidos principalmente a resolver cuestiones planteadas en demandas judiciales. Algunas deficiencias metodológicas detectadas en los estudios disponibles han subrayado la necesidad de realizar nuevas investigaciones sobre la seguridad de los implantes. Así, los estudios disponibles se centran en un pequeño número de enfermedades autoinmunes bien definidas y en el cáncer, en lugar de proporcionar una evaluación exhaustiva de todas las enfermedades, síntomas o complicaciones. El tamaño muestral no es lo suficientemente grande como para detectar claramente un aumento del riesgo en las enfermedades tan raras consideradas. Adicionalmente, los estudios incluyen a mujeres que han llevado los implantes durante distintos períodos de tiempo, algunos de los cuales son muy cortos. Los implantes utilizados para reconstrucción en mujeres que han padecido cáncer de mama no han sido evaluados suficientemente (son casos infrarrepresentados en los estudios). Debido a la heterogeneidad intrínseca del problema, es comprensible que, aunque un estudio estuviese perfectamente diseñado, únicamente respondería a una parte del problema. Los estudios ideales deberían analizar por separado a los pacientes con implantes salinos y de silicona, considerar las distintas generaciones de implantes de gel de silicona, centrarse en el uso de los implantes a largo plazo, diferenciar entre pacientes intervenidas por razones cosméticas de aumento del volumen de la mama de aquellas en las que es precisa una reconstrucción, evaluar como resultado cualquier riesgo de enfermedad grave, compararlo con el grupo control adecuado y emplear un tamaño muestral suficientemente grande.

Los estudios disponibles sobre los principales efectos potenciales sobre la salud asociados con los implantes mamarios han sido reiteradamente analizados y revisados. En general, la mayoría de los estudios epidemiológicos publicados no encontraron problemas significativos para la salud asociados con los implantes mamarios de silicona.

\section{Efectos sistémicos}

Cáncer._La carcinogenicidad y la asociación de los implantes mamarios de silicona a las neoplasias malignas de la mama y a otras localizaciones de cáncer han sido analizados y revisados en humanos, con resultados negativos.

Resumiendo en primer lugar los datos experimentales, parece claro que la implantación subcutánea de compuestos de silicona en roedores puede producir tumores locales en el lugar de implantación. Para comprender mejor las implicaciones prácticas de estos hallazgos, estudios toxicológicos han examinado los efectos carcinogénicos, mutagénicos y teratogénicos de la silicona (Bryson G, Bischoff F, 1967). Se han analizado los efectos que puedan tener dosis de magnitudes mucho mayores que las empleadas en mujeres con implantes mamarios de silicona. Se han observado efectos tóxicos a niveles de exposición muy elevados. Por tanto, no se cree que este fenómeno ocurra en humanos. Aunque se ha informado de algunos casos de cáncer de mama en mujeres a las que se ha inyectado silicona para aumentar el volumen mamario, estos casos no constituyen pruebas suficientes de los efectos carcinogénicos de la silicona en huma- 
nos. Los estudios epidemiológicos no han encontrado un riesgo elevado de cáncer de mama en mujeres con implantes. De hecho, análisis de grandes grupos de mujeres que están participando en estudios de cohortes y de casos y controles han mostrado que no existe asociación, e incluso se ha observado una mínima reducción en la incidencia de cáncer de mama en mujeres con implantes mamarios (Berkel H et al., 1992; Birdsell DC et al., 1993; Brinton L et al., 1996; Bryant $\mathrm{H}$ and Brasher, 1995; Deapen et al., 1997; Friis S et al., 1997; Kern KA et al., 1997; McLaughlin JK et al., 1998; Park AJ et al., 1998).

Adicionalmente, en un informe elaborado por el Grupo Independiente de Revisiones (IRG), el Comité de Carcinogenicidad en el Reino Unido concluyó que no existen pruebas de riesgo de cáncer en humanos. Las pruebas disponibles no apoyan la asociación entre los implantes mamarios de silicona con otras neoplasias malignas, diferentes a tumores de mama (Herdman R, 2000a).

El informe del IOM concluyó que no existe aumento en cáncer de mama primario o recurrente en mujeres con implantes. Sin embargo, debido a la falta de seguimiento a largo plazo de estas mujeres, todavía es temprano para descartar completamente un aumento de riesgo de cáncer por implantes mamarios de silicona.

Para tratar de resumir las pruebas actuales, parece que existen suficientes estudios consistentes y convincentes para apoyar la conclusión de falta de asociación entre cáncer de mama e implantes, aunque se necesita investigación suplementaria para descartar por completo el riesgo de cáncer a largo plazo. Todavía son muy limitadas las pruebas disponibles de que los implantes mamarios de silicona no están asociados con cánceres distintos a los de mama (otros tumores sólidos, sarcoma, linfoma o mieloma), y se espera que los estudios en curso y los futuros puedan aclarar esta cuestión. Las pruebas disponibles no apoyan la asociación entre implantes mamarios de silicona y otros cánceres diferentes a los de mama.

Mamografía y cáncer de mama.-Un problema secundario que plantean los implantes de silicona es su posible interferencia con las lecturas de mamografías, al «ocultar» potencialmente una lesión sospechosa y retrasar así la detección de un cáncer de mama. Los implantes mamarios pueden interferir con las pruebas diagnósticas de imagen utilizadas en cribado y diagnóstico precoz de cáncer de mama, al comprimir y distorsionar el tejido mamario, requerir proyecciones especiales y, particularmente, al ocultar parte del tejido mamario. En ocasiones, puede resultar difícil distinguir un tumor de mama de los depósitos de calcio formados en tejido cicatricial en una mamografía (12 estudios relevantes resumidos por IOM). Los implantes subpectorales no interfieren tanto con la mamografía como los implantes subglandulares. El técnico que realiza una mamografía necesita saber si la mujer tiene un implante, de manera que pueda emplear técnicas especiales para obtener la mayor calidad en la mamografía y evitar romper el implante, lo cual supone un riesgo potencial. Es importante mencionar que, a raíz de un estudio muy reciente (Deapen et al., 2000), las pruebas de que los implantes mamarios no tienen un efecto relevante sobre el retraso diagnóstico o la mortalidad por cáncer de mama son más convincentes. Sin embargo, la mamografía debería realizarse de manera rutinaria y emplear las vistas de Eklund (Roger Herdman, comunicación personal, abril 2000). Todavía no hay estudios disponibles acerca de la mortalidad diferencial por cáncer de mama atribuida a las diferencias en la detección y al posible retraso diagnóstico en mujeres con o sin implantes mamarios.

Enfermedad neurológica.-Algunos autores también han informado acerca de efectos y síntomas neurológicos en mujeres con implantes mamarios (Ostermeyer-Shoaib B and Patten BM, 1996). Estos estudios son, principalmente, series y estudios de casos, y sus hallazgos no parecen ser consistentes con otros estudios experimentales y observacionales.

Para resumir las pruebas disponibles, en 1997 el Practice Committee of the American Academy of Neurology (Comité de la Academia Americana de Neurología) revisó la literatura científica publicada y datos de estudios no publicados (Ferguson JH, 1997), y concluyó que la calidad de las pruebas de los estudios existentes era muy pobre y no apoyaba la asociación o relación causal entre implantes mamarios de gel de silicona y trastornos neurológicos.

Dos estudios epidemiológicos recientes y de gran tamaño, uno realizado en Dinamarca (Winther JF et al., 1998) y otro en Suecia (Nyrén O et al., 1998), basados en las bases de datos nacionales de los registros de alta hospitalaria, no pudieron demostrar una frecuencia mayor de enfermedades como esclerosis múltiple, neuritis, enfermedad de Lou Gehrig o enfermedad de Meniere (un trastorno del oído interno) en mujeres con implantes. No se ob- 
servaron diferencias estadísticamente significativas en la ocurrencia de trastornos neurológicos entre el grupo de estudio y el grupo control (mujeres de la misma edad sometidas a cirugía de reducción de mama). Además, estudios toxicológicos y en animales no apoyan la hipótesis de que los depósitos de gel de silicona causen enfermedades neurológicas. Las pruebas sugieren que dichas enfermedades no son más comunes en mujeres con implantes mamarios que en mujeres sin ellos.

El informe de IOM concluyó que las pruebas disponibles sobre enfermedades o síndromes neurológicos causados por, o asociados con, implantes mamarios de silicona son insuficientes o no basadas en una metodología correcta. Sin embargo, el IOM también reconoció en su informe que si un implante se rompe, desplaza o comprime nervios puede causar dolor y otros problemas neurológicos localizados.

Para concluir, y aunque se ha informado acerca de algunas series de casos de mujeres con implantes de mama que sufren de enfermedad o síntomas neurológicos, los estudios epidemiológicos mejor diseñados y dirigidos no aportan pruebas de que los implantes de silicona causen estos signos, síntomas o enfermedades. Se necesitan estudios suplementarios en esta área para descartar completamente un aumento de riesgo.

Enfermedades del tejido conjuntivo bien definidas (relacionadas con trastornos autoinmunes).-Estudios publicados recientemente muestran que las mujeres con implantes mamarios rellenos de gel de silicona no sufren un riesgo mayor de padecer enfermedades autoinmunes bien definidas (enfermedades del tejido conjuntivo potencialmente mortales), como esclerodermia, lupus eritematoso, artritis reumatoide, síndrome de Sjögren, dermatomiositis o polimiositis, y trastornos como la fibromialgia y el «síndrome de fatiga crónica».

Una revisión de 17 estudios epidemiológicos (10 estudios de cohortes, 4 de casos y controles y 2 transversales revisados por el IOM) sobre enfermedades del tejido conjuntivo y los resultados de tres metaanálisis (Perkins LL et al., 1995; Hochberg MC and Pelmutter DL, 1996; Edworthy SM et al., 1998) destacan por su consistencia en sus resultados negativos (no se observa incremento del riesgo o asociación de los implantes con estas enfermedades). Uno de los estudios de mayor tamaño fue el Nurses' Health Study, un estudio de cohortes con seguimiento a largo plazo de 87.505 mujeres, que no mostró asociación entre los implantes y las enfermedades bien definidas del tejido conjunti- vo o las enfermedades reumáticas (SánchezGuerrero J et al., 1995).

El comité del IOM concluyó que no existen pruebas para afirmar que los implantes mamarios de silicona contribuyan a un aumento del riesgo de padecer enfermedades autoinmunes o del tejido conjuntivo.

Al examinar los estudios de casos y controles y de cohortes realizados entre 1970 y 1998, las revisiones y metaanálisis centrados en la incidencia de enfermedades del tejido conjuntivo bien definidas, el IRG concluyó que no existen pruebas epidemiológicas de asociación de los implantes mamarios de gel de silicona con cualquier enfermedad del tejido conjuntivo establecida. Según el IRG, si existe algún riesgo de padecer una enfermedad del tejido conjuntivo, parece ser demasiado pequeño para ser detectado y cuantificado.

La respuesta biológica global a la silicona es consistente con las respuestas convencionales a cuerpo extraño, y no muestra una reacción tóxica inusual.

El objetivo principal del US National Science Panel's (NSP) (Panel Científico Nacional de EE.UU.) era revisar y evaluar la literatura científica relacionada con la posibilidad de una asociación causal entre los implantes mamarios de silicona y las enfermedades del tejido conjuntivo, los signos y síntomas relacionados y la disfunción del sistema inmunológico. El informe concluyó que era evidente la falta de asociación entre los implantes mamarios y cualquiera de las enfermedades individuales del tejido conjuntivo, la combinación de todas las enfermedades u otras condiciones autoinmunes/reumáticas. Un metaanálisis incluía únicamente estudios que distinguían los implantes rellenos de gel de silicona de cualquier otro tipo. Los resultados eran consistentes con otros metaanálisis que definían más ampliamente los implantes mamarios. No se encontró ninguna asociación entre los implantes rellenos de gel de silicona y cualquiera de las enfermedades definidas del tejido conjuntivo u otras condiciones autoinmunes/reumáticas.

Un metaanálisis exhaustivo y consistente sobre la relación de los implantes mamarios de silicona y los riesgos de enfermedades del tejido conjuntivo publicado muy recientemente (Janowsky EC et al., 2000) revisó nueve estudios de cohortes, nueve estudios de casos y controles y dos estudios transversales. El estudio se ha extraído en parte del informe del NSP. Este estudio incorpora ocho estudios no incluidos en los tres metaanálisis anteriores. 
Los autores ajustaron por factores de confusión y realizaron un análisis específico restringido a los implantes mamarios rellenos de gel de silicona. No se obtuvieron pruebas de que los implantes mamarios estén asociados a un aumento significativo del riesgo relativo ajustado de enfermedades del tejido conjuntivo combinadas o individuales, o con otras condiciones autoinmunes o reumáticas. No se encontraron pruebas de aumento significativo del riesgo en los análisis sin ajustar ni en los análisis restringidos a los implantes mamarios rellenos de gel de silicona.

Enfermedad atípica del tejido conjuntivo o enfermedad sistémica nueva.-Un número apreciable de mujeres que padecen enfermedades sistémicas graves atribuyen su enfermedad a sus implantes de silicona. En la mayoría de los casos, los implantes de silicona no parecen estar relacionados con la causa de estas enfermedades, ya que éstas parecen ocurrir con la misma frecuencia en mujeres sin implantes.

Algunos estudios han señalado la existencia de una enfermedad mal definida y atípica (Patten BM and Ostermeyer-Shoaib B, 1995; Ericsson AD, 1998; Brawer AE, 1996), pero éstos son, principalmente, estudios de series de casos sin grupos control y cuentan con tamaños muestrales muy pequeños. Algunos estudios han apuntado a una disminución o desaparición de los síntomas tras la extracción del implante (Kaiser W et al., 1990), y un estudio adicional encontró una duración significativamente menor de los implantes en mujeres asintomáticas comparado con mujeres sintomáticas (Zandman-Goddard G et al., 1999). Algunos clínicos que han tratado a mujeres con implantes de mama de silicona que presentan síntomas declaran que existe una enfermedad específica relacionada con la silicona, en ocasiones conocida como siliconosis del síndrome adyuvante de implantes de silicona (Shanklin DR and Smalley, 1998).

La cuestión se complica por el hecho de que los síndromes propuestos, a menudo, implican síntomas subjetivos mal definidos (49 signos y síntomas listados, Tugwell P, en el NSP 1998). Lo que es importante es que aunque, desde un punto de vista científicamente ortodoxo, éstos son estudios e informes de casos anecdóticos, queda patente la necesidad de realizar estudios suplementarios en esta materia.

Por otro lado, el informe del IOM concluyó que no existe base científica rigurosa o convincente ni pruebas significativas de la existencia de una enfermedad sistémica "nueva», como algunos investigadores han declarado, causada por la presencia de los implantes de silicona.
Las pruebas de la existencia de una enfermedad atípica se consideran insuficientes (series de casos, pocos describen un síndrome reproducible), y otros estudios controlados han proporcionado pruebas contrarias más sólidas.

El informe del NSP describe los problemas al analizar estos estudios (signos y síntomas inespecíficos, síntomas autorreferidos no verificados, duración del implante desconocido, número pequeño de mujeres estudiadas, las quejas declaradas son muy comunes en la población general) y afirma que no pudieron identificarse características particulares de los implantes mamarios de silicona.

El informe del IRG también puntualiza las dificultades de identificar, con los datos disponibles, un síndrome específico asociado con los implantes mamarios de gel de silicona. Muy pocos estudios han comparado un grupo no sesgado de mujeres con implantes con un grupo de población comparable, para examinar la frecuencia de tales síntomas. El IRG concluyó que faltan pruebas para determinar la existencia de enfermedades del tejido conjuntivo o condiciones no definidas como, por ejemplo, «toxicidad de la silicona». Es posible que otras condiciones, como por ejemplo una infección crónica leve, puedan ser las responsables de algunos de los cuadros clínicos inespecíficos descritos por mujeres con implantes de silicona (fatiga y dolores musculoesqueléticos) y, por tanto, se necesita investigación adicional sobre este tema.

Al mismo tiempo, sin embargo, los estudios disponibles no descartan la posibilidad de que un grupo de mujeres con implantes pueda presentar un pequeño aumento en el riesgo de padecer dichas condiciones, o que algunas mujeres puedan desarrollar otros síntomas inmunológicos relacionados que no puedan incluirse dentro de las descripciones de enfermedades «clásicas».

En resumen, los estudios epidemiológicos indican que las pruebas de la existencia de una enfermedad atípica o síndrome nuevo son insuficientes y no existe apoyo sólido y convincente para la presencia de estos trastornos. Sin embargo, la existencia de un síndrome o síndromes específicos en mujeres con implantes de mama de silicona no puede probarse ni descartarse por completo en este momento, y merecen un análisis adicional.

Efectos «verticales« (de madre a hijo)

Riesgos para los lactantes.-Generalmente, la concentración de silicio en la leche materna 
ha sido causa de preocupación para algunos especialistas en este campo. Una de las mayores preocupaciones, en relación con los implantes, ha sido los posibles efectos negativos de la silicona, un compuesto de silicio (véase la sección 3. Ficha técnica), sobre los lactantes amamantados. Sin embargo, los niveles de silicio en la leche de vaca y las leches de continuación comerciales son mucho mayores que los encontrados en la leche de madres que, por razones estéticas, tienen un implante mamario y están amamantando a sus hijos. La exposición a silicona, en sus muchas formas, es abundante (dieta, medio ambiente) y, por tanto, la exposición de los hijos nacidos de mujeres con implantes no es sustancialmente mayor a la de hijos de madres sin implantes. No existen pruebas de niveles elevados de silicona en la leche materna, o de cualquier otra sustancia que pudiera ser dañina para el lactante, y tampoco existen diferencias en los niveles de silicio, tanto en la leche como en la sangre, entre madres lactantes con implantes y sin ellos. No hay pruebas de enfermedades o defectos congénitos causados por la silicona o cualquier otro componente de los implantes de mama, debido a su capacidad para atravesar la placenta y llegar al feto.

Por otro lado, existen pruebas limitadas de que una incisión periareolar para implantar la prótesis podría interferir con la lactancia natural.

El informe del IOM concluyó que las pruebas de asociación entre los implantes mamarios de silicona en madres y los efectos sobre la salud de sus hijos son insuficientes o erróneas.

El informe del IRG revisó los artículos sobre esta materia (la mayoría son estudios individuales en lugar de estudios de comparación de casos) y concluyó que la literatura publicada no justifica las declaraciones de que existen efectos significativos, clínicamente relevantes, en hijos de mujeres con implantes.

Para resumir, los estudios han concluido que no parecen existir pruebas sobre los efectos relevantes sobre la salud de los lactantes amamantados por mujeres con implantes mamarios de silicona (enfermedad del tejido conjuntivo o autoinmune).

\subsubsection{Efectos de los implantes a corto, medio y largo plazo (cuatro, ocho y doce años)}

Efectos locales

Complicaciones locales.-Riesgos potencialmente relevantes para la salud (destacados como el principal en los estudios recientes) son las complicaciones locales directamente relacionadas con los implantes de mama, como la ruptura, el desplazamiento del gel de silicona, la contractura capsular (encogimiento del tejido cicatricial alrededor del implante, el cual puede causar endurecimiento doloroso de la mama o distorsionar su apariencia) y la infección. Algunos de los riesgos causados por los implantes de silicona se atribuyen a la fuga del gel de silicona a través de la cápsula rota de la silicona de los implantes. Las complicaciones locales se han considerado como el principal problema de seguridad (Herdman R, 2000b). Así, los estudios publicados muestran que entre el 5 y el 51\% de las mujeres con implantes de silicona presentan rupturas, lo que representa un rango muy amplio (revisado por el IOM).

La alta frecuencia relativa de complicaciones locales experimentada por mujeres con implantes mamarios de silicona es bastante significativa. Aunque normalmente estas complicaciones no representan un riesgo vital, pueden causar malestar, molestias, desfiguración, dolor y otros síntomas que pueden llevar a la explantación. Cuando se requieren procedimientos correctores adicionales, éstos pueden suponer un riesgo potencial suplementario (por ejemplo, cirugía adicional). Aunque la cirugía de mama tiene un mínimo riesgo de muerte, pueden presentarse complicaciones serias al extraer, revisar o reemplazar los implantes.

La ocurrencia de complicaciones locales y perioperatorias presentada en los informes es sumamente variable. Las diferencias que se observan son debidas a la variabilidad biológica individual, diferencias en las características de las mujeres (edad, comorbilidad, indicación del implante), tipos de implantes, tipo de estudio (diseño, investigación clínica o básica), técnicas quirúrgicas y habilidad y experiencia de los cirujanos.

El informe ANDEM concluyó que las complicaciones locales son muy frecuentes y constituyen la principal preocupación sanitaria. Se considera que la frecuencia de contractura capsular fibrosa varía desde el 41 al 56\% a los cuatro años para los implantes de superficie lisa, y alrededor del 10\% para los rugosos. La frecuencia de ruptura es de un 2 a un $14 \%$ a los diez años, y aumenta con el tiempo. A los diez años existe una baja tasa de fuga, próxima al 17\% de los casos. La incidencia de complicaciones locales no se conoce para los implantes mamarios de nueva generación. 
El informe del IRG presta especial atención a los efectos locales (contractura capsular, infección, fuga del gel, ruptura) y reconoce que la incidencia precisa de estas complicaciones no es bien conocida y los datos científicos son incompletos. El IRG recomienda que la investigación en torno a esta cuestión sea prioritaria.

El informe IOM presenta tres conclusiones generales principales sobre las complicaciones locales y perioperatorias: primero, estas complicaciones son tan frecuentes que deben considerarse la cuestión principal de seguridad de los implantes mamarios de silicona (incluye reoperaciones, rupturas, pérdidas de volumen, contracturas, infecciones, hematomas y dolor en general); segundo, los riesgos se acumulan a lo largo de la vida del implante, pero no se dispone de datos cuantitativos fiables al respecto para los implantes modernos, puesto que históricamente los estudios disponibles son bastante deficientes (falta de datos de muestras representativas de la población, falta de información sobre las características de los implantes que afectan a las complicaciones y falta de la detección precisa y fidedigna de las complicaciones); tercero, la información que concierne a la naturaleza y elevada frecuencia relativa de complicaciones locales y reoperaciones es un elemento esencial para el consentimiento informado adecuado de las mujeres que demandan un implante mamario. Consideramos que éstas son conclusiones sensatas y prácticas. Por otro lado, debería enfatizarse la importancia de establecer guías clínicas y quirúrgicas normalizadas.

Necesidad de una reoperación y reemplazo del implante.-Las mujeres sometidas a cirugía reconstructiva sufren tasas de complicaciones mayores que aquellas sometidas a cirugía cosmética. La operación para una reconstrucción inmediata es más seria ya que implica un procedimiento quirúrgico importante (mastectomía o eliminación de la mama), además del implante. Algunos estudios han sugerido que entre un 30 y un $40 \%$ de estas pacientes sometidas a cirugía reconstructiva pueden sufrir complicaciones. Ese porcentaje puede aumentar cuando se utiliza un expansor para generar crecimiento del tejido en la zona de la mama, y las complicaciones son, posiblemente, más frecuentes cuando la mama ha sido sometida a radioterapia. La mayor probabilidad de efectos secundarios graves tras una reconstrucción debe sopesarse con los beneficios psicológicos esperados de la intervención.

Las mujeres sometidas a dicha operación por razones estéticas presentan una menor fre- cuencia de complicaciones. Un gran estudio prospectivo realizado por McGhan Medical Corporation (Corporación Médica de McGhan) con 2.855 mujeres con implantes salinos modernos mostró que un 18\% de las mujeres intervenidas para aumentar el volumen de la mama, y un 36\% de mujeres intervenidas para reconstrucción, experimentaron complicaciones durante el mismo año en que recibieron el implante (infección, grave contractura, pérdida de volumen o extracción del implante). Un estudio realizado en la Clínica Mayo en 1997 concluía en el New England Journal of Medicine que el 24\% de las mujeres que reciben un implante mamario padecerán una complicación que requerirá una intervención quirúrgica adicional en los cinco años siguientes al implante.

Parece ser que las mujeres con implantes de silicona tienen mayor probabilidad de contractura muscular que las mujeres con implantes salinos (Gylbert LO et al., 1990).

Los implantes mamarios tienen una vida media limitada, no bien establecida. La probabilidad de necesitar el reemplazo del implante, al menos una vez, es alta, y algunas mujeres han precisado varios reemplazos. El comité del IOM observó que un gran número de mujeres con implantes podría esperar una intervención adicional en los primeros cinco años de recibir el implante original. Un estudio de mujeres sometidas a una reconstrucción, seguidas durante una media de seis años, mostró que el $16 \%$ de las que recibieron un implante salino requerían reemplazo a causa de la pérdida de volumen, y otro $8 \%$ debido a desplazamiento o contractura grave (Gylbert LO et al., 1990). Otro estudio mostró una pérdida del 18\% del volumen del implante en mujeres con implantes de gel o expansores submusculares para reconstrucción mamaria. Un estudio de menor tamaño de mujeres con complicaciones mostró que, durante un seguimiento medio de doce años, se realizaban aproximadamente unas tres intervenciones por mujer. La probabilidad de necesitar una operación de reemplazo se acumula a lo largo del tiempo. Estos hechos merecen una consideración adicional en estudios actuales y futuros.

Ruptura.-Cuando el implante de silicona se rompe, el gel puede escaparse o fugarse a otros tejidos (ruptura extracapsular). A menudo, el gel permanece en el espacio entre la cápsula fibrosa y el implante, y la ruptura pasa inadvertida (ruptura intracapsular). La cirugía necesaria para la ruptura extracapsular consiste en la extirpación del implante, 
además de la cápsula alrededor del implante, (capsulectomía). Esta intervención requiere anestesia, incisión quirúrgica y sutura. El procedimiento quirúrgico también puede incluir la sustitución por un nuevo implante.

La frecuencia de ruptura es obtenida en la mayoría de los estudios basándose en la observación y análisis de implantes extraídos (estándar del diagnóstico de ruptura). También se obtiene mediante técnicas mamográficas y en estudios de seguimiento de cohortes de pacientes. En las series de casos descritas por algunos cirujanos la detección de la ruptura suele depender de las quejas de los pacientes, del cribado rutinario mediante mamografía o del examen físico, ninguno de los cuales es un método completamente fiable. Las tasas de ruptura declaradas por los fabricantes, que suelen ser más bajas, se basan en devoluciones, quejas, demandas judiciales y otras fuentes de información y, probablemente, se ven afectadas por la infradeclaración y una baja sensibilidad del método utilizado.

Numerosos y diferentes estudios han obtenido tasas de ruptura de los implantes de gel muy variables, con un rango que va desde un 0,3 a un 96\%. Existe una clara relación entre la edad del implante y la frecuencia de ruptura. Como ejemplo, algunos de los resultados presentados en los estudios indican una ruptura del 62,5\% a los diez años (Malata CM et al., 1994), del $71,2 \%$ a los catorce años y del $95,4 \%$ a los veinte años (Robinson OC et al., 1995).

De hecho, la alta variabilidad de estas frecuencias de ruptura se debe al tipo y al modelo de implante analizado, la fecha de implantación, los tipos de mujeres estudiadas y a otros factores. Es importante considerar que no es fácil detectar las rupturas, que la composición de los implantes cambia con los años y que los estudios disponibles no aportan información sobre rupturas más tardías (debido a los cortos períodos de seguimiento).

Teniendo en cuenta la época de uso del implante, los implantes de primera generación (1963-1972) presentan pocas rupturas, los implantes de segunda generación (1972-mediados de los años ochenta) experimentan una tasa de ruptura del 95\% a los doce años, y los de tercera generación (finales de los ochenta hasta la actualidad) mostraban en 1992 una ruptura del 3,5\% (Peters WJ et al., 1996). Actualmente, no se posee suficiente información sobre los efectos a largo plazo de los implantes de tercera generación, por lo que no es posible predecir con precisión la frecuencia de ruptura de estos implantes. La informa- ción disponible sugiere que la ruptura es más común en implantes rellenos de gel que en los actuales implantes rellenos de solución salina y en los expansores (IOM), aunque se necesitan nuevos estudios para resolver esta cuestión.

Algunos autores estiman, basándose en observaciones recientes, que probablemente menos del 10\% de los implantes de gel modernos se romperán antes de los cinco años, las rupturas seguirán acumulándose y la prevalencia de ruptura aumentará en los años venideros. Las implicaciones de seguridad relacionadas con la ruptura incluyen los riesgos de cirugía adicional y anestesia (explantación o reemplazo).

Es necesario tener en cuenta el efecto del sesgo de los estudios a la hora de valorar las tasas de ruptura de implantes rellenos de gel. Como se ha señalado, los estudios se basan principalmente en series de explantes (sobreestimación de frecuencia de ruptura), en lugar de medir la ruptura en mujeres más representativas empleando herramientas de diagnóstico suficientemente sensibles. Las series de explantes no proporcionan una buena base para la estimación de la futura frecuencia de ruptura de los implantes modernos, debido a la inclusión en los estudios de implantes en desuso y no considerar la variabilidad existente en los tipos de implantes. No se conocerán las tasas de ruptura de los implantes modernos hasta que se completen estudios observacionales, prospectivos y a largo plazo de un grupo de mujeres suficientemente grande y cohortes aleatorizadas, empleando métodos de detección fidedignos (imagen por resonancia magnética, IRM).

Pérdida de volumen. - La pérdida de volumen es básicamente un problema de los implantes rellenos de solución salina y no de los rellenos de silicona.

Los primeros modelos de implantes salinos sufrían pérdidas de volumen frecuentemente; modelos posteriores han mostrado menor probabilidad de que esto ocurra, con una frecuencia del 5 al 10\% tras diez años (IOM).

El comité del IOM concluyó que la pérdida de volumen de los modernos implantes salinos en el primer año puede estar entre un 1 y un $3 \%$, y este porcentaje puede incrementarse lentamente con el tiempo. El informe del IOM recomienda, vehementemente, la realización de estudios suplementarios para responder a preguntas relacionadas con las tasas actuales de ruptura y pérdida de volumen del implante. 
Contractura capsular.-Un importante componente de la reacción de cuerpo extraño es la producción de una cápsula cerrada de tejido fibroso cicatricial alrededor del implante. Una contractura capsular grave puede causar una presión dolorosa y desfigurante, además de una distorsión tanto del implante como del tejido sobrepuesto. Las complicaciones resultantes pueden ser serias, incluyendo una intervención médica para desestructurar la cápsula, extraerla o incluso reemplazar el propio implante. Adicionalmente, la cirugía posee sus propios riesgos, que incluyen infección, posibles rupturas y los riesgos de la anestesia. Algunos de estos procedimientos médicos, en especial la "capsulotomía cerrada», donde se aplica una fuerte presión al exterior de la mama para ayudar a romper la cápsula fibrosa, se realizan repetidamente en las mismas mujeres. Los problemas de contractura capsular causaron un $28 \%$ de los procedimientos secundarios llevados a cabo en mujeres con implantes para aumentar el volumen mamario y un $14 \%$ de los procedimientos secundarios en los casos de reconstrucción mamaria.

La severidad de la contractura suele medirse utilizando la clasificación de Baker (estándar más común), que cuenta con cuatro categorías:

Clase I. La mama aumentada es tan blanda como una no aumentada.

Clase II. La mama es menos blanda y el implante puede palparse, pero no es visible.

Clase III. La mama es más firme y el implante puede palparse fácilmente y resulta visible (o se observa una distorsión).

Clase IV. La mama está firme, dura, sensible, dolorida y fría. La distorsión es acusada.

La mayoría de los cirujanos considera satisfactorias las dos primeras categorías de contractura, pero no las dos últimas.

La prevalencia de contractura obtenida en los estudios depende de varios factores, como la variabilidad en la detección, la técnica de colocación de los implantes, la rugosidad y otras características del implante, la utilización de esteroides, el sesgo de selección y la duración del seguimiento. Los informes publicados emplean distintas unidades (número de pacientes, número de mamas intervenidas), clases de Baker u otra clasificación, incluyen contracturas tipos II a IV, o III a IV.

Las mujeres han mostrado una tolerancia considerable a las contracturas. Así, muchas mujeres que presentan contracturas de clases
III o IV no consultan, y muchas se manifiestan satisfechas con sus implantes al ser entrevistadas. Un estudio de 1990 subrayaba que el $85 \%$ de las mujeres parecían satisfechas con sus implantes, aun cuando el 35\% había experimentado una contractura grave (Gylbert LO, 1990). Un informe de 1997 sobre 186 implantes mostró que las contracturas de clases III y IV seguían ocurriendo (cien por cien a los veinticinco años) (Strom SS et al., 1997). Los tratamientos de la contractura, aparte de la capsulotomía cerrada, incluyen la «capsulotomía abierta», que consiste en la realización de una incisión para descomponer la cápsula y una "capsulectomía» o extracción quirúrgica de la propia cápsula. Esta operación también puede suponer la extracción o el reemplazo del implante, además de la pérdida de tejido mamario. La repetición de capsulotomías, tanto abiertas como cerradas, tiene progresivamente menos probabilidades de éxito.

A pesar de que sólo existe un número limitado de estudios, las pruebas disponibles sugieren que los implantes salinos tienen una tasa menor de contractura comparados con los implantes de silicona (IOM). También se notifican menos casos de contractura severa en implantes de superficie rugosa que en implantes de superficie lisa, en mujeres que se someten a la operación con fines cosméticos que con fines reconstructivos, en mujeres sometidas a reconstrucción inmediata respecto a mujeres sometidas a reconstrucción más tardía y en implantes submusculares comparado con implantes submamarios. Esta menor incidencia de contractura severa en implantes submusculares se considera muy importante.

\subsubsection{Efectos en el postoperatorio y seguimiento}

Todos los riesgos quirúrgicos generales asociados con cualquier tipo de operación son posibles. Éstos incluyen: complicaciones de la anestesia general, síntomas y signos como dolor, náuseas, vómitos, hematoma, hemorragia o trombosis. También es posible la necrosis cutánea. La probabilidad de padecer necrosis cutánea puede incrementarse por los tratamientos de radiación, medicamentos parecidos a la cortisona o un implante demasiado grande para el espacio disponible.

A continuación se presenta una breve descripción de algunas de las complicaciones más relevantes.

Dolor: El dolor asociado con la implantación es frecuente y constituye una de las razones principales para extraer el implante y reem- 
plazarlo (motivo del 15 al 20\% de las peticiones de extracción). Algunos autores han informado sobre las molestias que presentan la mayoría de las mujeres tras la cirugía y, en ocasiones, este dolor puede mantenerse a largo plazo. Las pacientes también declaran más dolor con implantes tras mastectomías, comparado con mastectomías sin implante (9 casos), y con la localización del implante submuscular en lugar de submamario. Un estudio (Wallace MS et al., 1996) informó sobre la frecuencia de dolor local reseñable tras reconstrucción (hasta un 50\%) y con menor frecuencia en mujeres con implantes para aumentar el volumen mamario (hasta un 38\%). El dolor también era más común después de implantes submusculares (50\%) que submamarios (21\%), y con implantes salinos (33\%) que con implantes de gel (22\%). Entre un 20 y un 29\% de los pacientes con dolor precisaron medicación para controlar el dolor. La cápsula del implante, especialmente cuando se localiza debajo de los músculos pectorales, puede causar compresión nerviosa dolorosa y hacer necesario un tratamiento adicional. El dolor tardío normalmente es debido a contractura, pero también puede deberse a infección bacteriana o ruptura.

Infección: La flora cutánea que reside en los conductos de la glándula mamaria normal a menudo puede cultivarse a partir de tomas de los implantes y puede ser causa de infección. Existen pruebas sugerentes de que la presencia de bacterias se correlaciona con la contractura. Sin embargo, no se ha probado que la infección sea una causa clara de contractura. Algunos investigadores han publicado hallazgos de una asociación entre la presencia de bacterias alrededor de los implantes y síntomas sistémicos o dolor de mama, aunque estas pruebas son limitadas. Se describen contracturas importantes con una frecuencia considerablemente mayor que los hematomas observados clínicamente.

Una infección crónica puede ocurrir con cualquier implante quirúrgico y, a continuación, el implante puede necesitar extracción o reemplazo. Algunos autores apoyan la idea de que infecciones subclínicas puedan contribuir a síntomas tales como fatiga, dolor muscular o articular, debilidad, fiebre intermitente y diarrea.

Hematoma: En series de casos y otros estudios observacionales se han referido de forma variable hematomas y seromas. Se considera que el hematoma es exclusivamente un contribuyente menor de la contractura. En los estudios de la Clínica Mayo, el hematoma cons- tituía el motivo de reoperación en el 3,5\% de las mujeres (Gabriel SE et al., 1997). La frecuencia con la que se describen hematomas a los pocos días de la implantación por aumento o reconstrucción, tanto con implantes de silicona como con los salinos, varía entre un 0,5 y un $5 \%$. En un número pequeño de casos ha sido preciso reoperar para corregir el problema. Es raro que los hematomas ocurran años después de la operación de implantación por contractura. Entre las principales consecuencias de los hematomas se incluyen las intervenciones adicionales, las infecciones asociadas y la posible asociación con contracturas.

\subsubsection{Conclusiones}

Los dos principales motivos de preocupación respecto a los posibles efectos sobre la salud de los implantes de mama de silicona (cáncer y enfermedades autoinmunes o del tejido conjuntivo bien definidas) han sido objeto de considerable atención científica y discusión en los últimos diez años. A pesar de las deficiencias metodológicas, y de otros tipos, de los estudios disponibles, generalmente podemos asumir que no existe aumento de riesgo relevante que pueda atribuirse a estas dos condiciones, ya que aparecen con la misma frecuencia en la población con implantes que en la población sin ellos. Parece haber estudios suficientemente consistentes y convincentes para apoyar la conclusión de falta de asociación entre cáncer de mama e implantes, aunque se están llevando a cabo estudios para descartar el riesgo a largo plazo de otros tipos de cáncer. No hay pruebas de que los implantes mamarios contribuyan a un aumento de enfermedades autoinmunes y del tejido conjuntivo. Sin embargo, los estudios disponibles no descartan la posibilidad de que un reducido grupo de mujeres con implantes pueda presentar un pequeño aumento en el riesgo de padecer dichas condiciones, o que algunas mujeres puedan desarrollar otros síntomas inmunológicos relacionados que no puedan incluirse dentro de las descripciones de enfermedades «clásicas».

No obstante, la literatura epidemiológica ha indicado que las pruebas para la existencia de una enfermedad atípica o síndrome nuevo son insuficientes y no existe apoyo sólido y convincente para la presencia de estos trastornos. Sin embargo, la existencia de un síndrome o síndromes específicos en mujeres con implantes de mama de silicona no puede probarse ni descartarse por completo en este momento, y merece un análisis suplementario. 
En general, se puede concluir que los estudios epidemiológicos mejor diseñados y dirigidos no obtienen pruebas de que los implantes de silicona causen enfermedades, signos o síntomas neurológicos.

No parece que existan pruebas de efectos sobre la salud de los lactantes amamantados por mujeres con implantes de silicona (enfermedades del tejido conjuntivo o autoinmunes).

La posible interferencia de los implantes mamarios con la realización e interpretación de mamografías, debido a la compresión y distorsión del tejido mamario, hace necesario considerar técnicas especiales para obtener mamografías de calidad y evitar romper el implante.

Las complicaciones quirúrgicas, locales y perioperatorias son tan frecuentes que estamos de acuerdo con informes previos donde se consideran el principal problema de seguridad de los implantes de silicona y de cualquier otro tipo de implante mamario. En general, las rupturas, pérdidas de volumen, contracturas, infecciones, hematomas, el dolor y la necesidad de intervenciones adicionales son la principal causa de las quejas de las mujeres. Los implantes mamarios tienen una vida media limitada, no bien establecida. En cualquier caso, la probabilidad de precisar el reemplazamiento del implante, al menos una vez, es alta. Actualmente, no se dispone de la información suficiente acerca de los efectos a largo plazo de los implantes de tercera generación, lo que dificulta la predicción de las frecuencias de ruptura, contractura y reoperación de dichos implantes. Faltan datos cuantitativos al respecto para los implantes modernos. Por tanto, la incidencia precisa de complicaciones locales y perioperatorias debería considerarse una prioridad en la investigación y un elemento esencial del consentimiento informado adecuado para mujeres que demandan un implante de mama.

\subsection{Visión global de la investigación primaria y de las revisiones relevantes. Período 1990-1999}

\subsubsection{Investigación llevada a cabo actualmente en la UE}

Se han llevado a cabo varias iniciativas de investigación y revisión en Europa, como el informe publicado en Francia por ANDEM
(1996) y la visión global exhaustiva llevada a cabo por el Grupo de Revisión Independiente en el Reino Unido (1998). También se han realizado varios estudios observacionales en países europeos.

Se han publicado dos estudios epidemiológicos recientes y de gran tamaño, uno en Dinamarca, basado en las bases de datos nacionales de los registros de alta hospitalaria, y el otro en Suecia, basado en tres grandes cohortes (Friis et al., 1997; Nyren et al., 1998, respectivamente). El estudio de la Sociedad Danesa de Cáncer incluyó a 1.135 mujeres con implantes de mama por razones cosméticas, 1.435 por reconstrucción y otros dos grupos de mujeres sin implantes. El estudio no detectó en mujeres con implantes un aumento de enfermedades sistémicas, como enfermedades definidas del tejido conjuntivo, esclerosis múltiple, neuritis, enfermedad de Lou Gehrig o enfermedad de Meniere (un trastorno del oído interno).

En Suecia se estudiaron tres cohortes de gran tamaño (Nyrén et al., 1998). Se realizó un seguimiento durante diez años a mujeres con implantes mamarios cosméticos (3.502), mujeres con implantes por reconstrucción (3.931) y mujeres sometidas a cirugía de reducción de mama (3.351), mediante cruce con los registros de alta hospitalaria. El autor concluyó que no existe un aumento de riesgo significativo de enfermedades del tejido conjuntivo o neurológicas, comparando estas cohortes de mujeres con la población general.

Recientemente, también se han llevado a cabo estudios epidemiológicos relevantes en países de la UE, como por ejemplo los estudios de cohortes realizados por Park et al. en Escocia (1998) y por Giltay et al. en los Países Bajos (1994). Ninguno de estos estudios detectó una asociación relevante entre los implantes de mama y las enfermedades del tejido conjuntivo.

En relación con las iniciativas emprendidas para clarificar cuestiones de seguridad y certificación apropiada de los implantes mamarios en Europa, esta materia se ha tratado con mucha atención y ha sido discutida entre la Comisión y los Estados miembros. Excluyendo a Francia, todos los países de la UE mostraron su conformidad con los Requerimientos Esenciales de la Directiva europea (93/42/EEC) como bases para la comercialización de los implantes de silicona (véase 1.1.4).

En el Reino Unido, la Medical Devices Agency (MDA) (Agencia de Dispositivos Médicos) estableció un Grupo Asesor Independiente de Ex- 
pertos y publicó un informe de revisión en 1992, actualizado en 1994. En 1993 se creó un Registro Nacional de Implantes de Mama. Para más detalles, véase la sección 1.1.4.

En España, un grupo de trabajo de expertos independientes revisó las pruebas disponibles y concluyó con la propuesta de establecer un registro de implantes y explantes.

El Consejo de los Países Bajos, Gezondheidsraad (GR), miembro del International Network of Agencies of Health Technology Assessment (Red Internacional de Agencias de Evaluación de Tecnologías Sanitarias), está llevando a cabo un proyecto de revisión sistemática por un panel de expertos sobre implantes mamarios de silicona.

Al cierre de este informe, no tenemos constancia de nueva investigación relevante en desarrollo sobre este tema que cuente con fondos de la UE.

En cuanto al inmediato futuro, nuevos desarrollos en la tecnología de implantes mamarios pueden cambiar la perspectiva actual. El gel de silicona cohesivo representa una innovación. Se ha probado y utilizado en Europa una nueva fórmula de hidrogel de polivinilpirrolidona (PVP) en implantes mamarios. Además, nuevos implantes salinos que se rellenan previamente, en lugar de rellenarse durante la implantación, con una solución estéril de agua salina pueden eliminar las fugas de la válvula y mejorar la esterilidad. En breve, estas innovaciones podrían proporcionar nuevas opciones a las mujeres que soliciten un aumento o reconstrucción de mama, pero necesitan revisión y atención adicionales, su seguridad no está aún establecida y se precisa tiempo para evaluar la toxicidad de nuevos materiales y sus efectos a largo plazo.

\subsubsection{Investigación actual en otros países del mundo}

Los implantes mamarios están disponibles desde los años sesenta. En 1976, la FDA americana incluyó los implantes mamarios en la clase II de dispositivos, cuya seguridad y efectividad se consideraban bien establecidas, requiriendo únicamente normativas de funcionamiento o estudios de control. En 1982, debido a los problemas descritos, se propuso incluir los implantes de mama en la clase III, en la que se clasifican los productos sometidos a los más estrictos controles, a los que se exige la presentación de que demuestren claramente su seguridad y efectividad. En 1988, todos los implantes se incluyeron en la cate- goría III. En abril de 1991, en respuesta a un creciente número de informes sobre reacciones adversas que aumentaron la preocupación acerca de la seguridad de los implantes rellenos de gel de silicona, la FDA publicó una reglamentación que exigía a los fabricantes la presentación de solicitudes de aprobación previa a su comercialización, con datos demostrando la seguridad y efectividad de los implantes antes del 9 de julio de 1991. Los datos aportados por los fabricantes no aportaban la información exigida sobre la seguridad de los dispositivos, por lo que la agencia los retiró del mercado en abril de 1992 y restringió su uso a ensayos clínicos.

El Panel Nacional Científico (NPS) (cuatro expertos en toxicología, inmunología, epidemiología y reumatología) presentó en 1998 un informe al Honorable S. C. Pointer, Juez para la Demanda Judicial Federal sobre Implantes de Mama. Este informe revisó la literatura científica relacionada con los implantes de mama de silicona y las enfermedades del tejido conjuntivo y disfunciones inmunológicas.

En 1997, el Instituto de Medicina (IOM) de la Academia Nacional de las Ciencias, por petición del Congreso americano, acordó realizar una evaluación exhaustiva de las pruebas que relacionaban los implantes de mama de silicona con problemas de salud. El informe final se presentó en 1999. El IOM distinguió claramente entre las complicaciones locales y las enfermedades sistémicas. El IOM determinó que no existían pruebas suficientes para concluir que los implantes mamarios causen efectos sistémicos como, por ejemplo, enfermedades autoinmunes. El IOM concluyó que no hay pruebas definitivas que relacionen los implantes mamarios con cáncer, enfermedades inmunológicas, problemas neurológicos u otras enfermedades sistémicas. Sin embargo, el IOM también concluyó que las complicaciones locales constituyen el principal problema de seguridad en los implantes mamarios de silicona.

En EE.UU., los implantes de silicona únicamente están disponibles en el contexto de estudios clínicos (centrados en la recolección de datos, mientras se autoriza el acceso a este dispositivo para pacientes de reconstrucción y revisión) o estudios de Exención de Dispositivos en Investigación (IDE) (orientados a la recogida de datos de seguridad y efectividad que apoyen su aprobación antes de su salida al mercado). Un estudio IDE también puede incluir pacientes intervenidas para aumento de volumen mamario.

Los estudios de Mentor Corporation's y McGhan Medical fueron aprobados por la FDA 
en 1992 y 1998, respectivamente, ambos limitados a pacientes sometidas a reconstrucción mamaria. En junio de 1998, la FDA aprobó el estudio IDE de McGhan Medical para pacientes intervenidas para aumento de volumen mamario, reconstrucción y revisión. Los datos clínicos de estos estudios se recogen y se presentan a la FDA anualmente. Hasta la fecha, ningún fabricante ha proporcionado datos para apoyar la seguridad y efectividad de sus implantes mamarios, por lo que ninguna solicitud de aprobación previa a la comercialización (PMA) o de protocolo de desarrollo de producto (PDP) ha sido aprobada para implantes de silicona.

Recientemente, la FDA exigió a los fabricantes de implantes salinos que presentaran datos respecto a la seguridad y efectividad, y varios fabricantes han presentado solicitudes PMA para sus implantes salinos en 1999. En marzo de 2000 tuvo lugar una reunión para revisar las solicitudes PMA y el Panel Asesor de la FDA recomendó su aprobación, pero la FDA todavía no ha tomado ninguna decisión y se espera que ésta se tome antes de finales de mayo de 2000.

\section{Estudios actuales en EE.UU. y Canadá}

Actualmente, el estudio más importante en desarrollo sobre los efectos a largo plazo de los implantes mamarios hasta la fecha incluye a 13.500 mujeres sometidas a la cirugía de implante antes de 1998. La investigadora principal es la Dra. Louise Brinton, Jefe del Área de Epidemiología Ambiental en el Instituto Nacional de Cáncer de los Institutos $\mathrm{Na}$ cionales de Salud (Environmental Epidemiology Branch at the National Cancer Institute of the National Institutes of Health). Los investigadores estudiarán si los implantes mamarios están relacionados con riesgos de padecer cáncer mamario, otros cánceres o trastornos del tejido conjuntivo. Los resultados del estudio sobre cáncer de mama estarán disponibles durante el año 2000; los hallazgos sobre otros cánceres y trastornos del tejido conjuntivo serán analizados en el año 2001. El objetivo de este estudio consiste en tratar de superar muchas de las limitaciones presentes en otros estudios, especialmente por su gran tamaño muestral y su enfoque en los efectos a largo plazo de los implantes mamarios.

Actualmente se está realizando otro estudio en EE.UU. para evaluar las tasas de ruptura. Este estudio puede aportar información muy relevante.
En 1992, el Ministro de Sanidad de Canadá pidió a todos los fabricantes de implantes que retirasen del mercado canadiense todos los implantes de silicona y emitió el informe Baines, en el que se destaca que la información científica disponible no es suficiente para una evaluación adecuada y se necesita más información acerca de la seguridad de los implantes. En 1996, Health Canada anunció un plan para financiar un Estudio de Implantes Mamarios en Ontario y Quebec, enfocado a los riesgos de cáncer, y que implicaría a 40.000 mujeres que hayan recibido un implante. También, el Conseil d'Evaluation des Technologies de la Santé du Québec (Consejo de Evaluación de Tecnologías Sanitarias de Quebec) está desarrollando actualmente un proyecto titulado «Efectividad de las técnicas alternativas de imagen para diagnosticar la fuga de los implantes de silicona».

\subsubsection{Conclusiones}

A lo largo de los últimos diez años se han realizado iniciativas e inversiones relevantes en varios países desarrollados (principalmente EE.UU. y países de Europa) para evaluar los efectos sobre la salud de los implantes mamarios de silicona. Agencias gubernamentales y grupos independientes han revisado extensamente y han realizado estudios epidemiológicos o metaanálisis sobre este tema.

En la actualidad, varios estudios están en desarrollo para evaluar los efectos a largo plazo de los implantes mamarios (principalmente sobre cáncer o enfermedades del tejido conjuntivo) en EE.UU. Los fabricantes en EE.UU. también están involucrados en estudios clínicos o en estudios de Exención de Dispositivos en Investigación (IDE) que se centran en la recogida de datos sobre la seguridad y efectividad para apoyar la salida al mercado de implantes rellenos de gel. Los datos clínicos de estos estudios se están recogiendo y enviando a la FDA. Es probable que los fabricantes de los implantes salinos comiencen nuevos estudios IDE.

A pesar de la investigación que se está llevando a cabo, se ha reconocido la falta de información y pruebas suficientes, y se han destacado como prioritarias algunas áreas de investigación:

- técnicas fiables para medir la concentración de silicona en fluidos y tejidos corporales, y estudio de la respuesta del tejido a la silicona; 
- resultados y efectos a largo plazo, efectos sistémicos sobre la salud en localizaciones distantes al lugar del implante (no sólo trastornos autoinmunes y cáncer) y posibles efectos sobre la salud de niños de mujeres con implantes;

- frecuencia de complicaciones locales, incluyendo los efectos en el lugar del implante.

\subsection{Información primaria obtenida}

El estudio de los problemas planteados por los implantes de mama de silicona resulta complejo.

No existen pruebas concluyentes en la literatura epidemiológica acerca de una asociación entre implantes mamarios de silicona y cáncer o enfermedades de tejido conjuntivo, las dos principales causas de preocupación. Los estudios apuntan a que las complicaciones locales pueden considerarse como el principal riesgo de estos implantes. Sin embargo, sin infravalorar la importancia de las complicaciones locales y la información disponible de los estudios epidemiológicos, también la documentación facilitada por los principales grupos y sectores implicados aporta información crucial que necesita ser adecuadamente considerada y requiere investigación suplementaria.

Así, hemos contactado con los principales sectores implicados para determinar sus puntos de vista y sus posiciones sobre los implantes mamarios de silicona: cirujanos, grupos de mujeres, sociedades científicas, pacientes, fabricantes, investigadores, autoridades gubernamentales de países de la UE y de otros países, y grupos de apoyo mutuo (ver tablas).

Hemos tenido noticias y recibido información de grupos de apoyo mutuo del Reino Unido/ Escocia, Países Bajos, Alemania, Bélgica, Suiza e Islandia; éstos incluyen: Silicone Support UK (SS/UK); Action Against Silicone Gel (AASG/UK); Silicone Information Network (SIN/UK); Stichting Steunpunt voor Vrouwen met (vragen over en/of problemen door) Siliconene borstprothesen (St. SVS/NL); German Support Group for Victims of Silicone Implants (GHG, DE); Selbsthilfegruppe Silikongeschadigter Frauen e.V. (SHG/BE) Silicone Support Suiza (SS/Suiza); Silicone Survivor Group, Iceland (SSG/Islandia), respectivamente.

El contacto con grupos de apoyo mutuo de mujeres ha subrayado la importancia de los siguientes aspectos:
1) La información a las pacientes es crucial. Un gran número de mujeres se queja de no haber recibido la información relevante acerca de los posibles riesgos de los implantes de mama antes de someterse a la operación. De hecho, cirujanos expertos también nos han informado de que no era práctica habitual proporcionar información a los pacientes antes de 1992. Un grupo significativo de mujeres afirman que no se les informó de los riesgos del procedimiento quirúrgico en sí, de la posibilidad de una infección o de la duración de los implantes. Al mismo tiempo, algunas mujeres que fueron sometidas a la extirpación y/u otras operaciones adicionales como resultado de complicaciones lo hicieron sin haber sido adecuadamente informadas o sin haber dado su consentimiento informado. Específicamente, se encontraron dos áreas críticas en las que la información recibida se considera insuficiente:

- La duración de los implantes no es eterna y es posible que haya que reemplazarlos o extraerlos, pese a lo que originalmente se creía y se difundía. Muchas mujeres, a las que no se les informó de que posiblemente sus implantes tendrían que ser reemplazados, experimentaron problemas tras años de su implantación, mucho después de que sus implantes debían ya haberse reemplazado. Las mujeres deben ser conscientes de esta información desde el principio.

- Las rupturas ocurren con frecuencia. Aunque no se dispone de información precisa, los estudios detectan un intervalo enorme en las tasas de ruptura, entre el 5 y el 51\%. Al mismo tiempo, algunos estudios apuntan a una tasa de ruptura del 50\% después de siete-diez años y hasta un 95\% después de veinte años. Inherentes a la ruptura están muchos de los problemas relacionados con inflamaciones locales y distantes, infecciones causadas por la fuga del gel, otros posibles problemas desconocidos debidos al desplazamiento del gel, sin mencionar la necesidad de una reoperación de emergencia. Actualmente, en EE.UU. hay estudios en marcha con el objetivo de precisar las tasas de ruptura, y el seguimiento de estos trabajos es importante. Adicionalmente, las mujeres deben recibir información acerca de la posibilidad de ruptura, y muchas de ellas no fueron informadas adecuadamente.

2) Es necesario distinguir entre las mujeres que desean un implante para aumentar el volumen mamario y las que lo desean por razones de reconstrucción, cuando se valoran las complicaciones locales (ruptura, contractura capsular e infección), sin tener en cuenta 
otros posibles riesgos, tales como los riesgos inherentes en los procedimientos quirúrgicos. La mayoría de las mujeres de los grupos de apoyo mutuo recibieron implantes por razones cosméticas y afirman que si se les hubiese proporcionado una información realista de los riesgos (sin tener en cuenta sus problemas de salud actuales) es posible que no hubiesen optado por un implante. Adicionalmente, debido a la ausencia de registros en Europa, no se conoce el número de mujeres con implantes ni se sabe cuántas intervenciones corresponden a reconstrucción us. aumento de volumen mamario. Sin embargo, las cifras en el Reino Unido apuntan a una mayor demanda de implantes por razones cosméticas, lo que acentúa la necesidad de proporcionar información adecuada y consentimiento informado, de manera que se pueda realizar una valoración apropiada de los riesgos y beneficios.

3) Un número significativo de mujeres con implantes de silicona afirman padecer síntomas serios inexplicables: fatiga crónica, mareos, pérdida de memoria, olvidos, insomnio, dolor abdominal, problemas intestinales y de vejiga, molestias y dolores, síntomas parecidos a la gripe, enrojecimiento o tumefacción de la piel, comezón en el cuero cabelludo, sarpullidos, hormigueo, cambios de temperatura extremos, extremidades frías, dificultades para tragar, dolor en la espalda, en las axilas, en las manos y en los pies, sequedad ocular e irritación. Estas mujeres, cuyos síntomas se iniciaron con distinto intervalo de tiempo desde el momento del implante y con diferente grado de gravedad, afirman haber estado sanas antes de la implantación y haber enfermado después, como resultado de su implante mamario. En algunos casos, las mujeres han notado una reducción de sus síntomas al extraer el implante; en otros casos, no se experimentó un cambio en los síntomas tras la extracción del implante. Hemos recibido información de mujeres europeas representándose a sí mismas o a grupos en sus respectivos países. Sus relatos y problemas de salud son muy similares. Nos han proporcionado referencias de médicos e investigadores que han denominado a estos síntomas "siliconosis» y que consideran que es una enfermedad aún sin clasificar, directamente asociada con la presencia de implantes de silicona (Shankin DR and Smalley DL, 1998). Aunque no existe investigación epidemiológica concluyente que apunte a esta asociación, estas mujeres están convencidas de que esta enfermedad existe. Aunque el número exacto de mujeres que experimentan estos síntomas es desconocido, debería tomarse en cuenta que, sólo en el Reino Unido, 2.000 mujeres firmaron la petición presentada al Parlamento Europeo para la prohibición de los implantes mamarios de silicona. Exclusivamente en Alemania, según el director del grupo de apoyo mutuo alemán, desde 1992, 6.000 mujeres enfermas con implantes de silicona han solicitado ayuda al grupo de apoyo mutuo. El Dutch Silicone Support Group ha contestado 17.500 llamadas (desde cinco minutos hasta una hora y media o más) y ha escuchado 4.000 relatos de mujeres enfermas desde que se formó en 1992.

4) Los grupos de apoyo mutuo destacan las deficiencias de los estudios epidemiológicos disponibles.

Los implantes mamarios de silicona se usaron durante años sin ningún tipo de regulación, estudio, control o monitorización. Es imposible saber el número exacto de mujeres con implantes. Para complicar el tema, existe una multitud de modelos de implantes, además de tres generaciones distintas de implantes de gel de silicona. Por esta razón, hasta 1990 no existían demasiados estudios o investigaciones sobre implantes de silicona que resultasen útiles a la hora de evaluar los posibles riesgos. Se ha prestado una gran atención a los implantes de silicona desde principios de los noventa, llevando a la realización de numerosos estudios diferentes. Sin embargo, estos estudios poseen algunas limitaciones, que se resumen a continuación (extraídos y resumidos de Diana Zuckerman [1998] y otras fuentes):

4.1) Pequeños tamaños muestrales. La falta de poder estadístico puede limitar la capacidad del estudio para detectar el riesgo de una enfermedad atípica.

4.2) Los estudios sólo se centraban en criterios clásicos de enfermedad, principalmente cáncer y enfermedades autoinmunes clasificables, y no en otros problemas y/o síntomas y la posibilidad de una enfermedad atípica nueva.

4.3) Ausencia de datos a largo plazo (por ejemplo, tras ocho-catorce años, cuando es más probable que surjan los problemas). Verdaderamente, los estudios sólo comenzaron a principios de los noventa; muchas mujeres incluidas en los estudios sólo llevaban de uno a cinco años con el implante (demasiado pronto tras el implante).

4.4) Las muestras utilizadas en los estudios no siempre eran apropiadas. En muchos 
estudios el método de muestreo es débil (se utilizan muestras de conveniencia), lo cual puede llevar a resultados que no se pueden generalizar.

4.5) La agrupación de diferentes tipos de implantes pertenecientes a distintas generaciones sesga los resultados (se cree que los implantes de segunda generación tienen mayor posibilidad de ruptura, pero se han estudiado al mismo tiempo que las otras generaciones de implantes), y mujeres con implantes de aumento y reconstrucción se consideran conjuntamente, aunque poseen distintos grados de complicación.

Por razones de objetividad, también debemos destacar que los estudios publicados que apoyan la idea de la asociación de enfermedades graves con los implantes de silicona tienen unas limitaciones intrínsecas muy claras, dado que sus diseños epidemiológicos son flojos, son principalmente estudios de casos sin grupos de control y con tamaños muestrales muy pequeños.

5) Es necesario afrontar adecuadamente las quejas de las mujeres con implantes. La toma de decisiones en Salud Pública no sólo se basa en la interpretación de los resultados de los estudios epidemiológicos, sino que tiene en cuenta la opinión e información proporcionadas directamente por los pacientes y la posición de otros sectores implicados. En general, las mujeres de grupos de apoyo mutuo en Europa nos han indicado que sienten no haber tenido «Voz» en el debate sobre implantes mamarios de silicona. Generalmente, sienten que los investigadores que han estado estudiando los implantes de silicona rehúyen la comunicación con ellas y piensan que sus posturas no se han reflejado adecuadamente, se sienten ignoradas por los cirujanos y no creen que sus gobiernos hayan prestado la atención adecuada a sus verdaderos problemas.

\subsection{Análisis de los niveles de regulación contemplados}

\subsubsection{Niveles alternativos de precaución recomendados teniendo en cuenta el conocimiento actual sobre cuestiones de salud}

Las diferentes perspectivas y puntos de vista acerca de la manera y el momento adecuados para establecer niveles apropiados de precaución han sido tema de debate no sólo en la
Unión Europea, sino en la mayoría de los países del mundo.

El objetivo principal al crear el Mercado Único en la UE era garantizar el libre movimiento de productos, basado en la prevención de nuevas barreras para el comercio, el reconocimiento mutuo y la armonización técnica. Sin embargo, la filosofía subyacente es, obviamente, hacer este objetivo compatible con un nivel aceptable de riesgo para la población.

Las directivas basadas en New Approach y Global Approach (nuevo enfoque y enfoque global sobre armonización técnica y normalización) sobre procedimientos de valoración de conformidad (Decisión del Consejo 90/683/ EEC, Decisión 93/465/EEC) siguen los principios siguientes:

La armonización legislativa se limita a las necesidades esenciales que deben cumplir los productos que salen al mercado de la Comunidad. En especial, estos requisitos tratan sobre la protección de la salud y seguridad de los usuarios (consumidores) y, en ocasiones, cubren otros requisitos (propiedad, medio ambiente).

Las especificaciones técnicas de los productos que cumplen los requisitos esenciales establecidos en las directivas serán normas armonizadas. La aplicación de las normas armonizadas es voluntaria.

Los productos fabricados de acuerdo con las normas armonizadas se benefician de la presunción de conformidad con los requisitos esenciales correspondientes.

La aplicación del nuevo enfoque requiere que las normas garanticen un nivel de protección con respecto a los requisitos esenciales establecidos por las directivas, y que las autoridades nacionales cumplan con sus responsabilidades para la protección de la seguridad y otros intereses cubiertos por la directiva.

Dado que éste es un proceso dinámico, el Parlamento Europeo y las organizaciones y organismos competentes dentro de los Estados miembros europeos necesitan abordar continuamente el reto de encontrar el equilibrio adecuado entre los derechos a la libertad de los individuos, por una parte las empresas de fabricación y comerciales, y, por otra parte, la necesidad de maximizar la reducción del riesgo para la salud humana y ambiental. Es evidente que la UE debe tener el derecho de establecer el nivel de protección sanitaria que considere apropiado.

Para enfrentarse a este reto se considera como primer paso la evaluación científica de 
los riesgos, seguido de la gestión y la comunicación del riesgo. Es decir, la evaluación científica debería ser un elemento clave para enfrentarse a este proceso. En ocasiones, la evaluación científica no clarifica por completo (con un grado de certeza razonable) el riesgo que se trata de determinar. La incertidumbre científica es un escenario muy común y, como se ha mencionado anteriormente, la situación es dinámica y el grado de incertidumbre científica cambia gradualmente con el tiempo. Mientras tanto, juzgar lo que se considera un nivel «tolerable» de riesgo para la sociedad es una materia de responsabilidad política.

La respuesta correcta no siempre es fácil y sencilla, y puede constituir desde una medida legislativa de obligado cumplimiento hasta el apoyo a proyectos de investigación o la declaración pública de recomendaciones, y todos los factores deben ser adecuadamente considerados. El procedimiento adaptado para proporcionar una base sólida para la respuesta correcta debería ser transparente e involucrar a todos los grupos interesados. El equipo responsable de este trabajo ha tratado (hasta un punto razonablemente factible) de cumplir este deseo transparente de involucrar a los grupos interesados en el área de los implantes de silicona para resumir los distintos puntos de vista. Pero pudiera ser que el Parlamento Europeo considere necesario valorar otras fuentes de información o aspectos adicionales. Por otra parte, es posible que cuestiones como la analizada en este informe necesiten revisión periódica (según surjan nuevos datos científicos).

La Comisión de las Comunidades Europeas preparó recientemente (febrero 2000) una Comunicación sobre el "Principio de Precaución», que constituye una buena referencia para este propósito. Según este documento, cuando se estima necesaria la acción, las medidas basadas en el principio de precaución deberían ser: proporcionales al nivel seleccionado de protección (teniendo en cuenta que en la mayoría de los escenarios es imposible hablar de riesgo cero); no se debería discriminar en su aplicación (lo cual significa que situaciones comparables deberían tratarse de igual manera); coherentes con medidas similares ya establecidas; basadas en un cuidadoso examen de los posibles beneficios y costes de la acción (o ausencia de acción); sujetas a revisión (siempre que surjan nuevas pruebas), y capaces de asignar la responsabilidad de obtener y presentar los datos científicos necesarios para una evaluación razonable y exhaustiva de los riesgos (que se pueda expresar cla- ramente dentro de los procedimientos de autorización estructurados y formalizados).

\subsubsection{Implicaciones de nueva legislación}

Teniendo en cuenta las consideraciones previas, las distintas alternativas pueden tener ventajas y desventajas, que hemos tratado de resumir en la sección de Opciones.

Para resumir, la opción del status quo es una opción legítima, dado que tenemos una buena base legislativa europea y no existen pruebas de riesgos serios, pero posiblemente rechace la perspectiva de los grupos de apoyo mutuo y las actuales áreas de incertidumbre científica en el campo de las complicaciones locales y efectos secundarios. Por otra parte, la necesidad de una mayor armonización de las guías clínicas, del control y garantía de calidad y del consentimiento informado resultan claros, y así ha sido destacado.

La opción que consiste en una completa prohibición de implantes mamarios de silicona podría basarse en la necesidad de recibir toda la información en relación con los riesgos y atender las peticiones por parte de algunos grupos. Sin embargo, también debemos tener en cuenta la demanda creciente de estos implantes por parte de las mujeres, especialmente considerando algunos de los problemas que presentan las principales alternativas (y datos incompletos referentes a muchas de estas alternativas). Además, estudios sobre implantes de silicona tienden a ser altamente consistentes al mostrar pruebas poco concluyentes acerca de los riesgos para la salud, y en señalar que las complicaciones locales son la principal preocupación para la salud y también están presentes en los implantes alternativos. Por tanto, los principios de consistencia y no discriminación irían en contra de esta opción. Finalmente, también existe el potencial daño económico a la industria, pérdidas de puestos de trabajo y el impacto sobre otras dinámicas sociales (la importancia del principio de coste/beneficio podría ser, quizás, un elemento a determinar con precisión).

Por último, la opción que consiste en no establecer una prohibición total, pero adoptar e implementar medidas críticas específicas para aumentar y mejorar la información a los pacientes, el seguimiento, la vigilancia y el control de calidad y apoyar líneas prioritarias de investigación (véanse las siete medidas propuestas en la sección de Opciones), podría ser razonablemente coherente con la filosofía subyacente en los principios de precaución europeos mencionados anteriormente. 


\section{Ficha técnica}

\subsection{Terminología y conceptos básicos}

Es imprescindible distinguir los términos relevantes. A pesar de su similitud fonética, en términos prácticos, se puede tratar de compuestos bastante diferentes.

\subsubsection{Silicio/Sílice}

Cuando se habla de silicio, nos referimos al segundo elemento más abundante de la corteza terrestre. En términos químicos, es un elemento no metálico (o semimetálico) con formas amorfa y cristalina. No se encuentra en su forma elemental, sino que aparece principalmente como óxidos o silicatos.

Sílice es la forma de dióxido de silicona, encontrada más comúnmente como arena. Es químicamente resistente a temperaturas normales, pero puede sufrir una variedad de transformaciones a presiones y temperaturas elevadas (mayores de $500^{\circ} \mathrm{C}$ ). El sílice amorfo y de alta pureza se emplea como agente de refuerzo para aumentar la resistencia de las gomas de silicona usadas en dispositivos médicos e implantes.

\subsubsection{Silicona y polidimetilsiloxano (PDMS)}

Silicona es el nombre que recibe una familia de polímeros fabricados por el hombre (no se encuentran de forma natural) y contienen átomos alternos de silicio y oxígeno. Dependiendo de las características específicas del polímero, existen distintos materiales (fluido, resinoso, parecido a la goma, extremadamente estable a altas temperaturas e impermeable). Éstos se emplean como pegamentos, lubricantes y aceites hidráulicos, y en el aislamiento eléctrico, en cosmética y en otros productos.

Los polidimetilsiloxanos (PDMS) son miembros destacados de la familia de la silicona de los compuestos orgánicos basados en silicio. Los compuestos de PDMS son polímeros, cuya longitud y entrelazado de la(s) cadena(s) afectan sus propiedades físicas.

Es importante puntualizar que los implantes cuentan con una cápsula externa de un elastómero, que es una sustancia reticular de elevado peso molecular. De hecho, la mayoría de ellos tienen una cápsula de silicona. También se emplean distintos tipos de rellenos (un tipo de gel). El gel de silicona es una sustancia re- ticular menos densa, esponjosa, permeable a fluidos de silicona de bajo peso molecular.

\subsection{Exposición general a siliconas. El uso de silicona en dispositivos médicos}

Los ciudadanos de países desarrollados se encuentran ampliamente expuestos a silicona, ya que este compuesto está presente en alimentos, cosmética, lubricantes para maquinaria, aislantes y una gran variedad de productos de consumo. La silicona se emplea en la elaboración de alimentos (por ejemplo, en comidas enlatadas y comidas preparadas) y como masilla y sellantes. También se utiliza en productos domésticos y personales como, por ejemplo, productos de limpieza, crema para las manos, productos para el pelo y la piel y desodorantes.

Además, la silicona también se incorpora en algunas medicinas y dispositivos médicos. Por ejemplo, el aceite de silicona se emplea frecuentemente como lubricante para jeringuillas y kits de donantes de sangre, y en cirugía se adopta para corregir el desprendimiento de la retina.

A continuación se presenta una lista de productos médicos que contienen silicona:

- Industria de productos médicos: catéteres, pipetas, adhesivosy fluidos.

- Industria farmacéutica: fluidos, emulsiones, antiespumantes, adhesivos y tubos de goma de silicona.

- Otros productos médicos: productos de silicona para la articulación temporomandibular; productos ortopédicos de pequeñas articulaciones; productos para grandes articulaciones; anticonceptivos implantables de uso prolongado; fluidos de silicona (inyecciones), y productos de implantes de silicona (detalles adicionales proporcionados a continuación).

\subsection{Implantes de mama. Cápsulas y materiales de relleno}

No existe un implante de mama «estándar». Existe una amplia gama de tallas, generalmente de un volumen comprendido entre 80 y 800 cc, aunque en ocasiones se han empleado implantes de 1.000 cc o expansores. El diámetro, o máxima dimensión, de los implantes varía desde 7,5 a 16,8 cm, y la proyección, o perfil, desde 1,5 a $7,5 \mathrm{~cm}$.

Se debe tener en cuenta que, con estas dimensiones, los implantes de mama se consi- 
deran los cuerpos extraños más grandes, tanto en superficie como en volumen, de los implantes aloplásticos (cuerpo extraño distinto del tejido humano), especialmente si se colocan bilateralmente. También se encuentran disponibles en formas variadas (redondas, ovales, en forma de lágrima o contorneadas).

Estos dispositivos cuentan con una cápsula externa de un elastómero, que es una sustancia reticular de elevado peso molecular. De hecho, la mayoría de los implantes tienen una cápsula de silicona. Los implantes cubiertos con una espuma de poliuretano representaron una alternativa como cápsula externa, pero se retiraron del mercado en 1991 debido a la preocupación de que esta cápsula pudiese aumentar el riesgo de cáncer (por desprendimiento de pequeñas cantidades de un producto químico denominado TDA, el cual se ha demostrado que causa cáncer en animales).

Independientemente de la cápsula descrita anteriormente, es posible encontrar implantes de cavidad única o de cavidad doble. Algunos de estos implantes se pueden inflar de tal manera que su volumen puede cambiar durante la implantación mediante el uso de expansores diseñados específicamente para ello.

Respecto a los materiales internos, se emplean distintos tipos de rellenos (un tipo de gel). El gel de silicona es una sustancia reticular menos densa, esponjosa, permeable a fluidos de silicona de bajo peso molecular. Es posible emplear otros rellenos que incluyen, principalmente, soluciones salinas, pero también hidrogel, «Trilucent»y otros geles.

\subsubsection{Implantes alternativos según su material de relleno}

\subsubsection{Implantes rellenos de gel de silicona}

Los implantes de mama de gel de silicona están compuestos de una cápsula externa de elastómero de silicona y rellenos de gel de silicona. Se encuentran disponibles desde 1962, y se han sucedido tres generaciones de estos implantes.

La primera generación de implantes se componía de una cápsula gruesa de silicona, de superficie lisa y rellenos de gel de silicona (una mezcla de silicona sólida y líquida). Estos implantes se fabricaron desde 1962 y fueron reemplazados a mediados de los años setenta. Los principales problemas con estos implantes eran: fugas del gel del implante y contractura capsular.
La segunda generación se componía de una fina cápsula de silicona, de superficie lisa y rellenos de gel de silicona (alta tasa de filtración del gel). Con este tipo de implante la contractura capsular se redujo, pero no la fuga del gel y el riesgo de ruptura era más elevado. Este tipo de implantes se fabricó desde los años setenta hasta finales de los ochenta.

La tercera generación de implantes se fabricaron con una cápsula más gruesa de silicona, una superficie rugosa y están rellenos de gel de silicona (alta tasa de filtración del gel). Presumiblemente, estos implantes reducen la contractura capsular, la ruptura y la fuga del gel. Este tipo de implantes se lleva fabricando desde finales de los ochenta hasta la actualidad.

\subsubsection{Implantes rellenos de solución salina}

Hace mucho (desde 1965) que la solución salina fue considerada como un relleno apropiado para implantes. Se trata de un material de relleno considerado más fisiológico y fácil de asimilar por el cuerpo en caso de ruptura. Sin embargo, también presenta algunas claras desventajas, incluyendo una tasa mayor de pérdida de volumen, una elevada probabilidad de deformación de la cápsula, un mayor peso, una onda fluida («efecto chapoteo») con ruidos que puede escuchar el propio paciente, y una peor apariencia que los implantes rellenos de gel de silicona (consistencia más delgada y arrugas visibles en la piel y/o palpables). En el mes de mayo, la FDA decidirá si aprueba o no los implantes salinos de Mentor y McGhan, basándose en el análisis de los resultados presentados por los fabricantes en sus informes y estudios. El Comité Asesor de la FDA recomendó su aprobación en la reunión mantenida en marzo de 2000.

\subsubsection{Otros implantes}

Otra opción han sido los llamados implantes rellenos de aceite purificado de soja, supuestamente más seguros que otros implantes debido a su carácter inicialmente biodegradable y su transparencia en las radiografías. En EE.UU. se ha desarrollado un ensayo clínico para evaluar la seguridad de estos implantes y la FDA está analizando los resultados. Existen datos pendientes, pero los riesgos potenciales están empezando a constatarse. Este implante se prohibió en el Reino Unido en 1999, debido a algunos problemas que se plantearon y a una falta de información acerca de sus efectos a largo plazo. 
Los implantes rellenos de hidrogel ofrecen nuevas posibilidades. Parecen ser más consistentes que los salinos, contienen materiales naturales y todavía se «perciben» como seguros. Sin embargo, se debe tener en cuenta que el hidrogel no es isotónico, absorbe agua y se puede hinchar hasta romperse, y su seguridad no está establecida. Se necesitan estudios a largo plazo, y todavía no se ha descartado que causen algún tipo de toxicidad.

El tejido autógeno se emplea principalmente en reconstrucción de mama. Dichas reconstrucciones se combinan frecuentemente con implantes. Se han empleado injertos de dermis, injerto de musculocutáneo abdominal o de otras localizaciones, y también injertos microquirúrgicos.

\subsection{Resumen técnico sobre los implantes de silicona y sus posibles efectos}

\subsubsection{Posibles beneficios}

Existen beneficios relevantes en términos de salud y calidad de vida para las mujeres que solicitan cirugía cosmética de mama. Aunque las razones que llevan a las mujeres a solicitar un implante de mama no se han estudiado en detalle, la confianza en una misma y la comodidad, aumento de la autoestima e imagen de una misma, el sentido positivo de sentirse más atractiva y la mejora de las relaciones sociales parecen ser las razones principales. Los implantes de mama parecen ser un procedimiento efectivo para satisfacer estas demandas.

\subsubsection{Posibles riesgos}

\section{Efectos sistémicos}

Cáncer-Existen estudios suficientemente consistentes y convincentes que apoyan la conclusión de falta de asociación entre cáncer de mama e implantes de mama. Sin embargo, el corto período medio de seguimiento de los estudios completados (y las todavía limitadas pruebas existentes en este campo) no permiten concluir si los implantes de mama de silicona están o no asociados a otros neoplasmas malignos (otros tumores sólidos, sarcoma, linfoma o mieloma), pero se espera que los estudios futuros y en curso aclaren estas dudas.

Existe cierta preocupación acerca de las posibles dificultades ocasionadas por los implantes de mama a la hora de realizar el cribado o diagnóstico precoz de cáncer de mama mediante mamografía. Una masa radiopaca podría ocultar alguna anormalidad de la mama y causar un retraso en la detección de cáncer de mama. Los datos disponibles no permiten llegar a ninguna conclusión definitiva, pero no se ha demostrado un aumento de la mortalidad por cáncer en mujeres con implantes. La realización de proyecciones mamográficas adicionales y un cuidado específico pueden ser medidas que ayuden a superar estos problemas.

Enfermedades neurológicas.-Se ha informado acerca de algunas series de casos de mujeres con implantes de mama que sufren de enfermedad o síntomas neurológicos. Estos hallazgos no son consistentes con otros estudios observacionales o experimentales. Las pruebas proporcionadas por estudios epidemiológicos para concluir que los implantes de mama de silicona causan signos, síntomas o enfermedades neurológicas son insuficientes.

Trastornos definidos del tejido conjuntivo.-Estos trastornos del sistema inmune, o de defensa, del cuerpo están principalmente relacionados con el tejido conjuntivo del cuerpo (el tejido conjuntivo incluye el tejido mucoso, fibroso, graso, el cartílago y el tejido óseo, que proporcionan apoyo a las estructuras corporales y mantienen unidas las partes del cuerpo). Existe cierta preocupación acerca de enfermedades como las siguientes:

- trastornos autoinmunes como el lupus;

- esclerodermia;

- artritis reumatoide;

- fibromialgia;

- «síndrome de fatiga crónica».

Para resumir, los estudios publicados recientemente indican que las mujeres con implantes de mama de silicona no presentan un mayor riesgo de padecer algunas enfermedades autoinmunes bien definidas y/o enfermedades del tejido conjuntivo potencialmente mortales.

Otros trastornos sistémicos.-Un gran número de mujeres con implantes de silicona ha experimentado una variedad de síntomas que no se pueden definir de manera sencilla. Estos síntomas incluyen dolor e inflamación de las articulaciones; tirantez, enrojecimiento o inflamación de la piel; glándulas o nódulos linfáticos inflamados; fatiga inusual o inexplicable; tumefacción de las manos y los pies; pérdida excesiva de cabello; problemas de memoria; cefalea; debilidad o molestias mus- 
culares. Sin embargo, estos síntomas pueden presentarse en personas sin enfermedades del tejido conjuntivo o sin implantes de mama. Por lo tanto, en este momento, no está claro que los signos o síntomas experimentados por estas mujeres se deban a sus implantes.

\section{Efectos «verticales» (de madre a hijo)}

Actualmente, no existen pruebas de niveles elevados de silicona en la leche materna, o de cualquier otra sustancia que podría ser dañina al lactante. Tampoco existen diferencias entre madres lactantes con implantes y sin ellos de los niveles de silicio tanto en la leche como en la sangre. No hay pruebas de enfermedades o defectos congénitos causados por la silicona o cualquier otro elemento de los implantes de mama al atravesar la placenta y llegar al feto. Para resumir, los estudios epidemiológicos actuales concluyen que no parecen existir pruebas de riesgos para la salud de los lactantes amamantados por mujeres portadoras de implantes de mama de silicona (con relación a trastornos del tejido conjuntivo o autoinmunes), aunque se necesita investigación suplementaria para descartar por completo este riesgo.

\section{Efectos locales}

Efectos derivados de procedimientos quirúrgicos:

- Posibles complicaciones causadas por la anestesia general (náuseas, vómitos y fiebre).

- Infección.

- Hematoma (acumulación de sangre que puede causar tumefacción, dolor y magulladuras, que puede requerir un drenaje quirúrgico).

- Hemorragia (sangrado anormal).

- Trombosis (coagulación anormal).

- Necrosis cutánea (muerte del tejido cutáneo por falta de flujo sanguíneo a la piel).

Efectos locales derivados del dispositivo implantado:

- Contractura capsular (endurecimiento de la mama debido a la cicatrización del tejido).

- Fuga o ruptura: los implantes de silicona pueden presentar ruptura y fugas lentas, li- berando el gel de silicona al tejido circundante; los implantes salinos pueden romperse de repente y perder rápidamente su volumen, requiriendo normalmente una extirpación o un reemplazo inmediato.

- Cambio o pérdida temporal o permanente de la sensación en el pezón o tejido mamario; formación de depósitos de calcio en el tejido circundante, causando, posiblemente, dolor y endurecimiento.

- Desplazamiento del lugar original, confiriendo a la mama una apariencia antinatural.

- Interferencia con las lecturas de la mamografía, retrasando, posiblemente, la detección de cáncer de mama al «ocultar» una lesión sospechosa.

\subsubsection{Riesgos y beneficios: desafíos para una decisión}

Parece sensato afirmar que se necesita contraponer los posibles riesgos asociados con la intervención (implantes de silicona) con los posibles beneficios percibidos por las mujeres, de manera que se puedan adoptar las decisiones políticas y legislativas más adecuadas.

Como se mencionó previamente (véase 2.4.1.), la Comisión de las Comunidades Europeas preparó recientemente una «Comunicación» sobre los «Principios de Precaución» (firmado en febrero de 2000) que sienta las bases para este propósito. De acuerdo con este documento (donde se estima necesario realizar una acción), las medidas basadas en dicho principio de precaución deberían ser:

- Proporcionales al nivel de protección seleccionado (teniendo en cuenta que el riesgo rara vez puede reducirse a cero).

- No discriminatorias a la hora de su aplicación (lo cual significa que situaciones comparables deben tratarse de la misma manera, a no ser que existan razones objetivas para no hacerlo).

- Coherentes con medidas similares ya establecidas (las medidas deben ser de envergadura y naturaleza comparable a situaciones previas equivalentes, cuando existan datos científicos disponibles).

- Basadas en un examen cuidadoso de los posibles beneficios y costes de la acción o falta de acción (incluyendo también consideraciones no económicas, tales como la 
eficacia de las opciones posibles y la aceptación por parte de la población).

- Sujetas a revisiones periódicas (siempre que surjan nuevas pruebas, con un plan de actualización y rectificación cuando sea necesario).
- Capaces de asignar la responsabilidad de obtener y presentar los datos científicos necesarios para una evaluación razonable y exhaustiva de los riesgos (que se pueda expresar claramente dentro de los procedimientos de autorización estructurados y formalizados). 


\section{Referencias bibliográficas citadas}

1. Berkel H, Birdsell DC, Jenkins H. Breast augmentation: a risk factor for breast cancer? N Engl J Med 1992; 326 (25): 1649-53.

2. Birdsell DC, Jenkins $H$, Berkel H. Breast cancer diagnosis and survival in women with and without breast implants. Plast Reconstr Surg 1993; 92 (5): 795-800.

3. Brawer AE. Clinical features of local breast phenomena in 300 symptomatic recipients of silicone gel-filled breast implants. J Clean Technol Environ Toxicol \& Occup Med 1996; 5 (3): 235-47.

4. Brinton LA, Malone KE, Coates RJ. Breast enlargment and reduction: results from a breast cancer case-control study. Plast Reconstr Surg 1996; 2: 269-75.

5. Bryant $\mathrm{H}$, Brasher PH. Breast implants and breast cancer-reanalysis of a linkage study. N Eng J Med 1995; 332 (23): 1535-9.

6. Committee on the Safety of Silicone Breast Implants of the Institute of Medicine. Safety of silicone breast implants (IoM report). Bondurant S, Ernster V, Herdman R, editors. Washington: National Academic Press; 1999.

7. Deapen DM, Bestein L, Brodi GS. Are breast-implants anticarcinogenic? A 14-year follow-up of the Los Angeles Study. Plast Reconstr Surg 1997; 5: 1346-53.

8. Deapen D, Hamilton A, Bernstein L, Brody GS. Breast cancer stage at diagnosis and survival among patients with prior breast implants. Plast Reconstr Surg. 2000 Feb; 105 (2): 535-40.

9. Diamond BA, Hulka BS, Kerkvliet NI et al. Silicone breast implants in relation to connective tissue diseases and immunologic dysfunction (NSP report). Independent National Science Panel, editor. USA. Federal District Judge Sam C. Pointer, Coordinating Judge for the Breast Implant Multi-District Litigation. 1998

10. Edworthy SM, Martin L, Barr SG, Birdsell DC, Brant RF, Fritzler MJ. A clinical study of the relationship between silicone breast implants and connective tissue disease. J Rheumatol 1998; 25 (2): 254-60.

11. Ericsson AD. Syndromes associated with silicone breast implants: a clinical study and review. J Nutr Envionm Med 1998; 8: 35-51.

12. Ferguson JH. Silicone breast implants and neurologic disorders: Report of the Practice Committee of the American Academy of Neurology. Neurology 1997; 48: 1504-7.

13. Friis S, McLaughlin JK, Mellenmkjaer L, Kjoller KH, Blot WJ, Boice Jr JD, Fraumeni Jr JF, Olsen JH. Breast implants and cancer risk in Denmark. Int J Cancer 1997; 71: 956-8.

14. Gabriel SE, Woods JE, O'Fallon M, Beard CM, Kurland LT, Melton JM. Complications leading to surgery after breast implantation. N Eng J Med 1997; 336 (10): 677-82.

15. Giltay EJ, Bernelot MH, Riley AH, Tan RG. Silicona breast prostheses and rheumatic symptoms: a retrospective follow up study. Ann Rheum Dis 1994; 53 (3): 194-6.

16. Gylber LO, Asplund O, Jurell G. Capsular contracture after breast reconstruction with silicone-gel and saline-filled implants: a 6 year follow-up. Plast Reconstr Surg 1990; 3: 373-7.

17. Herdman R and Fahey JrT. Silicone implant on cancer. Cancer Invest (submited). 2000a.

18. Herdman, R. Personal Comunication. April, 2000b.

19. Hochberg MC, Pelmutter DL. The association of augmentation mammoplasty with connective tissue disease, including systematic sclerosis (scleroderma): a meta-analysis. Curr Top Microbiol Immunol 1996; 210: 411-7.

20. Independent Research Group (IRG report). Silicona Gel Breast Implants. Minister of Health in the UK, B.J., editor. England: Minister of Health in the UK. 1998.

21. Janowsky EC, Kupper LL, Hulka BS. Meta-analyses of the relation between silicone breast implants and the risk of connective-tissue disease. N Engl J Med 2000; 342 (11): 781-90.

22. Kaiser W, Biesenbach G, Zazgornik J. Human adjuvant disease: remission of silicone induced autoinmune disease after explanation of breast augmentation. Ann Rheum Dis 1990; 49 (11): 937-8. 
23. Kern KA, Flannery JT, Kuehn PG. Carcinogenic potential of silicone breast implants: a Connecticut statewide study. Plast Reconstr Surg 1997; 100 (3): 737-47.

24. Malata CM, Varma S, Scott M, Liston JC, Sharpe DT. Silicone breast implant rupture: common/serious complication? Med Prog.Technol. 1994; 20 (3-4): 251-60.

25. McLaughlin JK, Nyren O, Blot WJ, Yin L, Josefsson S, Fraumeni Jr JF, Adami HO. Cancer risk among women with cosmetic breast implants: a population-based cohort study in Sweden. J Natl Cancer Inst 1998; 2: 156-8.

26. Nguyen JM, Lairy G and Fleurette FAr. Les implants mammaires remplis de gel de silicone. Agence Nationale pour le Développement de l'Évaluation Médicale (ANDEM), editor. Paris: Service des Études. 1996.

27. Nyrén O, McLaughlin JK, Yin L, Josefsson S, Engqvist M, Hakelius L, Blot WJ, Adami HO. Breast implants and risk of neurologic disease: a population- based cohort study in Sweden. Neurology 1998; 50 (4): 956-61.

28. Ostermeyer-Shoaib B, Patten BM. Human adjuvant disease: presentation as a multiple sclerosis-like syndrome. South Med J 1996; 89 (2): 179-88.

29. Park AJ, Chetty U, Watson AC. Patient satisfaction following insertion of silicone breast implants. $\mathrm{Br}$ J Plast Surg 1996; 49 (8): 515-8.

30. Park AJ, Black RJ, Sarhadi NS, Chetty U, Watson AC. Silicone gel-filled breast implants and connective tissue diseases. Plast Reconstr Surg 1998; 101 (2): 261-8.

31. Patten BM, Ostenmeyer-Shoaib B. Disquisition on human adjuvant disease. Perspect Biol Med 1995; 38 (2): 274-90.

32. Perkins LL, Clark BD, Klein PJ, Cook RR. A meta-analysis of breast implants and connective tissue disease. Ann Plast Surg 1995; 35 (6): 561-70.

33. Peters W, Smith D, Lugowsky S. Failure properties of 352 explanted silicone-gel breast implants. Canadian J Plast Surg 1996; 4 (1): 55-8.

34. Robinson OG, Bradley EL, Wilson DS. Analyses of explanted silicone implants: A report of 300 patients. Ann Plast Surg 1995; 34: 1-7.

35. Sánchez-Guerrero GJ, Colditz GA, Karlson EW, Hunter DJ, Speizer FE, Liang MH. Silicone breast implants and the risk of connective-tissue diseases and symptoms. N Engl J Med 1995; 332 (25): 1666-70.

36. Shanklin DR, Smalley DL. The immuno-pathology of siliconosis. History, clinical presentation, and relation to silicosis and the chemistry of silicio and silicone. Inmunol Res 1998; 18 (3): 125-73.

37. Strom SS, Baldwin BJ, Sigurdson AJ, Schusterman MA. Cosmetic saline breast implants: A survey of satisfaction, breast-feeding experience, cancer screening and health. Plast Reconstr Surg 1997; 100 (6): 1553-7.

38. Wallace MS, Wallace AM, Lee J, Dobke MK. Pain after breast surgery: a survey of 282 women. Pain 1996; 66: 195-205.

39. Winther JF, Bach FW, Friis S, Blot WJ, Mellemkjaer L, Kjoller K, Hogsted C, McLaughlin JK, Olsen JH. Neurologic disease among women with breast implants. Neurology 1998; 50 (4): 951-5.

40. Zandman-Goddard G, Blank M, Ehrenfeld M, Gilburd B, Peter J, Shoenfeld Y. A comparison of autoantibody production in asymptomatic and symptomatic women with silicone breast implants. J Rheumatol 1999; 26 (1): 73-7.

NOTA: EXISTEN 1.300 REFERENCIAS BIBLIOGRÁFICAS ADICIONALES, NO CITADAS EN EL TEXTO, DISPONIBLES PARA SU CONSULTA. 
Anexo: Tablas 


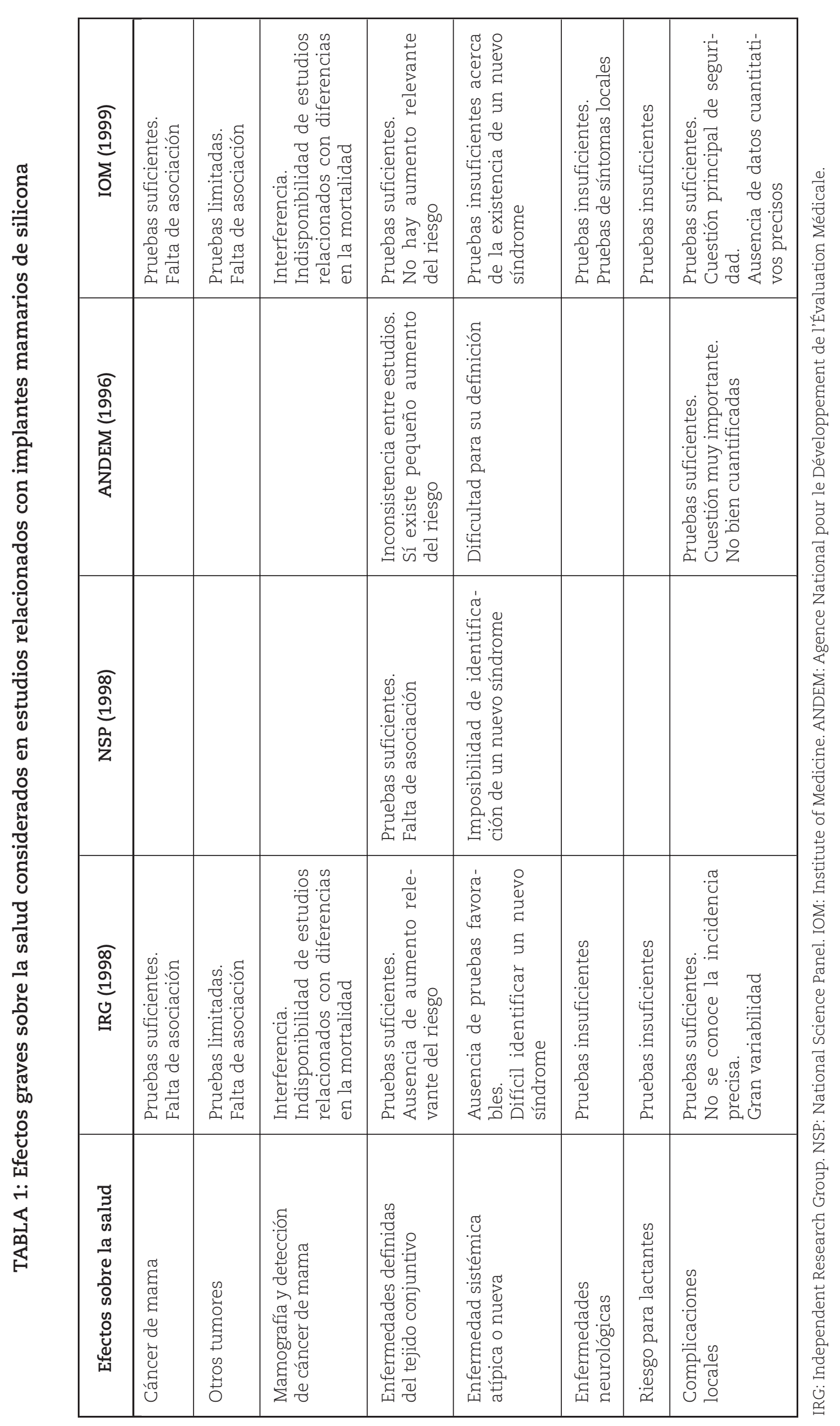




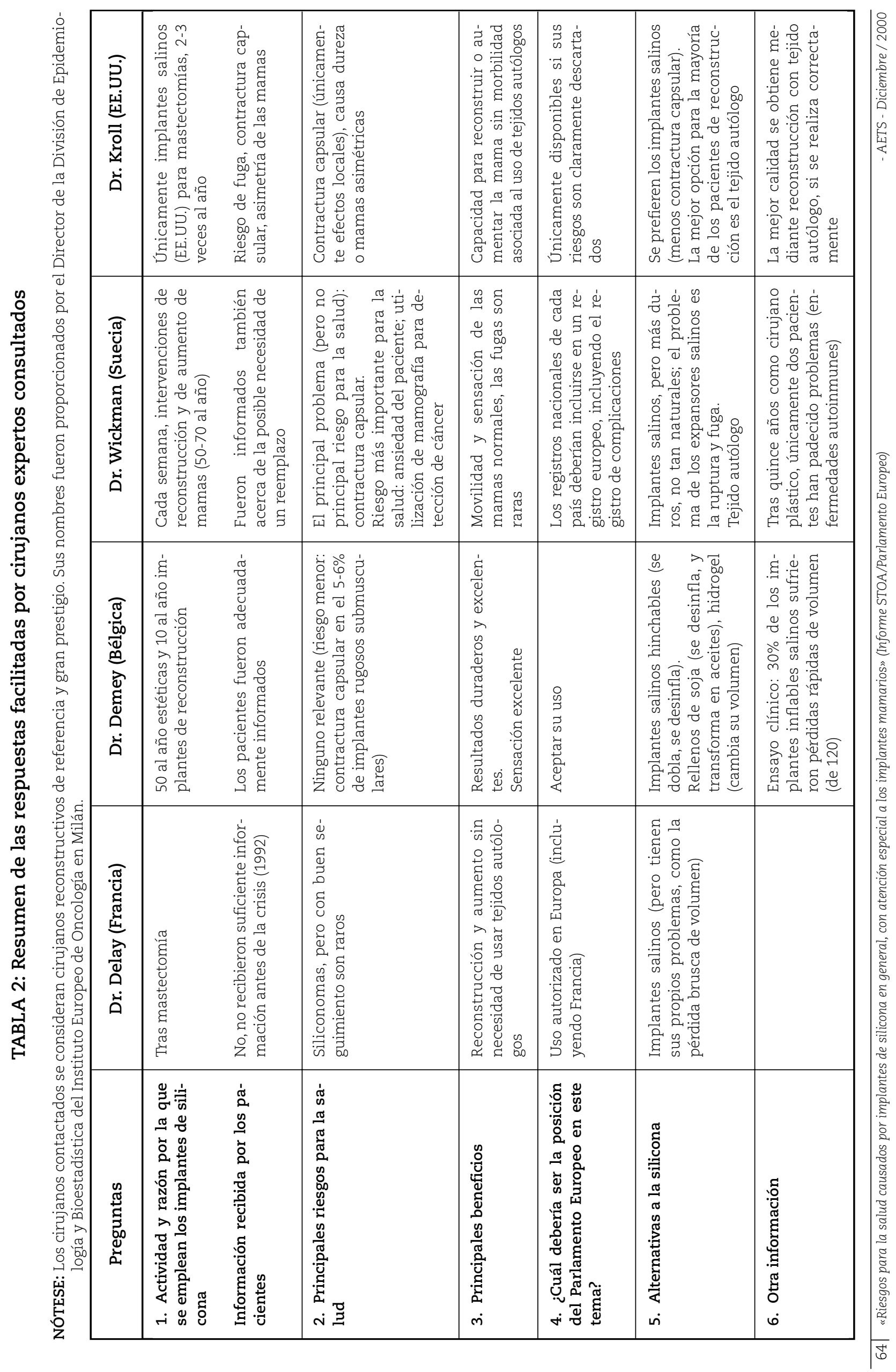




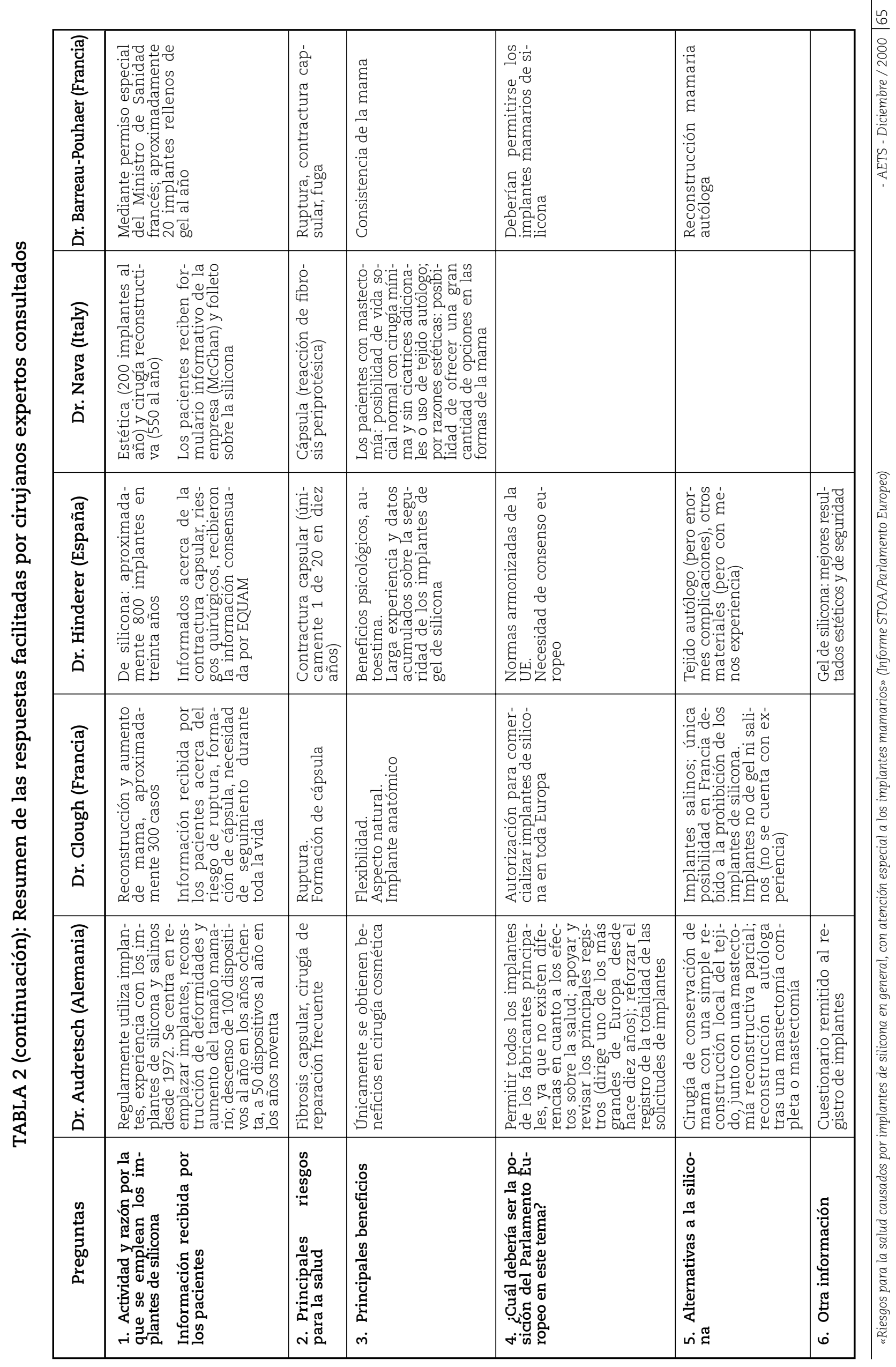


TABLA 3: Resumen de las respuestas obtenidas mediante cuestionario a mujeres con implantes de mama $(n=30)$ (en porcentaje)

\begin{tabular}{|c|c|c|}
\hline Edad actual (media \pm desviación estándar) & \multicolumn{2}{|l|}{31,2 años $\pm 7,8$ años } \\
\hline \multirow{2}{*}{ ESTADO CIVIL ACTUAL } & Soltera & 66,7 \\
\hline & Casada & 33,3 \\
\hline \multirow{3}{*}{ NIVEL DE EDUCACIÓN } & Superó 8. ${ }^{\circ}$ EGB, pero no BUP & 13,3 \\
\hline & BUP/Formación Profesional & 46,7 \\
\hline & Universidad & 40,0 \\
\hline \multirow{2}{*}{ TIPO DE CIRUGÍA } & Reconstrucción de mama & 13,3 \\
\hline & Razón estética & 86,7 \\
\hline \multirow{3}{*}{ RAZONES PARA SOMETERSE A CIRUGÍA } & Mama pequeña & 76,7 \\
\hline & Mamas asimétricas & 6,7 \\
\hline & Mamas caídas, postparto & 16,7 \\
\hline \multirow{4}{*}{$\begin{array}{l}\text { NIVEL DE SATISFACCIÓN } \\
\text { CON IMPLANTE MAMARIO }\end{array}$} & Muy satisfecha & 73,4 \\
\hline & Algo satisfecha & 20,0 \\
\hline & Indiferente (ni satisfecha ni insatisfecha) & 3,3 \\
\hline & Algo insatisfecha & 3,3 \\
\hline \multirow{2}{*}{ PROBLEMAS TRAS IMPLANTE MAMARIO } & No & 90,0 \\
\hline & Sí $(*)$ & 10,0 \\
\hline
\end{tabular}

(*) Se describieron problemas en tres casos, aproximadamente un año después de la intervención quirúrgica (una contractura capsular de grado I, una reintervención por tamaño excesivo del implante y una reintervención para corrección de la posición del implante). 


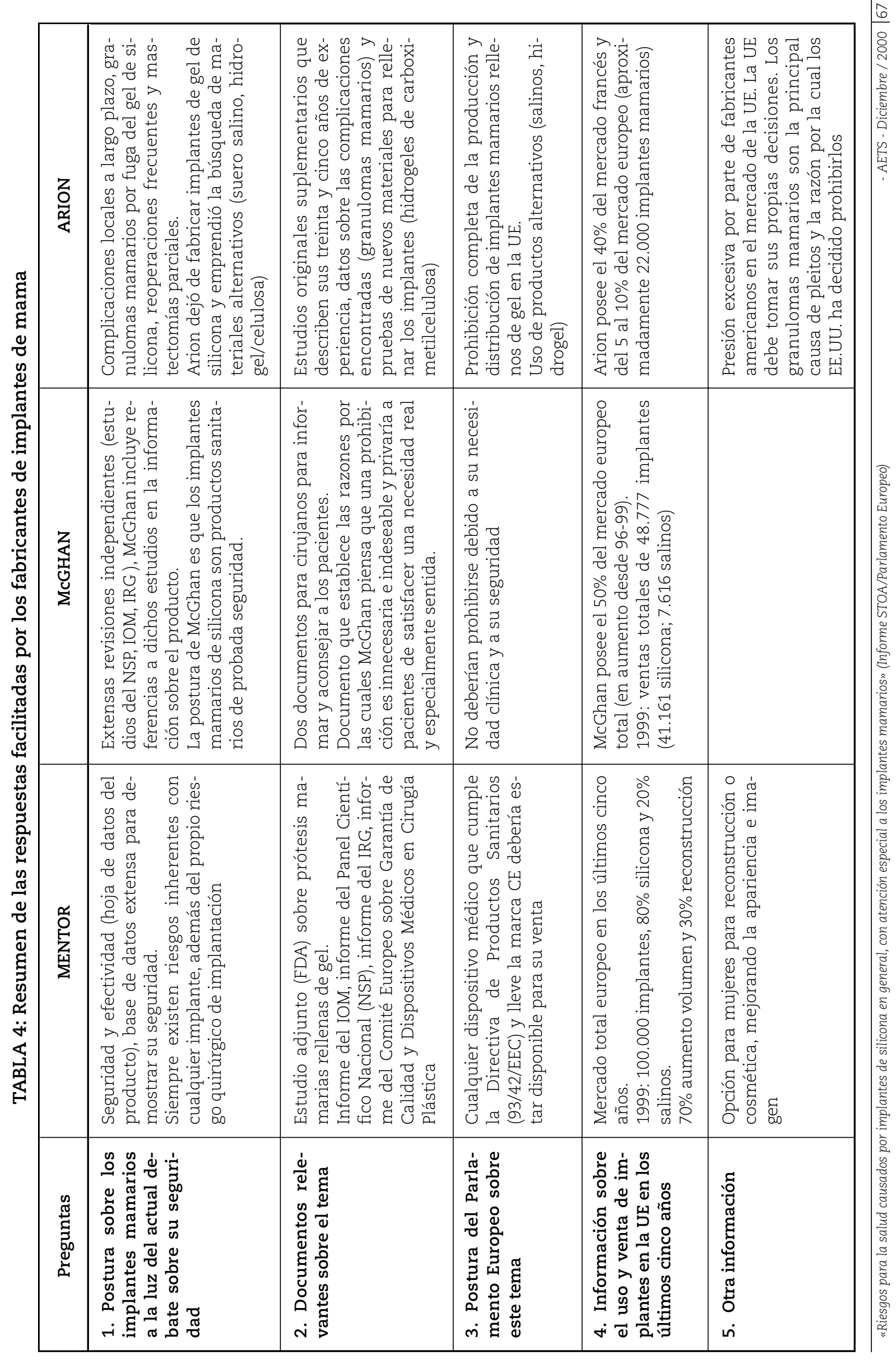




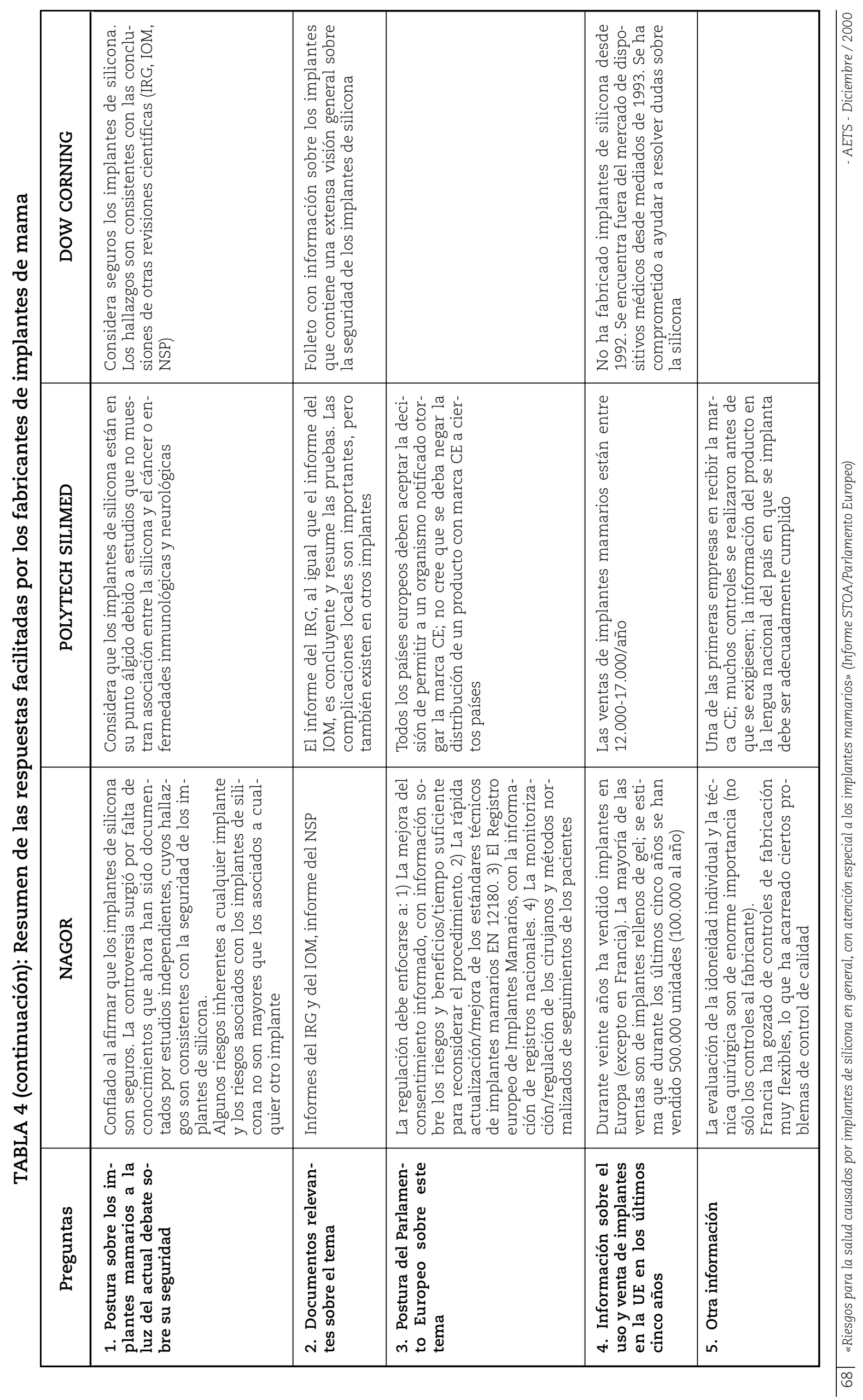




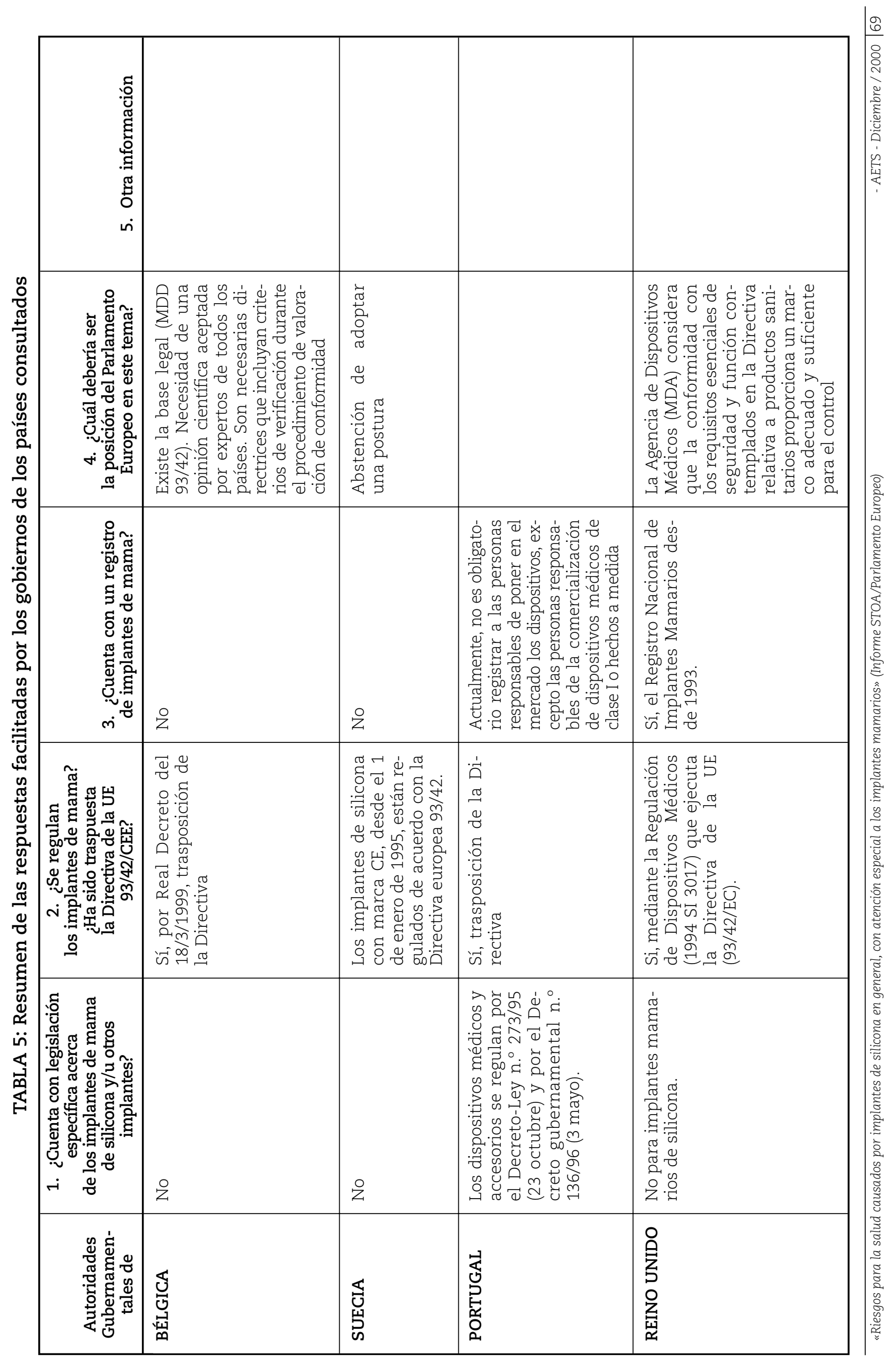




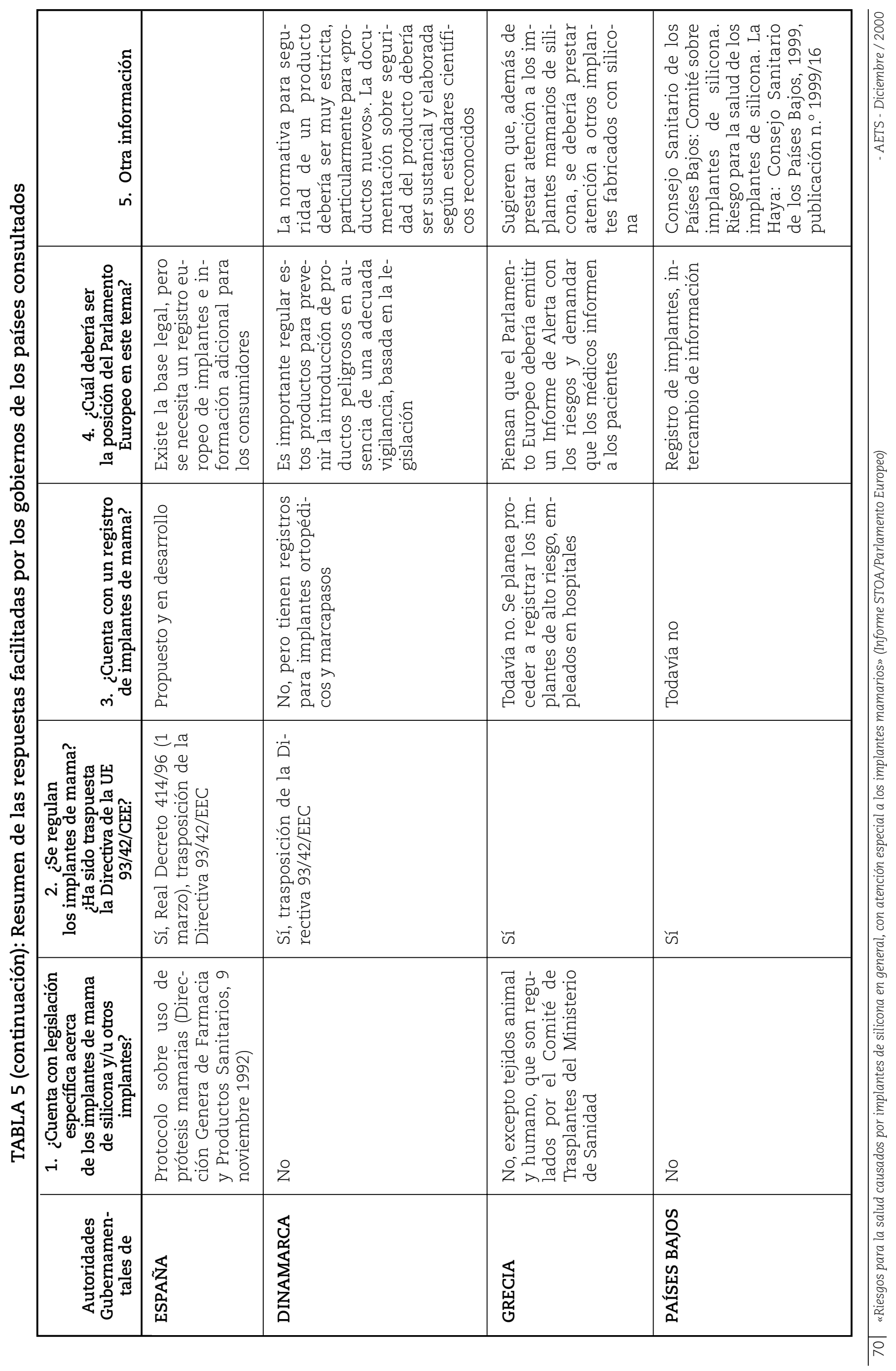




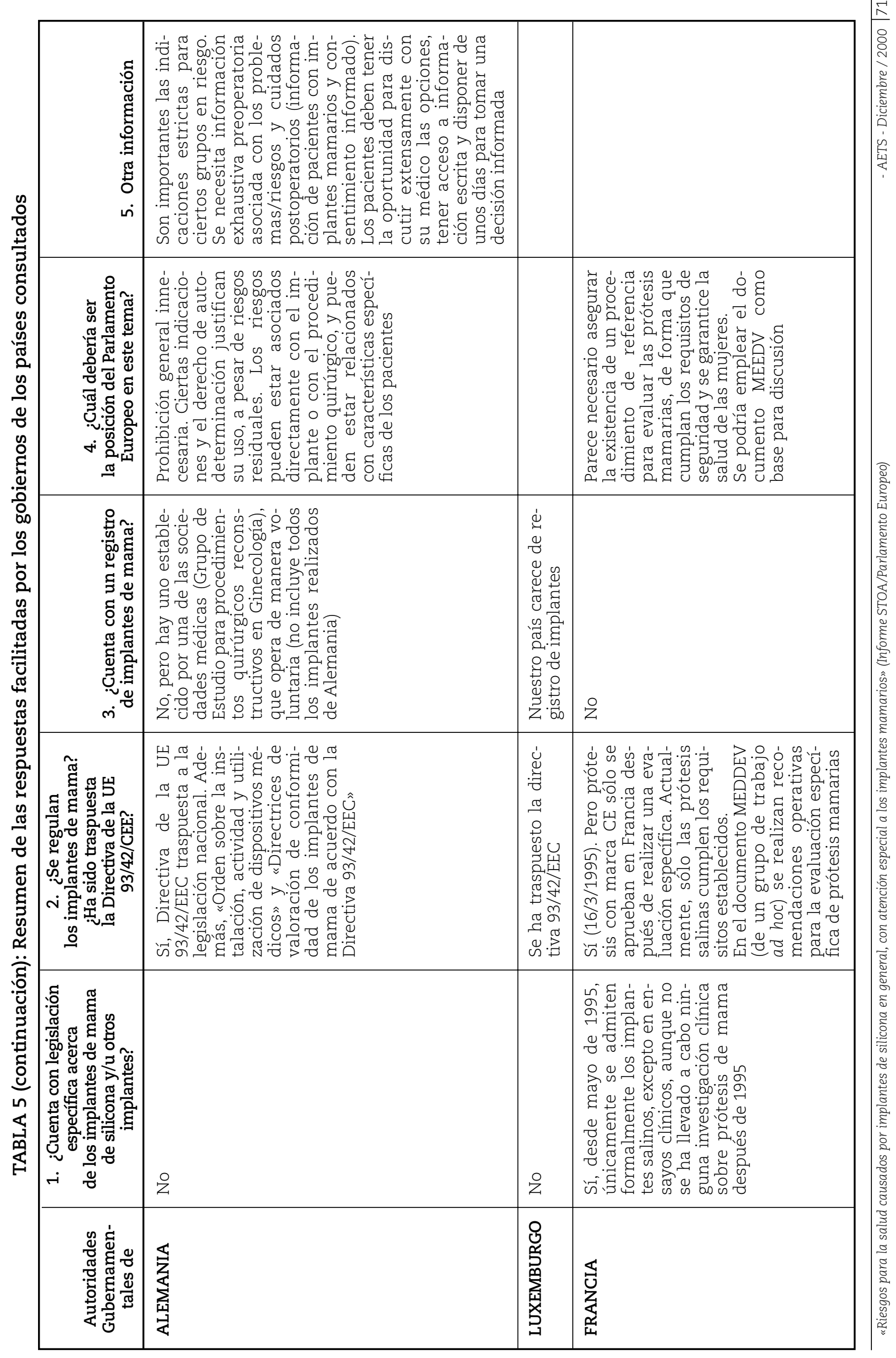



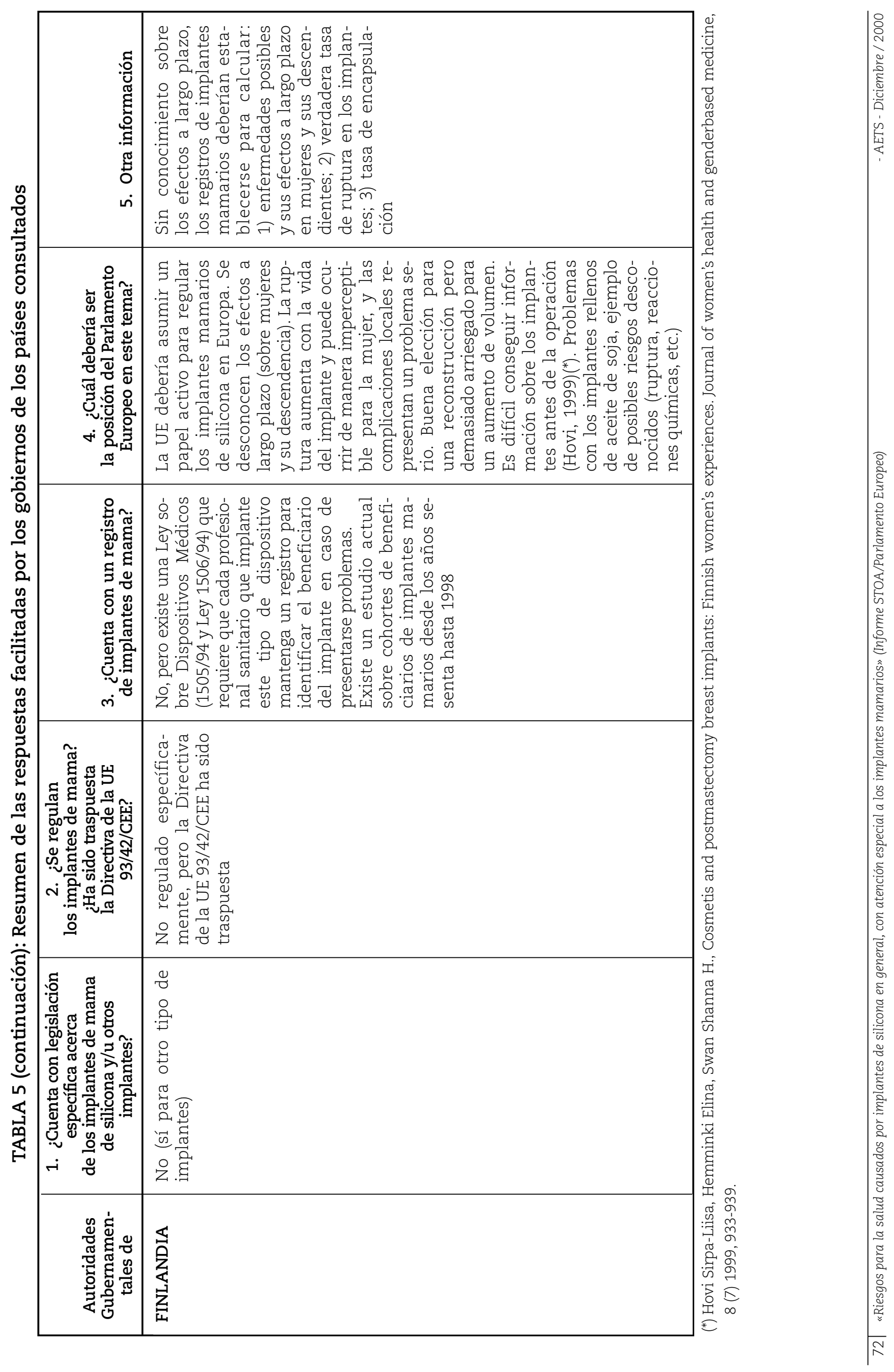